\title{
Stand growth scenarios for Tectona grandis plantations in Costa Rica
}

\author{
Diego Pérez \\ Department of Forest Ecology \\ Faculty of Agriculture and Forestry \\ University of Helsinki
}

\begin{abstract}
Academic dissertation
To be presented with the permission of the Faculty of Agriculture and Forestry of the University of Helsinki, for public discussion in Lecture Hall B5 of the Department of Forest Ecology, Viikki, on June $3^{\text {rd }} 2005$ at 12 o'clock noon.
\end{abstract}

Helsinki 2005 
Title of dissertation: Stand growth scenarios for Tectona grandis plantations in Costa Rica

Author: Diego Pérez

Dissertationes Forestales

Thesis supervisors:

Pasi Puttonen

Department of Forest Ecology, University of Helsinki, Finland

Lauri Valsta

Department of Forest Economics, University of Helsinki, Finland

Markku Kanninen

Center for International Forestry Research (CIFOR), Indonesia

Pre-Examiners:

Glenn Galloway

Tropical Agricultural Research and Higher Education Center (CATIE), Costa Rica

Timo Pukkala

Faculty of Forestry, University of Joensuu, Finland

Opponent:

K. M. Bhat

Kerala Forest Research Institute, India

ISSN 1795-7389

ISBN 951-651-100-7

(2005)

Publishers:

The Finnish Society of Forest Science

Finnish Forest Research Institute

Faculty of Agriculture and Forestry of the University of Helsinki

Faculty of Forestry of the University of Joensuu

Editorial Office:

The Finnish Society of Forest Science

Unioninkatu 40A, 00170 Helsinki, Finland

http://www.metla.fi/dissertationes 
Pérez, D. 2005. Stand growth scenarios for Tectona grandis plantations in Costa Rica. Dissertationes Forestales 1. 77 p.

Fast-growing, high-yield tree plantations are an increasingly significant source of wood in the tropics. In these areas, improved wood productivity is an important economic goal. In Costa Rica and other countries in Central America, most of the tree plantations, especially those of advanced age, have not had the productivity expected of them. In the general context of a closer relationship between management practices and quality wood production, the general objective of this research was to develop a set of intensive management scenarios that could lead to alternative timber production practices with attainable and promising economic returns.

Data for the different studies were collected in different regions of Costa Rica, covering almost all climatic conditions where T. grandis plantations have been established and where the species has adapted well. The study consisted fundamentally of the measurement of growth and yield parameters at the stand level and of the analysis of wood properties at the individual tree level and the interrelationship between silvicultural management and site conditions.

High intensity, timely thinnings yielded both individual tree and stand volume, i.e. the objective of high individual tree growth was met without a severe reduction in stand yield. Pruning up to a reasonable height and on time caused no reduction in tree growth and stand yield. Moreover, pruning may improve stem form (higher form factor, lower stem taper) and heartwood content.

Important characteristics, such as heartwood content and wood density, were found to be related more to tree age than to silvicultural management practices, especially at early plantation stages.

Growth scenarios for 20 and 30 year rotations with the objectives of high individual tree growth and high stand growth were developed for high, medium, and low quality sites. Different site classes, production objectives, rotation periods, and discount rates resulted in marked differences in the financial profitability projections of the developed scenarios.

Keywords: Merchantable volume, Thinning regimens, Pruning regimens, Reforestation costs, Wood prices, Financial analysis. 


\section{PREFACE}

This work forms a part of the results of a research project on the growth and yields of Tectona grandis plantations in Costa Rica an Central America, carried out from 1997 to 2002 under an agreement between the University of Helsinki- Finland and the Tropical Agricultural Research and Higher Education Center (CATIE) - Costa Rica, and lead by Dr. Markku Kanninen.

This study has been financed by the Academy of Finland, grant no. 37518 (Stand dynamics and management of fast growing tree species in Central America, 1997-1999), grant no. 47704 (Feasibility of tree and forest planting in Central America, 2000-2002), and partially grant no. 201566 (LUCCAM project - Land Use Changes and Carbon Flows in Central America, 2003-2005), and published with the support of the University of Helsinki, Department of Forest Ecology.

I would like to express my gratitude to Dr. Markku Kanninen, who has believed in this study since the beginning of the journey and has encouraged me on a daily basis and for over five years of hard but unforgettable joint work to make real today's final research product. So many years working under Dr. Kanninen's supervision has brought my knowledge of forest silviculture to levels of understanding far beyond my expectations. Finally, his remarkable leadership of the research project, which this study is part of, has given me an invaluable example of team work, professionalism, and friendship, three fundamental ingredients for success.

I am grateful to Dr. Pasi Puttonen and Dr. Lauri Valsta, from which I received unconditional support during these five years of research, especially during my stays in the beautiful country of Finland, where I also collected unforgettable memories and valuable knowledge. Their understanding, guidance, constant encouragement and constructive criticism were essential for the completion of this study. My sincere gratitude to Dr. Glenn Galloway and Dr. Timo Pukkala for their valuable revision and suggestions given to the final version of the document. Special thanks to Dr. K. M. Bhat for accepting the chair of the opponent at the thesis dissertation.

I want to thank all the professors and friends that I met at the University of Helsinki and at CATIE, who somehow contributed to my evolution as a professional and as a person. "In the end we are nothing but the sum of our experiences".

Dedico esta tesis (y el esfuerzo de cinco años) a mis padres Fressy e Isaías, por quienes no desfallecí en los días difíciles que encontré en este largo camino. 


\section{LIST OF ORIGINAL PAPERS}

I. Pérez, L.D.; Kanninen, M. 2003. Heartwood, Sapwood and bark content, and wood dry density of young and mature teak (Tectona grandis) trees grown in Costa Rica. Silva Fennica 37(1): 45-54. http://www.metla.fi/silvafennica/

II. Víquez, E.; Pérez, L.D. 2005. Effect of pruning on tree growth, yield, and wood properties of Tectona grandis plantations in Costa Rica: results of a pruning trial. In revision (Silva Fennica, http://www.metla.fi/silvafennica/ ).

III. Pérez, L.D.; Kanninen, M. 2005. Effect of thinning on stem form and wood characteristics of teak (Tectona grandis L.f.) in a humid tropical site in Costa Rica. Silva Fennica 39(2) 00-00 (In Press) (http://www.metla.fi/silvafennica/).

IV. Kanninen, M.; Pérez, L.D.; Montero, M.; Viquez, E. 2004. Intensity and timing of the first thinning of Tectona grandis plantations in Costa Rica: results of a thinning trial. Forest Ecology and Management 203:89-99. http://www.elsevier.com/locate/foreco doi:10.1016/j.foreco.2004.07.054

V. Pérez, L.D.; Kanninen, M. 2003. Provisional equations for estimating total and merchantable volume of Tectona grandis trees in Costa Rica. Forests, Trees and Livelihoods 13(4): 345-359. http://www.foreststreesandlivelihoods.co.uk/

VI. Pérez, L.D.; Kanninen, M. 2005. Stand growth scenarios for Tectona grandis plantations in Costa Rica. Forest Ecology and Management 210: 425-441. http://www.elsevier.com/locate/foreco. doi:10.1016/j.foreco.2005.02.037 


\section{TABLE OF CONTENTS}

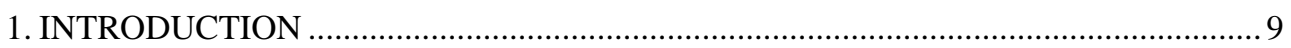

1.1.Tectona grandis plantations worldwide.........................................................................9

1.2.Tectona grandis plantations in Costa Rica ........................................................... 10

1.3.Previous studies on management tools and guidelines for Tectona grandis

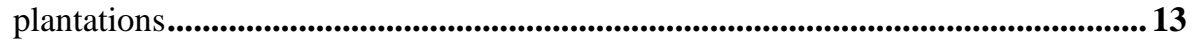

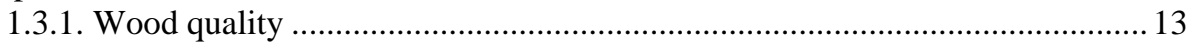

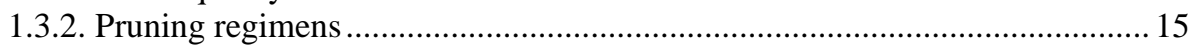

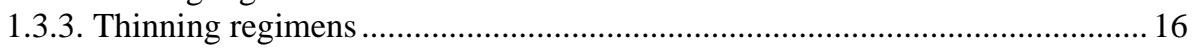

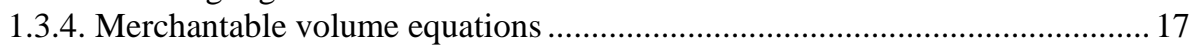

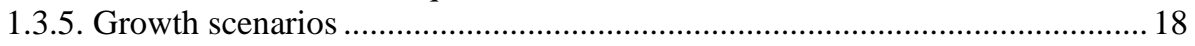

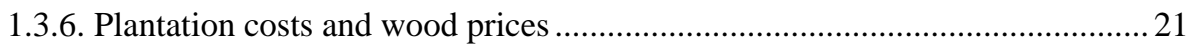

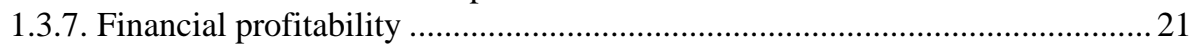

1.4. Objectives of the study ...................................................................................................... 22

Study I: The most appreciated wood properties of teak trees and their relationship

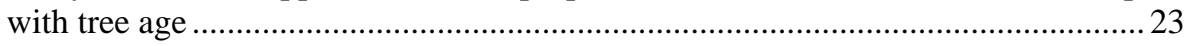

Study II: The effects of pruning on tree growth and wood quality.......................... 23

Study III: The effects of stocking on wood quality ................................................. 23

Study IV: The effects of thinning on tree growth and stand yield........................... 23

Study V: Total and merchantable volume equations............................................. 24

Study VI: Stand growth scenarios ..................................................................... 24

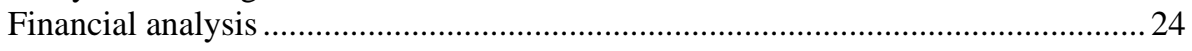

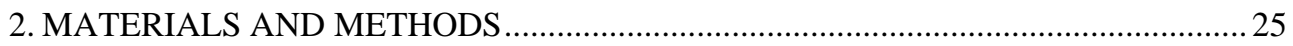

2.1. Site location and data set ......................................................................................................... 25

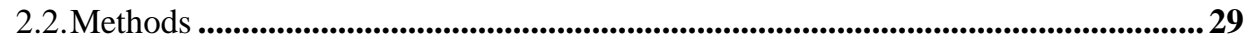

Study I: The most appreciated wood properties of teak trees and their relationship

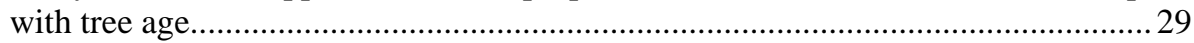

Study II: The effects of pruning on tree growth and wood quality ........................... 29

Study III: The effects of thinning on wood quality .................................................. 29

Study IV: The effects of thinning on tree growth and stand yield ............................. 30

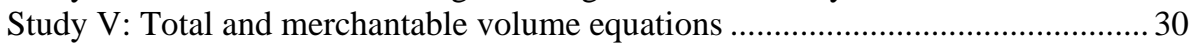

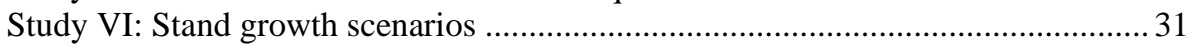

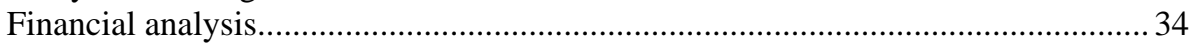

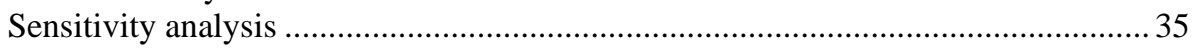

3.1. Wood quality (Study I) ........................................................................................................... 36

3.2.Pruning regimens and the effect on wood properties and tree growth (Study II).................................................................................................................................. 36

3.3. Thinning regimens and the effect on wood properties (Study III) ............................ 38 
3.4. Thinning regimens and the effect on tree growth and stand productivity (Study IV) .40

3.5.Total and merchantable volume equations (Study V) ..................................................42

3.6. Growth scenarios (Study VI) ........................................................................................42

3.7.Financial analysis .............................................................................................................46

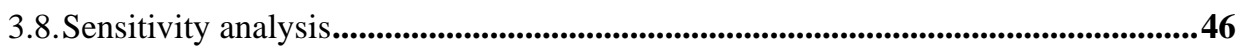

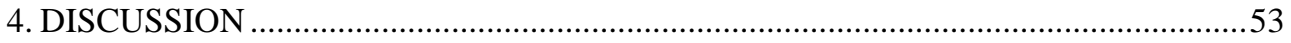

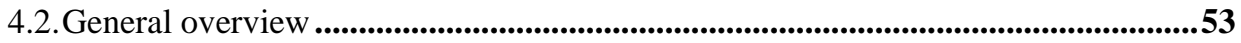

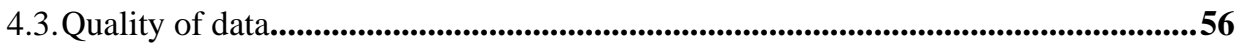

4.4. Accuracy of models ......................................................................................................56

4.5.Integrated growth scenarios ............................................................................58

4.5.1. Effect of silvicultural management on wood properties.................................58

4.5.2. Effect of silvicultural management on tree growth and stand yield ...............60

4.5.3. Growth simulation techniques of the management scenarios .........................62

4.5.4. Applicability of the management scenarios ..................................................66

4.6. Financial aspects of the growth scenarios ....................................................................67

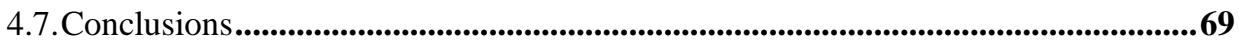

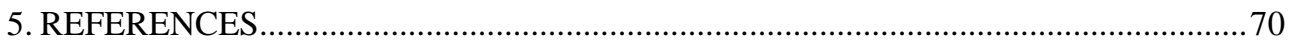




\section{INTRODUCTION}

\subsection{Tectona grandis plantations worldwide}

The excellent properties and versatile nature of teak (Tectona grandis L. f.) timber and its eminent suitability for an array of uses is well documented. The potential for growing and managing teak in different ecological zones and under different situations (objectives) is being increasingly recognized, leading to intensive domestication and cultivation of the species in countries/regions beyond its natural habitat. Despite the value of teak timber and its increasing demand, its full potential for providing direct revenue as well as value-added down-stream processing and for contributing to the national income has not been fully utilized.

Despite all the efforts invested in reforestation, i.e. 5.7 million hectares planted worldwide in year 2000 according to the FAO (2000), the currently available Tectona grandis (teak) timber resources are far below the needs of the huge worldwide market demand (Ball et al. 2000). In the last TEAKNET (Asia-Pacific Network) meeting held in 1999 in Chiang Mai (Thailand), the lack of planting stock, especially of superior quality, was identified as the primary cause of the teak timber deficit. Increased yield, higher uniformity and shorter rotations are strong incentives for developing the intensively managed $T$. grandis plantations, which are gaining a worldwide reputation due to the attractiveness and durability of teak wood. Market demands have prompted the establishment of plantations within and beyond its native countries (Hoare and Patanapongsa 1988, Monteuuis and Goh 1999, Bhat 2000).

Although several research projects have refined many aspects of teak silviculture, there are gaps in what is known about managing and use, growing teak in such vital aspects as site requirements, stand dynamics, short-rotation intensive management, wood processing, grading rules and product marketing. The importance of stocking density, for instance, is still vague as thinning intensities and periods have not been properly defined in relation to production objectives. Very often administrative decisions prevail over technical criteria and stands are thinned either too late or less intensively than recommended, causing a negative effect on individual and stand growth. Most of the tree plantations in the tropics grown for saw timber require early, heavy and repeated thinnings in order to sustain their characteristic rapid diameter growth (Galloway et al. 2001). Delaying thinning or carrying out slight interventions at early stages prompts inter-tree competition. On the contrary, too early or too strong interventions, although not common, cause site under-occupancy and the consequent loss in stand productivity.

Teak occurs naturally in parts of India, Myanmar, Laos and Thailand. It has been naturalized in Java, where it was probably introduced some 400-600 years ago (Troup 1921, Kadambi 1972, White 1992). Early introductions of teak outside Asia were made in Nigeria, with the first plantations being of Indian origin in 1902 and subsequently of Burmese origin (Horne 1966). Teak planting in what is now eastern Ghana started around 1905 and a small plantation of teak was established in Côte d'Ivoire in 1929 from plantation seeds obtained from then Togoland. Teak was introduced to countries of Tropical Africa to supplement local timber supplies because of its excellent timber properties. Perhaps the first pure teak plantation in Tropical America was established in Trinidad in 
1913 with seeds from Burma. Teak planting in Honduras, Panama, and Costa Rica started between 1927 and 1929 (Ball et al. 2000).

Teak is the world's most cultivated high-grade tropical heartwood, covering approximately 6.0 million hectares worldwide (Bhat and Hwan Ok Ma 2004). Of this net area of teak plantations, about $94 \%$ are in Tropical Asia, with India (44\%) and Indonesia (31\%) contributing the bulk of the resource. Other countries of the region contribute significantly with $17 \%$ in total (Thailand, Myanmar, Bangladesh, Sri Lanka). About 4.5\% of the teak plantations are in Tropical Africa and the rest are in Tropical America, mostly in Costa Rica and Trinidad and Tobago (Pandey 1998). The Asian Pacific region (5.3 million hectares) have been managed under 35 to 80 -year rotations, yielding annual productivities of 5 to $20 \mathrm{~m}^{3} \mathrm{ha}^{-1}$ year $^{-1}$, while teak plantations in Africa (310,000 hectares) are harvested at shorter rotations of 20 years, yielding between 4 and $13 \mathrm{~m}^{3} \mathrm{ha}^{-1}$ year $^{-1}$ (Bhat and Hwan Ok Ma 2004). Central and South American teak plantations (205,000 ha) are being managed under similar short rotation scenarios of 20-25 years, however they have shown higher yields of up to $40 \mathrm{~m}^{3} \mathrm{ha}^{-1}$ year $^{-1}$ (average of $20-25 \mathrm{~m}^{3} \mathrm{ha}^{-1}$ year ${ }^{-1}$ on medium and high quality sites).

Teak has been grown under plantation conditions for 150 years. In the last decade, its high value as timber of excellent appearance and mechanical resistance, and the appearance of strong markets for teak products which parallels an increasingly declining stock of natural stands, have attracted particular attention to the potential of teak plantations as a high return investment possibility (Ball et al. 2000).

\subsection{Tectona grandis plantations in Costa Rica}

Fast-growing, high-yield tree plantations are an increasingly significant source of wood in the tropics. In these areas, the improvement of wood productivity is an important economic goal. In Costa Rica and other countries in Central America most of the tree plantations, especially those of advanced age, have not had the expected productivity. The main causes for this have been bad site selection, use of non-improved genetic planting material, and lack of appropriate silvicultural management (Torres et al. 1995, De Camino et al. 1998, Castro and Raigosa 2001).

T. grandis was introduced in Costa Rica and other countries in Central America between 1927 and 1929. Until the year 2000, approximately 223,000 ha of T. grandis plantations were established in this region (Pandey and Brown 2000). In the past 10 years, Costa Rica has steadily increased the annual plantation rate of several species to an approximate total of 11,000 hectares per year. In 2000, the total area of plantations reached 178,000 hectares, of which 30,300 ha $(17.0 \%)$ corresponded to Tectona grandis (FAO 2000).

Governmental incentive programs have encouraged the establishment of commercial tree plantations in Costa Rica, reaching 140,000 ha by the year 2000 (Sage and Quiros 2001). Projects and private companies in Central America urgently need relevant growth and yield information for those species most widely used in reforestation projects. Determining the production throughout the rotation is particularly necessary in the case of advance-aged plantations (over 20 years).

The important property requirements of end-users in fast-grown T. grandis are straight, least-tapered boles with reduced flutes/buttresses and knots, low proportions of juvenile and tension wood, high proportions of heartwood, and optimum wood density and strength. The two mayor factors that influence sawn wood grade and recovery are unsound hollow knots and deep flutes in the logs (Bhat 1998). However, no scientific-based recommendations are 
available in the literature and many silvicultural activities, such as pruning and thinning, are carried out, in most cases, based on visual assessment and common sense. No studies are available on the maximization of wood quality properties by means of intensive teakplantation management in Central America.

Linking forest management to timber industry is fundamental. Connections between silvicultural management and wood quality are limited, providing only size-related characteristics (girth and height growth, stand volume) as useful information. Particular grading rules set up by international markets for natural teak obtained in Asia, are currently limiting the selling options of several forest companies in Central and South America due to difficulties in meeting such stringent demands, mainly those having to do with minimum log dimensions and wood defects. Therefore, efficient management practices leading not only to maximum per-hectare volume production but also to a desirable individual-tree commercial volume production are strongly needed. Lack of sufficient financial information to evaluate the profitability of $T$. grandis plantations is discouraging new projects willing to invest in reforestation.

Several studies on growth and silvicultural management are available for teak plantations in the Tropics, however, they have been somewhat scattered and without practical or conclusive results. Available management prescriptions and growth projections lack high-quality supporting data, complementary studies on stand competition, volume projections, merchantable volume estimates, information on the effect of different management regimens (on growth, yield, and quality), reforestation and management costs, wood prices and market grading, and financial analyses justifying the investment. Within the next 10 years, most of the teak plantations in Costa Rica will be thinned for a second, third, or forth time, or even harvested at rotation ages between 20 and 30 years. Final yield (total and merchantable volume according to market requirements), total management costs, wood prices, and management options are urgently needed to inform owners, investors, and consumers about the real stock of commercial timber available at present and future, and the possible expected value of their plantations.

The present study focuses on management scenarios developed according to production objectives, plantation quality classes, and rotation periods, aiming at producing high quality timber. The study does not cover all the factors influencing a tree plantation system, as they are numerous and some are very complex, e.g. genetic and climatic resources, fertilization regimens, land preparation, site conditions and soil quality, wood processing industry, among others. The general framework of the study is presented in Figure 1. Management prescriptions should reflect the objectives of production, which should have a level of detail for estimating not only total yield but also the merchantable volume according to type of products. The type of products should reflect the market demand (dimensions, quality, and aspect) and should be reflected in the stand management design.

Pruning and thinning are key silvicultural activities, and together with the rotation length, are decisive factors for achieving different levels of quality and yield of round wood products. In this study, round wood is the last stage of the chain of production; further processing into board feet or furniture is not considered, as the many possible products and insufficient information make a deeper analysis difficult to achieve. A financial analysis complements the set of growth scenarios with different possible economic returns. 


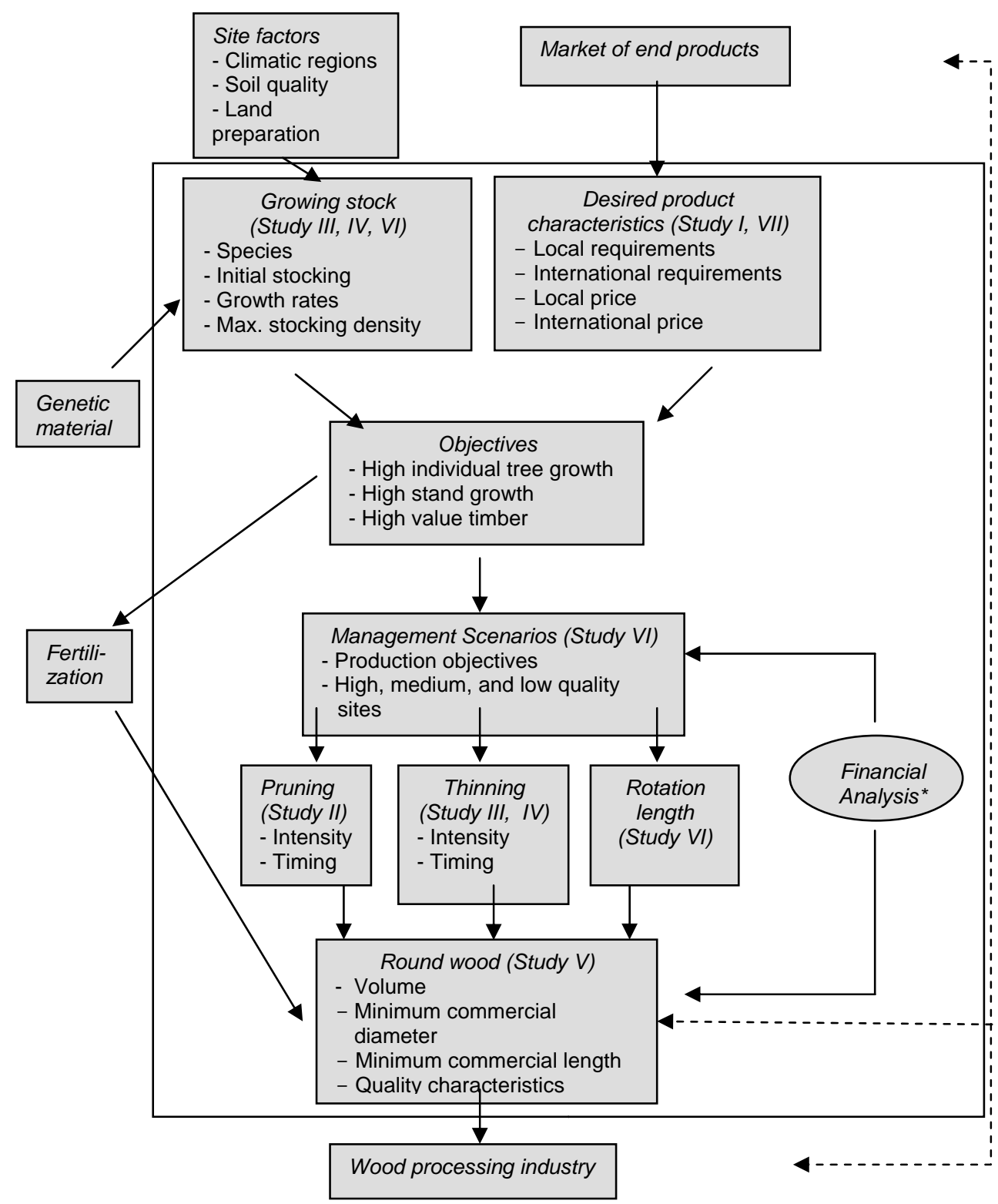

* The financial analysis is a complement of the set of growth scenarios, to be find in the main discussion of the thesis.

Figure 1. General framework of the study. This study focuses on issues within the box marked with solid line. 


\subsection{Previous studies on management tools and guidelines for Tectona grandis plantations}

\subsubsection{Wood quality}

T. grandis is suitable for multiple end-uses, including construction, furniture and cabinets, railway sleeper cars, decorative veneer, joinery, ship and vehicle body building, mining, reconstituted products, etc. The quality of teak timber, which could be improved by high input management, depends partly on tree form and partly on basic wood structure and strength properties. The major structural factors that should receive attention are, among others: stem size, bole shape, knot size and frequency, and heartwood-sapwood proportions (Bhat 2000). Evidence of similitude in wood mechanical properties between new (21 years) and old (65 years) T. grandis trees offers scope for reducing the rotation age of fast-grown wood without affecting timber strength. Nevertheless, the available data on the effects of spacing and thinning regimens on wood quality are insufficient for designing an efficient management strategy (Bhat 2000).

High proportions of heartwood and high dry density are the two most desired wood characteristics for plantation-grown teak (Tewari 1999, Baillères and Durand 2000). Several studies report the heartwood content and the variations in dry wood density, from pith to bark, with stem height, age, stand density, and climatic conditions for teak in different countries (Nair and Chavan 1985, Bhat 1995, Brennan and Radomiljac 1998, Trockenbrodt and Josue 1998, Priya and Bhat 1999, Bhat et al. 2001). A few similar studies have been carried out for younger teak ( $<10$ years) in Costa Rica and documented by Moya (2000), Arce (2001), Moya (2001), as well as for mature teak (26 years), documented by González et al. (1979). Most mature trees contain a central core of heartwood usually darker in color than the surrounding sapwood, which often darkens considerably when the cut surface is exposed to air. The transformation from sapwood usually occurs abruptly over a few rows of cells (Hillis 1987).

In Costa Rica, teak trees present a heartwood proportion of $55 \%$ of the total volume at 30 years, increasing logarithmically with increasing age and consequently with DBH. Arce (2001) found heartwood proportions of 33-37\% in 10-year-old teak grown in a dry region of Costa Rica. Cross-sectional area of heartwood at DBH has been reported to increase with increasing age (up to 80-90\%), this at ages greater than 30 years on plantation-grown teak in different regions of the world (Bhat 1995, Kokutze et al. 2004). Little importance has been given to the proportion of heartwood in many countries where teak forests are older than 50 years, since this characteristic is not a matter of discussion for older trees (over 40 years of age) containing over $90 \%$ of cross-sectional area of heartwood at DBH. Lately, the need to produce fast growing teakwood in a maximum of 20-30 years increased the importance of producing high heartwood content, which is considered a determinant factor during visual assessment and wood valuation.

In timber with clearly demarcated sapwood and heartwood, those trees with higher percentages of heartwood will yield more saleable timber; conversely, a high proportion of sapwood is not a problem in treated poles because it is easily penetrated by preservatives and thereafter may be more resistant to pests and fungal infections than the heartwood itself (Oteng-Amoako 2004). In Costa Rica and other Central American countries, grading rules are based mostly on visual assessment, i.e. on quality characteristics such as wood defects and heartwood color. Heartwood color and content determine, in most cases, whether the 
log will be valued as high or poor-quality wood, with a corresponding gain/loss of up to $50 \%$ of its potential value.

Another important property of teak wood is its density. Basic wood density is considered an important indicator of wood quality and strength, and the heartwood of tropical woods is the most appreciated for its aesthetic value (Wiemann and Williamson 1989, Bhat 1995, Tewari 1999, Bailléres and Durand 2000). Strong relationships between wood density and some mechanical properties (e.g. static bending, module of elasticity, module of rupture, stress proportional limit) were found by Betancur et al. (2000) for 13year-old teak grown in Colombia. In general, the average values of dry wood density found in Costa Rica (0.55-0.70 $\left.\mathrm{g} \mathrm{cm}^{-3}\right)$ are similar to those reported elsewhere for plantationgrown teak (Kandya 1974, González et al. 1979, Sanwo 1987, Bhat 1995, Vallil 1997, Brennan and Radomiljac 1998, Baillères and Durand 2000, Betancur et al. 2000, Bhat 2000, Moya 2001).

Not enough is known about the possible relationships between management guidelines, growth and yield, and wood quality. Growth projections and management scenarios are built and followed without considering many wood properties that are crucial for a high value market grading, such as heartwood content, wood color and grain, wood defects (especially knots), and wood density, among others. The production of high quality products with a higher value on international teak markets will prompt the establishment of new plantations in the tropics and attract more investment in the developing countries of Central America.

When living parenchyma cells in the outer, functional sapwood begin to die, the substances they contain are used as energy to fuel the production of phenols and quinines, which protect the tree from pathogen and insect attack (Datta and Kumar 1987). Heartwood is defined as the inner layers of the wood, which, in the growing tree, has ceased to contain living cells, and in which the reserve materials (starches) have been removed or converted into heartwood. The amount of heartwood varies considerably with age, site and growth rate, and between trees within the same stand at the same age. This implies a strong influence of cell age, growth of the individual tree and a strong genetic heritability (Hillis 1987). High heritability for heartwood has been shown for Pinus banksiana Lamb by Magnussen and Keith (1990) and Pinus sylvestris by Fries and Ericsson (1998). Bhat (1998) showed that increase three growth rate does not retard the formation of heartwood. However, the amount of heartwood in teak is related to tree age (Okuyama et al. 2000) and silvicultural practices (Morataya et al. 1999).

Increases in heartwood area following fertilization and thinning were not statistically significant, whereas sapwood area was significantly increased by both fertilization and thinning in a research study carried out on Scots Pine (Pinus sylvestris L.) in northern Sweden by Mörling and Valinger (1999). The authors conclude that the amount of heartwood in individual trees is not affected by fertilization and thinning, even though the growth pattern of the trees did change. The influence of tree size and tree form on the size and shape of heartwood and sapwood in Pinus sylvestris was reported by Ojansuu and Maltamo (1995). They found that the proportion of heartwood was related to stand density and social status of the tree, and reported a monotonic sapwood area taper from the base to the top of the stem.

The effects of growth rate and silvicultural treatments on amount of heartwood have been reported previously in conifer species. Ericsson (1966) reported lower heartwood content in thinned stands (33\%) than in unthinned stands (40\%) in a survey study on Pinus sylvestris stands. Margolis et al. (1988) reported an increased heartwood area in heavily pruned Abies balsamea trees. In a study on the effects of pruning regimes in 25-year-old 
Pinus sylvestris by Långström and Hellqvist (1991), pruning reduced growth and increased heartwood area.

Studies on the relationship among crown composition, crown structure and stem growth, suggest that sapwood formation is high correlated with the amount of foliage, and consequently also with the area or spacing of the trees within a plantation. Curtin (1970), Krajicek et al. (1961), and Kendall and Brown (1978), for example, have studied these relations in eucalyptus trees, oak trees and conifers (respectively), while Vincent (1964) and Ramnarine (1994) carried out similar studies on T. grandis. Recent studies carried out in Costa Rica, like those of Morataya et al. (1999) and Pérez (1998) confirm the relationship between sapwood and foliage biomass, and the further relationship with stand density and silvicultural management (thinning and pruning).

Långström and Hellqvist (1991) and Park (1994), evaluated the effects of different pruning regimens on tree growth, sapwood area, and timber quality in conifer species. Branchiness strongly affected the value of saw timber irrespective of the end use; however it was not always possible to transform differences in branchiness into differences in timber value. Mäkelä et al. (1997) found in simulations carried out for Scots Pine, that heartwood content is related to stand density management, being greatest in the suppressed trees of dense stands and least in the dominant trees of sparse stands. As sapwood must continually be laid down concurrent with crown growth, the amount of sapwood can only be maintained at an optimum by the formation of heartwood. Heartwood formation acts as a regulatory mechanism for controlling the amount of sapwood; therefore, it is possible to influence the formation of heartwood by managing the stand density (Bamber 1976).

\subsubsection{Pruning regimens}

Although teak is an established high-value tree for commercial planting, the resulting timber may not produce the expected quality and yield (Tze 1999). Pruning has been a common, though empirically developed, silvicultural technique used to obtain high quality timber (Hubert and Courrand 1988). Knots are widely considered as the most determinant defect for wood quality classification; to the point of influencing the origin and magnitude of other defects such as pith eccentricity, stem-form deviation from the geometric cylinder shape, and bending (Rosso and Ninin 1998).

International grading rules have strict standards for classifying high-quality timber, including the appearance of knots (number, frequency, diameter, sound or unsound). Yield and market prices decrease considerably for trees without pruning interventions, since lumber must be almost free of knots in order to be sold at attractive prices. For instance, international grading rules do not allow the presence of knots on timber wood of "special" grade. For first quality or grade 1, the permissible amount of knots is one per linear meter, with a maximum diameter of $1.25 \mathrm{~cm}$. For the lowest grade within international standards (grade 3), a total of three knots per linear meter with a maximum of $3.81 \mathrm{~cm}$ of diameter is

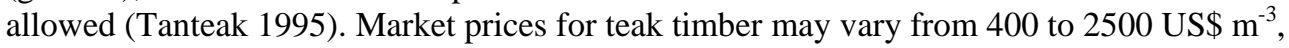
depending on the grading rate assigned to the product.

Torres et al. (1995) carried out a silvicultural evaluation of tree plantations in Costa Rica, and found that pruning is more often considered to be a cleaning activity rather than a silvicultural technique. More often is the practice of drastic pruning (removal of almost all the branches) of young trees in teak farms and even in medium-size companies. There are few recommendations for pruning intensities for timber species in Costa Rica. In general, it is recommended to prune trees up to $50 \%$ of the total height just after the first thinning (Keogh 1987, Chaves and Fonseca 1991, Galloway 1993), or according to commercial log sizes, i.e. up to $2.5 \mathrm{~m}$ sections (Murillo and Camacho 1997). Majid and Paudyal (1992) 
consider that pruning should be done at early stages in order to minimize knotty cores. Moreover, early pruning (at 2 or 3 years of age for tropical species) should be performed on all trees to avoid suppression by neighboring trees. Hubert and Courrand (1988), Hochbichler et al. (1990), and Raets (1964) consider that the diameter at pruning height should be three times greater at harvesting than it was at pruning, in order to make the activity economically profitable.

In many countries where large-scale teak plantations have been established recently, the importance of intensive and on time pruning interventions is not yet clear. In Central America, for instance, pruning is carried out arbitrarily, i.e. executed after visual assessment using subjective criteria, without considering important scientific and economical criteria such as maximization of volume free of knots vs. costs of pruning. The pruning of teak trees must be carried out intensively during early plantation stages, since later the costs of the activity increase while the benefits decrease.

\subsubsection{Thinning regimens}

Intensive management practices for teak plantations worldwide are focusing on proper thinning regimens, as it has been clearly shown that high intensity thinning offers greater advantages than low intensity-thinning for saw timber production objectives,. In Costa Rica, the government started to promote the establishment of teak plantations for high yield and high quality timber in 1980. However, yields have been lower than expected (mean DBH of 35 to $40 \mathrm{~cm}$ and stand volume of 200 to $300 \mathrm{~m}^{3} \mathrm{ha}^{-1}$ expected at age 20 years). Despite the large-scale planting, widespread intensive management is relatively new and little is known about the optimum spacing and thinning guidelines needed to maximize productivity. T. grandis appears to be a strongly site sensitive species and with strong discriminative growth, i.e. a quarter of the trees can account for more than half of the BA increment as vertical dominance appears due to competition (Lowe 1976).

Few scientifically-based recommendations for thinning teak plantations in Central America are available in the literature. Therefore, current management practices have been developed from general management guidelines for tropical tree species and adapted to each site's growing conditions by trial and error. Thus, management guidelines for teak in Costa Rica are not well documented and although plantations have been better-managed in terms of stocking density in the last 10 years, the real potential of the species is still been undermined by the absence of intensity management guidelines, which so far have been very general suggesting that $25 \%$ to $50 \%$ of the standing trees be removed 3 to 4 times during 20 to 30 year rotation cycles, and that the thinning timing be determined based on indicators such as BA, crown area occupancy, or the yearly growth increment.

As T. grandis grows faster in Central America than in many other countries, it is difficult to compare management regimens and growth responses. Ramnarine and Jhilmit (2003), for instance, indicate that in Trinidad and Tobago teak is managed in 50-year rotations, with 6 thinning interventions under an initial planting density of 2,200 trees per ha, for a Mean Annual Increment in total volume (MAI $\mathrm{Vol}_{\text {ol }}$ ) of 7 to $10 \mathrm{~m}^{3} \mathrm{ha}^{-1}$ year $^{-1}$ in high quality sites. Scenarios for teak plantations in Trinidad and Tobago, developed by Ramnarine (1994), contemplate a maximum production of $125 \mathrm{~m}^{3} \mathrm{ha}^{-1}$ and $100 \mathrm{~m}^{3} \mathrm{ha}^{-1}$, with a mean DBH of $20 \mathrm{~cm}$ and $32 \mathrm{~cm}$, for 20 -year-rotation stands without thinning and for stands with three thinning interventions, respectively. Management prescriptions for fastgrown T. grandis are numerous, e.g. for teak in Brazil (Torres 2000), in the Neotropics (Centeno 1997), in Costa Rica (Vasquez and Ugalde 1995), in Tanzania (Evans and Wood 1994), in Ivory Coast (Dupuy and Verhaegen 1993), among others, however each study deals with specific areas of management or growth potential and does not present a precise 
set of integrated guidelines for an intensive management applicable to Central American growing conditions.

Very few tests have been established to evaluate the sensitivity of tree growth and stand productivity to different thinning intensities and periods. Chaves and Chinchilla (1991) established one of the few known thinning trials in Costa Rica, evaluating the growth response of teak plantations after several thinning intensities (BA over $23 \mathrm{~m}^{2}$ ha' lowered to BA between 15 and $20 \mathrm{~m}^{2} \mathrm{ha}^{-1}$ ). They found yearly increases of $5.0 \mathrm{~m}^{2} \mathrm{ha}^{-1}$ on the most intensely thinned plots. Vasquez and Ugalde (1995) evaluated teak plantation growth in several regions of Costa Rica, and concluded that on medium quality sites thinnings should allow the BA to grow between 15 and $20 \mathrm{~m}^{2} \mathrm{ha}^{-1}$ and over $20 \mathrm{~m}^{2} \mathrm{ha}^{-1}$ on high quality sites.

Although thinning is a fundamental and well-known management practice in forestry, particularly important in fast-growing forest species such as teak, the frequency and timing of the interventions is still carried out based on insufficient technical criteria unrelated to the production objectives. High individual tree growth, high stand productivity, or a point in between, should be defined as the main objective of production and a thinning regimen should be developed accordingly. How thinning frequency and timing affects the production of trees with specific dimensions must be known in order to define the best strategy to follow.

\subsubsection{Merchantable volume equations}

Accurately predicting intermediate and final harvests depends largely on the availability of individual-tree volume equations. Management practices for $T$. grandis have been improved in the last decade, however accurate volume equations are not available yet; the only results reported for Costa Rica are those generated by Camacho and Madrigal (1997), and they are limited to $\mathrm{DBH}<30 \mathrm{~cm}$ (total volume equations) for fixed minimum diameters of 5.0 and $8.0 \mathrm{~cm}$ (merchantable volume equations). In other regions and countries, volume equations for teak have been reported by Chakrbarti and Gaharwar (1995) for Karnataka, Madhya Pradesh, West Bengal and another 9 states in India; by Gonzales (1985) for Nueva Vizcaya (Philippines); by Hamzah and Mohamed (1994) for Mata Ayer in Malaysia; by Moret et al. (1998) for Venezuela; by Nunifu and Murchinson (1999) for northern Ghana; by Phillips (1995) for Sri Lanka; by Ramnarine (1994) for Trinidad in Tobago; by Sandrasegaran (1969) for north-western Malaya, and by Singh (1981) for Kerala, West Bengal, Madhya Pradesh and another 6 states in India.

Since growing rates, management regimens, and production objectives are specific to each country or world region, volume equations should not be generalized assuming that trees have similar bole shapes. For instance, different thinning and pruning regimens alter the stem form significantly (taper, wood defects, eccentricity, and height/DBH ratio) and consequently volume predictions may not be accurate if calculated independent of the stand characteristics. This has been the case in Central American countries, where volume estimates have been made either by using volume equations developed in other regions (with different growth patterns and management regimens, such as India) or using general geometric volume equations with a form factor allowance. Furthermore, commercial volume of teak stands has been arbitrarily estimated from the visual classification of the trees in terms of number of logs up to a "commercial height" and a general diameter reduction factor, which shows the urgent need for merchantable volume equations.

Most of the volume equations tested for $T$. grandis elsewhere predicts higher values than those few existing models for Costa Rica. Nevertheless, this occurs at DBH $>30 \mathrm{~cm}$, since below this diameter, most of the models show similar trends. One reason for the differences among models is the maximum DBH limit of the sample data used to test the 
model, as only a few models included large trees (e.g. Gonzales 1985, Ramnarine 1994, Chakrbarti and Gaharwar 1995, Moret et al. 1998). Most of the other models tested for $T$. grandis previously, including those of Camacho and Madrigal (1997) for Costa Rica, used young and middle-aged trees with $\mathrm{DBH}<30 \mathrm{~cm}$.

Estimating the total volume of trees and stands, as well as the merchantable volume of standing trees and eventually harvested logs, is extremely important for the biological asset valuing of teak plantations. It is necessary to have an accurate estimate of the wood volume to be harvested and its eventual commercial value prior to each thinning and the final harvest. To accomplish this, accurate volume equations and sampling procedures have to be properly developed and implemented in the analysis. Additionally, accurate growth and yield projections and the concomitant return-on-investment projections must be made, and scientifically-based tools to determine asset value (such as total and merchantable volume equations) must be implemented to ensure the financial credibility and attractiveness of a tree plantation project.

\subsubsection{Growth scenarios}

Costa Rica and other countries in Central America have a variety of fertile soils (sandy loam, well-drained, pertaining to the Inceptisols order), high rainfall regimens (760 to 5000 mm year ${ }^{-1}$ ), and climatic regions (humidity over $70 \%$, temperatures between 25 and $30{ }^{\circ} \mathrm{C}$ in average, within the life zones Tropical Dry Forest, Very Humid and Humid Premontaine Forest, and Tropical Rain Forest), which create a set of suitable conditions for the culture of teak (Chavarría and Quirós 1985, Bertsch 1995, Briscoe 1995, Vasquez and Ugalde 1995, Montero 1999). These exceptional environmental conditions enable the species to achieve higher individual and stand growth rates, making it difficult to compare with those reported for other countries in Tropical America. Consequently any management guideline or regimen developed elsewhere should not be implemented in Costa Rica without first adapting it to local conditions.

Ramnarine (1994), Hedegart (1988), Weerawardane (2000), and Maung (2000), for example, report growth rates, management schedules, and stand yield for T. grandis in Trinidad and Tobago, Tanzania, Sri Lanka, and Myanmar, respectively, that would be difficult to implement in Costa Rica due to differences in rotation length, individual tree growth, initial planting densities, stocking densities and thinning regimens, production objectives, etc., that would be applicable only to medium and low quality site classes in Costa Rica. Ramnarine (1994), for example, suggests a standing volume of $100 \mathrm{~m}^{3} \mathrm{ha}^{-1}$ and a cumulative volume of $250 \mathrm{~m}^{3} \mathrm{ha}^{-1}$ at 20 years, in comparison to over $200 \mathrm{~m}^{3} \mathrm{ha}^{-1}$ of standing volume and over $400 \mathrm{~m}^{3} \mathrm{ha}^{-1}$ of cumulative volume suggested for T. grandis in Costa Rica and other countries in Latin America (Vásquez and Ugalde 1995, Vallejos 1996, Centeno 1997, Pérez et al. 2000).

Production objectives, management strategies, and administrative directions towards the overall development of a forest stand need to be canalized through a set of growth scenarios. This important guiding tool is fundamental for orienting the operative department towards the achievement of the production goals of the company. The growth scenarios should reflect the expected future growth and value of a plantation, and point the way to achieving the expectations for particular site conditions and management strategies.

Initial spacing and the first thinning are the most important decisions in a rotation because they largely define the course and flexibility of subsequent operations and are critical to the maintenance of stand vigor and growth (Lewis et al. 1976, in Evans 1992). Crown closure has been found to be a good indicator for first thinning in tropical plantations grown for saw timber, because this characteristic correlates well with initial 
reductions in diameter growth (Muziol and Sanchez 1992, in Galloway 2001). Crown expansion requires energy and late thinned trees already suffering from low carbohydrate availability will be slow to respond to thinning, if they do so at all. Furthermore, diameter growth lost during periods of inter-tree competition can only be recovered by lengthening the rotation in stands that do respond to thinning (Oliver and Larson 1990).

Crown closure may be a good indicator for the first and second thinning of fast growing tropical plantations, but it is not useful for determining final stand density. In wellestablished, dense, young plantations, competition for light drives crown recession which leads to rapid reductions in diameter growth. As stands are opened up by early thinnings, however, site factors play a major role in determining potential tree growth. The existence of hundreds of small, unthinned plantations across diverse geographical regions makes it possible to determine site potential over a wide range of climatic and edaphic conditions (Galloway 2001).

Basal area curves level off quickly in dense and fast-growing tropical plantations, so that estimates of maximum BA (the point where BA begins leveling off, and the stand approaches site potential) can be determined at relatively young stages. Estimates of maximum BA for species growing on diverse sites can provide a useful tool for planning thinning regimens and for defining final stand density. With these values, and if the desired final tree size is known, one can derive an approximate projection of appropriate stocking for final rotation (Galloway 2001).

An efficient way to increase teak plantation productivity is to optimize stand density and rotation age (Jayaraman and Zeide 2003). Thinning is usually carried out in order to improve the economic output of the plantation. Part of the wood, which otherwise would be lost or remain until the clear felling, is harvested at an earlier stage of the rotation. The remaining stand has, through released competition, more rapid diameter growth, thus enabling a shorter rotation or larger dimensions, or both. Finally, by thinning, the best quality trees can be left for the final felling (Persson 1986).

Individual tree volume increases in an optimal sigmoid pattern as long as no limitations arise. At first, growth is slow, while foliage, fine roots and other tissues develop. A period of rapid development follows, during which the increments in foliage and root growth outpaces the growing energy demands required for respiration. This period corresponds to the time when a tree grows most rapidly in volume. A tree will remain in this period of rapid growth until it approaches physiological maturity or until it enters into competition with other trees. If a young tree enters into severe competition, its volume growth rate will be rapidly reduced (Galloway et al. 2001).

Crown recession and inhibition of lateral crown expansion is extremely important in young stands. Trees suffering from lateral competition will continue to grow in height, but as the stand ages, relative crown size decreases. Energy demand increases as the trees grow in height because live tissues are active in respiration (in the trunk and roots), increasing with time (Waring and Schlesinger 1985). For this reason, less photosynthate is available to be allocated to diameter growth, and with time, even to height growth. Consequently, in dense plantations subjected to marked inter-tree competition, height growth is not a reliable measure of site productivity (Galloway et al. 2001). According to Chadwick and Larson (1990), when suppressed trees are released, their limited photosynthetic surface area expands very slowly, eventually causing resumption of normal height growth and crown expansion. When dominant trees are released, the large crowns and rapid height growths allow rapid crown expansion. Consequently, drastic and difficult-to-recover reduction in stand BA and total volume occurs when tree diameter growth has been permitted to reduce markedly due to competition. 
In growth and yield models, competition or growth modifiers are usually defined as a function of stand BA or other variables indicating stocking density of the stand (Hilt and Teck 1988, Wykoff and Monserud 1988, Monserud and Sterba 1996). Predictions of stand development depend largely on ecological concepts. Qualitative silviculture applies principles, concepts and models from population ecology, production ecology and biometrics to assess and make predictions relating to various aspects of stand development. It also relates how density influences stand structure, canopy dynamics and production efficiency (Jack and Long 1996).

The foremost purpose of a thinning model is to predict the outcome of a thinning, whether to model a component of forest growth or to determine the immediate result of removing trees from a stand. Construction of a thinning model is an empirical process; the model has to serve as an explanation for advisable observations. Given satisfactory performance of a model with respect to the observations, it is assumed that the model is suitable for thinning predictions in similar stands (Daume and Robertson 2000). Success in the management of plantations of fast-grown tropical tree species can only be achieved by performing intensive and timely silvicultural interventions (Lowe 1976, Larson and Zaman 1985, Ola-Adams 1990). It is necessary to determine which spacing promotes early canopy closure to control weed growth and to reduce coarse branching as well as to optimize wood production on an individual and stand basis (Ola-Adams 1990).

Ola-Adams (1990) concluded after evaluating a spacing trial in Nigeria that T. grandis should be planted at densities between 1189 and 1680 trees ha $^{-1}$, as individual tree growth declines at higher densities and stand growth potential is not reached at lower densities. Other studies suggest that the critical point for the BA of $T$. grandis plantations varies between 15 and $32 \mathrm{~m}^{2}$ ha $^{-1}$ (Lowe 1976, Keogh 1979, Torres 1982). However, if the objective is to maximize individual tree size, the upper BA limit will certainly have to be reduced to $25 \mathrm{~m}^{2} \mathrm{ha}^{-1}$ and less, for medium and high quality sites. In another thinning trial established in Costa Rica, Chaves and Rodriguez (1995) found that for a seven-year-old $T$. grandis plantation the highest increment of $\mathrm{DBH}$, total height, and BA corresponded to the treatments were the BA had been reduced to $17 \mathrm{~m}^{2} \mathrm{ha}^{-1}$.

Two major factors influencing sawn wood grade and recovery are unsound hollow knots and deep flutes in the logs. However, no adequate data are available for the timber grown with intensive silvicultural practices, including pruning (Bhat 1998). Height growth is less sensitive to fluctuations in carbohydrate production than diameter growth and is generally less affected by pruning treatments. Pruning changes the distribution of growth along the bole. Removing productive lower branches reduces diameter increases on the lower bole, whereas the upper bole is nearly unaffected. Annual diameter or volume growth rates of severely pruned trees may eventually recover to equal unpruned tree growth rates, but cumulative growth rates are unlikely to recover lost growth (O’Hara 1991). Generally, plantations are denser and have more uniform spacing than natural forests. In many, if not most species, natural pruning is never a satisfactory option, even after branch senescence if production of clear wood is a management objective (Galloway 2005, personal communication).

Hubert and Courrand (1988) consider that the diameter at pruning height must be three times greater at the end of the rotation in order to recover the investment in pruning. Hochbichler et al. (1990) made similar assumptions when defining the maximum pruning height and intensity for oak stands. Trees fostered by the elimination of undesired branches showed increased timber quality. In some cases measuring or estimating the largest branch diameter is enough for grading a log (Houllier et al. 1995). More precise methods for evaluating knot formation under different stand scenarios include tree growth models for estimating the cumulative cross-sectional area of all branches that were ever attached to the 
stem. The development of branchiness under different stocking and pruning interventions can be then predicted (Mäkelä 1997).

Silvicultural strategies are formulated so that tree plantations meet specific objectives. Production objectives vary widely in Central America ranging from fuel wood to saw timber. All stands grown for saw timber require early, heavy and repeated thinnings in order to sustain the rapid diameter growth of the selected trees. An adequate number of trees are required initially to suppress weed competition and to ensure a sufficient number of final crop trees of good quality (Galloway 2001).

\subsubsection{Plantation costs and wood prices}

Besides the esthetic characteristics of the wood (with special attention to the golden-yellow color), sufficient size is one of the most important criteria in saw milling. A minimum size is required in many processes and increased log diameter usually means increased sawing yield (Persson 1986, Kyaw Min 1996b). Teak logs and saw timber are graded on the basis of the defect system determined by visual assessment. Teak log grading in depots considers, among other defects, bend, taper, hollowness, splits, sound and unsound knots, fluting, twist, surface and heart cracks, sapwood, and pith (Suri 1974, Kyaw Min 1996a, Kyaw Min 1996b).

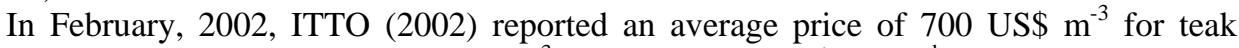
round wood, ranging from 2,000 US\$ $\mathrm{m}^{-3}$ for teak logs of $1^{\text {st }}$ and $2^{\text {nd }}$ grade quality to 600 US $\$ \mathrm{~m}^{-3}$ for $4^{\text {th }}$ grade teak logs (which would be the rating to be given to Costa Rican plantation-grown logs with a minimum diameter of 29-48 cm).

There is no uniform grading and pricing system for teak wood in Central America and other tropical countries. Buyers and sellers mutually determine the price after reaching a consensus on the basis of log size, wood quality, and volume under negotiation. T. grandis timber prices in Costa Rica do not fluctuate less than elsewhere; local forest companies, focused on foreign markets, are exporting logs (mainly to India) with prices ranging from 70 to over 500 US $\$ \mathrm{~m}^{-3}$, according to timber characteristics (i.e. minimum diameter, defects, heartwood proportion, maturity).

The lack of cost data for different silvicultural activities in tree plantations has created an environment of relative uncertainty among investors, projects, and farmers regarding the economic feasibility of tree plantations. In addition to this, the lack of standardized grading rules and wood prices for most tropical hardwoods in Central America increases the level of uncertainty. Gomez and Reiche (1996) carried out a survey on the costs of establishing and managing tree plantations and agroforestry systems in Costa Rica up to the fifth year of production. Thinning, harvesting, and management costs beyond year five have been estimated since then based on different un-published and officially unacknowledged information sources.

\subsubsection{Financial profitability}

There have been very few published reports about the profitability of teak plantations in Costa Rica (and Central America) mainly due to the lack of precise information on plantation costs and wood prices. T. grandis plantations are still young (less than 15 years); therefore those few reports on profitability are supported partially by real costs and revenues and partially by projections. Other reports on the profitability of teak plantations in different regions of the world (mainly in Asia), are not comparable to Central America due to lower growth rates, different timing and intensity of management practices, and longer rotation periods implemented in Asiatic teak culture, as discussed previously. 
Oviedo (1997) carried out a study determining the optimal financial and biological turnover for five reforestation species in Costa Rica, based on growth projections, cost reports, and wood prices gathered from different sources. For T. grandis plantations, the highest return on investment was obtained on high quality sites (NPV $=10223 \mathrm{US} \$ \mathrm{ha}^{-1}$; interest rate of 5\%), while the lowest return was obtained on low quality sites (NPV = 5201 US\$ ha ${ }^{-1}$; interest rate of 5\%). In India, economic studies on teak plantations and teak wood trade suggest a generally positive commercial environment to profit from teak investments in the country. Chundamannil (2000), for example, indicates an NPV of 9,182 US\$ ha ${ }^{-1}$ (6\% interest rate) for 58 year-old rotations on high quality sites in Kerala, an IRR of $45.2 \%$, and a Cost/Benefit Ratio of 8.9. Devi et al. (2003) report an NPV between 2,831 and 5,628 US\$ ha ${ }^{-1}$, an IRR between 20 and 29\%, and a Cost/Benefit Ratio between 4.0 and 7.15, at an interest rate of $5 \%$ and for 60 year old rotations on teak plantations on high quality sites in Kerala, India.

Studies on the economic feasibility of teak planting are needed to guarantee forest investors a positive environment for establishing forest projects in the country. In addition to the benefits and attractiveness of investing in natural resource managing and environmentally-friendly projects, high levels of interest from investors still rely on the economic feasibility of these projects. Supporting information on this area is still insufficient for teak plantation investments in Costa Rica, as there are few reports on costs, revenues, and overall financial balance of previous companies and projects.

\subsection{Objectives of the study}

The general objective of this study was to develop a set of practical tools for the intensive management of $T$. grandis in Costa Rica (applicable to other countries in Central America), aiming at the optimal balance between individual tree growth and stand yield, and considering the greater biological asset value resulting from improved wood quality. The research was based on the hypothesis that intensive management options (thinning, pruning, short rotation periods) lead to higher returns on investment than the maintenance activities and sporadic silvicultural interventions commonly practiced on the teak plantations of Costa Rica.

The specific objectives of this study were:

(1) To study determinant wood properties for high quality timber grading (Study I).

(2) To evaluate the effects of pruning on tree growth, wood quality, and stand yield (Study II).

(3) To evaluate the effects of thinning on stem form and wood quality (Study III).

(4) To evaluate the effects of thinning on tree growth and stand yield (Study IV).

(5) To develop total and merchantable volume equations as an aid for estimating the biological asset value of teak stands (Study V).

(6) To develop a set of stand growth scenarios for the intensive management of teak plantations in Costa Rica (Study VI).

(7) To carry out a financial analysis based on actual plantation costs and timber prices for Central American teak grown under different proposed growth scenarios (compliment to growth scenarios, presented in the main document).

More in detail, the specific objectives of each study were: 
Study I: The most appreciated wood properties of teak trees and their relationship with tree age

The aim of the study was to evaluate the heartwood, sapwood, and bark content, and wood dry density in young and mature T. grandis trees. The research was based on the hypothesis that middle aged (less than 30 years old) plantation-grown teak planted in Costa Rica presents similar (proportionally stand characteristics) heartwood proportion and wood density to that of advanced age teak (over 60 years old) planted elsewhere. For hypothesis testing, linear and non-linear regression analyses were used to determine the relationship of heartwood, sapwood and bark content, and wood dry density with tree age, DBH, stand density, and geographic location (plantation sites). Afterwards, results were compared with those reported in the literature for teak growing in different regions of the world, particularly in Asia.

\section{Study II: The effects of pruning on tree growth and wood quality}

This study aimed at developing a biologically- and physiologically-based methodology for carrying out the pruning of teak trees up to a maximum height (through consecutive interventions). The research was based on the hypothesis that pruning improves tree quality (stem form, stem taper, heartwood content, in addition to the imminent reduction of knots) without a reduction in tree growth and stand productivity (in relation to non-pruned trees). For hypothesis testing, trees from the thinning trial carried out at the age of 6.1 years were selected for stem analysis, measuring total stem volume (projecting to per hectare values), and evaluating stem form and heartwood content, aiming at studying the effects of pruning on wood quality and stand yield.

\section{Study III: The effects of stocking on wood quality}

The aim of the study was to evaluate different tree quality properties in relation to different stocking density management regimens. The research was based on the hypothesis that thinning improves tree quality (stem form, stem taper, heartwood content, and wood density) without affecting tree growth and stand productivity (in relation to non-thinned stands). For hypothesis testing, heartwood, sapwood, and bark content, and wood basic density were obtained from trees harvested in a thinning trial. In order to evaluate the effect of stand density on heartwood content at stand level, per hectare volume was estimated for each treatment based on the average percentage of heartwood volume of the sampled trees.

\section{Study IV: The effects of thinning on tree growth and stand yield}

The study aimed at evaluating the response of different thinning regimens on individual tree growth and stand yield. The research was based on the hypothesis that on time and heavy thinning regimens maximize individual tree growth without detrimentally affecting stand productivity (in relation to non-thinned stands), i.e. heavy thinning is better than light, and on time thinning is better than late. For hypothesis testing, the thinning trial of Study III served for evaluating individual growth and stand yield under different thinning intensities and timing. Different thinning intensities (from $25 \%$ up to $60 \%$ of the standing trees) were applied at age four years in some treatments and at age six years in others. 
Study V: Total and merchantable volume equations

The aim of this study was to develop equations which best predict individual-tree total volume and merchantable volume for $T$. grandis in Costa Rica. Linear and non-linear regression analyses were used to model the relationship of total volume with $\mathrm{DBH}$, with DBH and total height, and with age, as well as to model the relationship of DBH (and total height) with merchantable volume at variable stem diameter and tree height.

\section{Study VI: Stand growth scenarios}

The aim of the study was to develop stand growth scenarios for T. grandis plantations under different management regimens, site quality conditions, and production objectives. A set of management scenarios with rotation periods of 20 and 30 years of age were developed for different site qualities (high, medium, and low), under two different management guidelines (high individual tree growth vs. high stand growth).

\section{Financial analysis}

For hypothesis testing of the general objective, a financial analysis was carried out which aimed at generating information on teak plantation profitability in Costa Rica under different site quality conditions, management regimens, and rotation periods. The Net Present Value (NPV) and the Internal Rate of Return (IRR) were used as indicators for the financial analysis. Four variables were chosen for the sensitivity analysis: (1) Land price, (2) Establishment costs (including land preparation), (3) Maintenance and management costs (including thinning and harvesting costs), and (4) Wood price.

Two different forest companies were evaluated in Costa Rica. Financial bookkeeping of Company A (medium to small sized with 400 ha of teak plantations) and Company B (large sized with 8,000 ha of teak plantations) were analysed in detail, with the goal of documenting the plantation costs of each company for the overall establishment and management of their forestry operations. Both companies were fairly young, with plantations younger than 10 years of age. A default management scenario was constructed for both companies, consisting of the land value and all operational and administrative costs. Plantation establishment and maintenance costs were obtained from company records for the first five years, while the costs from year 6 on were estimated based on unpublished data. Fully documented reports on commercial teak plantation investments in Costa Rica were unavailable at the time of the study. Another five scenarios of plantation management costs for teak in Costa Rica, cited in the literature, were included in the analysis for comparison purposes. Three cases refer to private plantations (company's internal working documents) reported by De Camino et al. (2002), whereas two cases reported by Pérez (1998) were constructed from different information sources.

Actual wood prices were collected during several visits to sawmills, furniture companies, and independent wood traders in local and international marketing business. In general, wood prices varied with quality, age, size, and provenance region of the trees. However, no clear trend could be identified in the search of a price classification for teak in Costa Rica. Average prices were calculated and implemented in the financial analysis. 


\section{MATERIALS AND METHODS}

The present study demanded the measurement of several private $T$. grandis plantations in Costa Rica. A preliminary visit was carried out on several plantations in the country (over 50 plantations), selecting for a second in depth visit those with important characteristics for the study (different ages, site qualities, locations, management intensities, stand quality). In a second visit, the pre-selected plantations were measured or re-measured (when preliminary measurements were available) at stand level as well as at the individual tree level (stem analysis).

As each plantation presented a different management regimen and site quality, and the oldest plantations presented inadequate management, the information collected had to be carefully analyzed in order to re-create intensive management scenarios for different site qualities and management objectives. In other words, no ideal plantation management examples near rotation period could be identified in the field as a demonstration of the potential growth and yield of the species in Costa Rica.

\subsection{Site location and data set}

Data for the different studies were collected in different regions of Costa Rica, covering almost all climatic conditions where $T$. grandis plantations have been established and the species has adapted well (Figure 2).

Several plantations of different ages and conditions were sampled at each site or region, (Table 1). The evaluation consisted of the establishment and measurement of sample plots as well as the harvest of trees for stem analysis and further analysis of wood properties.

The different studies (I-VI) are based on field information collected by the author from private plantations available at the moment (Table 2). The sample data was very heterogeneous in terms of climate, site quality, management system, age, and the distribution of these and other characteristics geographically, as in the end some areas presented many more sample points than others. There are no proper records in the national forestry inventory on the existence of teak plantations in the country, as all the projects are privately funded. A small proportion has been covered by forestry incentives and, therefore, is registered; however, these records contain little information on the plantations' management history. 


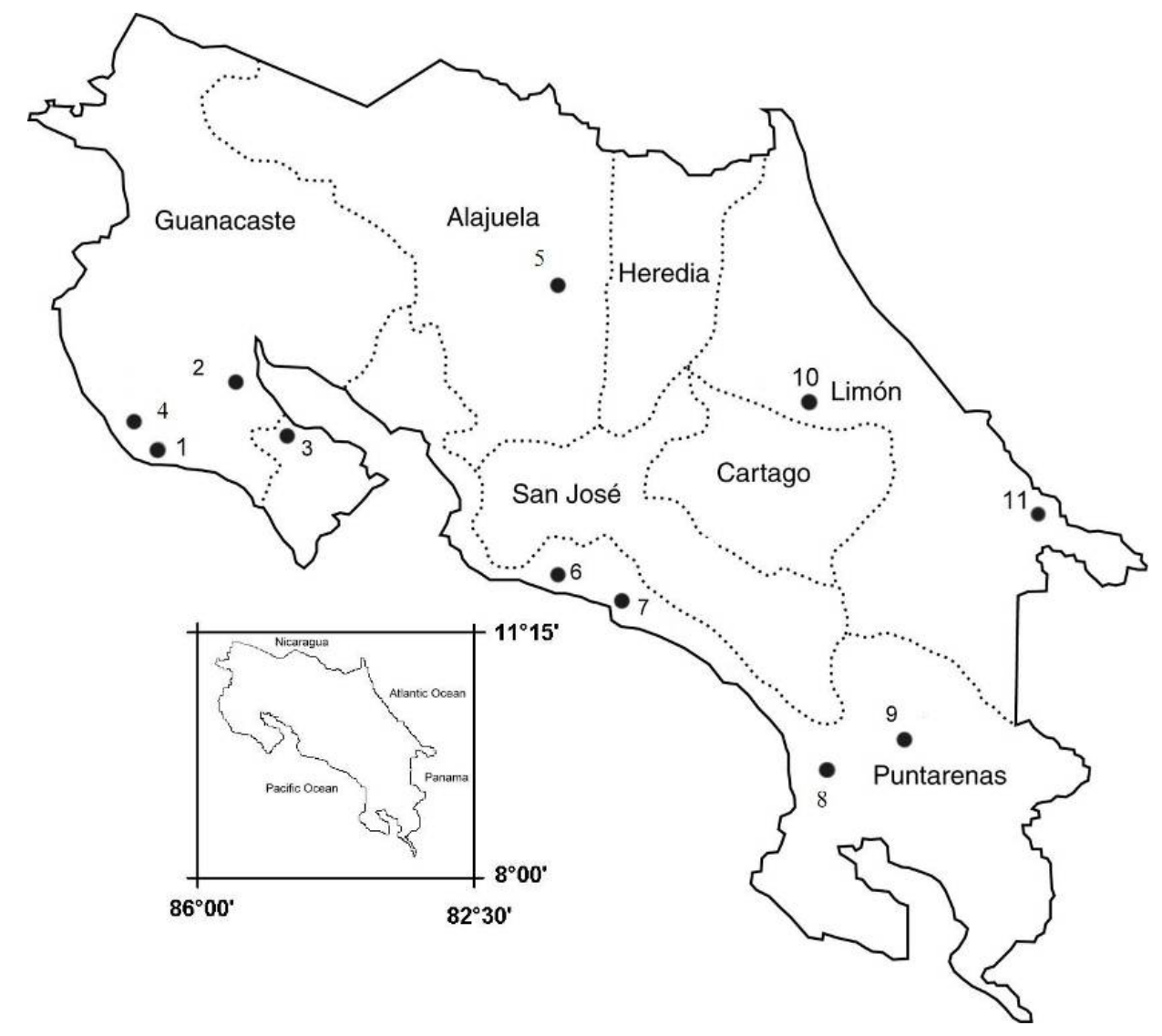

Figure 2. Location of the research sites were $T$. grandis plantations were evaluated for the different studies. 
Table 1. General data from the research sites in Costa Rica where teak plantations were evaluated.

\begin{tabular}{|c|c|c|c|c|c|c|c|}
\hline $\begin{array}{l}\text { Site } \\
\text { code }\end{array}$ & Location & $\begin{array}{l}\text { Precipitation } \\
\left(\mathrm{mm}^{-1}{ }^{-1}\right)\end{array}$ & $\begin{array}{c}\text { Dry } \\
\text { months }{ }^{\text {a) }}\end{array}$ & $\begin{array}{c}\text { Elevation } \\
\text { (m) }\end{array}$ & $\begin{array}{c}\text { Mean annual } \\
\text { temperature } \\
\left({ }^{\circ} \mathrm{C}\right)\end{array}$ & 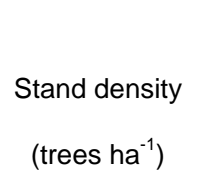 & $\begin{array}{l}\left.\text { Age }^{\mathrm{b}}\right) \\
\text { (years) }\end{array}$ \\
\hline 1 & Carrillo & 1659 & 6 & 100 & 26.1 & $667-736$ & $8-10$ \\
\hline 2 & Jicaral & 1659 & 6 & 85 & 26.8 & $333-750$ & $11-18$ \\
\hline 3 & Tempisque & 1901 & 6 & 30 & 27.1 & 389 & $14-20$ \\
\hline 4 & Garza & 2205 & 6 & 90 & 25.9 & 816 & 6 \\
\hline 5 & San Carlos & 3393 & 1 & 90 & 26.1 & $640-1600$ & 8 \\
\hline 6 & Parrita & 3117 & 3 & 25 & 26.0 & $156-541$ & $13-47$ \\
\hline 7 & Quepos & 3900 & 3 & 70 & 25.9 & 775 & 19 \\
\hline 8 & Palmar Norte & 3644 & 3 & 80 & 27.0 & 893 & 23 \\
\hline 9 & Buenos Aires & 3627 & 4 & 300 & 27.0 & 357 & 27 \\
\hline 10 & Guapiles & 4107 & 0 & 250 & 26.0 & 494-896 & $5-12$ \\
\hline 11 & Cahuita & 3000 & 0 & 50 & 26.0 & Lines $^{c)}$ & 9 \\
\hline
\end{tabular}

a) Months with less than $100 \mathrm{~mm}$ annual rainfall.

b) Single age entry means that sampled trees were of same age (does not mean average age)

c) Trees planted in lines at a distance of $3.0 \mathrm{~m}$ from one another. 
Table 2. Description of the field data used in the different studies.

\begin{tabular}{|c|c|c|c|}
\hline Study & Site* & Data & Comments \\
\hline I & $1-11$ & $\begin{array}{l}\text { A total of } 87 \text { trees between } 13 \text { and } \\
47 \text { years of age were felled for stem } \\
\text { analysis. The dry density was } \\
\text { determined from all the } 11 \text { study } \\
\text { sites ( } 32 \text { trees); heartwood, sapwood } \\
\text { and bark content were measured in } \\
70 \text { trees from sites } 1-9 .\end{array}$ & $\begin{array}{l}\text { Trees from sites } 10 \text { and } 11 \\
\text { presented no heartwood } \\
\text { content at the time of } \\
\text { evaluation. In addition, wood } \\
\text { samples could only be taken at } \\
\text { the base of the tree and at the } \\
\text { base of the crown. }\end{array}$ \\
\hline II & 4 & $\begin{array}{l}\text { The trial consisted of a complete } \\
\text { block randomized design with four } \\
\text { treatments and three replications, } \\
\text { established on a } 2 \text {-year-old } \\
\text { plantation. Each plot contained } 25 \\
\text { trees, planted at } 3.5 \times 3.5 \text { m spacing. } \\
\text { Thirty-six trees from the thinning } \\
\text { carried out at age } 6 \text { years were } \\
\text { selected for stem analysis. }\end{array}$ & $\begin{array}{l}\text { Study area was classified as a } \\
\text { high quality site, presenting } \\
\text { high growth increments and } \\
\text { good stem form. Site was very } \\
\text { homogenous with no significant } \\
\text { differences at the } \\
\text { commencement of the } \\
\text { experiment (age } 4 \text { years). }\end{array}$ \\
\hline III & 5 & $\begin{array}{l}\text { The trial consisted of randomized } \\
\text { complete blocks, with } 8 \text { treatments } \\
\text { and } 3 \text { replications, established in a } 4 \text { - } \\
\text { year-old plantation. Each treatment } \\
\text { consisted of } 80 \text { trees in square } \\
\text { blocks of } 500 \mathrm{~m}^{2} \text {. A total of } 24 \text { trees } \\
\text { ( } 3 \text { individuals per treatment, } 1 \text { per } \\
\text { replication) were harvested for stem } \\
\text { analysis. }\end{array}$ & $\begin{array}{l}\text { The study on wood properties } \\
\text { was planned after the thinning } \\
\text { intervention; therefore the } \\
\text { harvesting of more individuals } \\
\text { was not possible as different } \\
\text { changes could occur on each } \\
\text { thinning treatment. }\end{array}$ \\
\hline IV & 5 & $\begin{array}{l}\text { The trial consisted of randomized } \\
\text { complete blocks, with } 8 \text { treatments } \\
\text { and } 3 \text { replications, established on a } \\
\text { 4-year-old plantation. Each treatment } \\
\text { consisted of } 80 \text { trees in square } \\
\text { blocks of } 500 \mathrm{~m}^{2} \text {. [Same trial used for } \\
\text { Study III] }\end{array}$ & $\begin{array}{l}\text { Study area was classified as a } \\
\text { medium quality site. One } \\
\text { replication presented significant } \\
\text { differences from the other two } \\
\text { upon commencement of the } \\
\text { experiment. }\end{array}$ \\
\hline V & $1-11$ & $\begin{array}{l}\text { A total of } 112 \text { trees (suppressed, } \\
\text { dominants and co-dominants) with } \\
\text { ages between } 5 \text { and } 47 \text { years were } \\
\text { felled for stem analysis. An } \\
\text { independent data set of } 44 \text { trees of } 6 \\
\text { and } 8 \text { years old was used to validate } \\
\text { the best models. }\end{array}$ & $\begin{array}{l}\text { The number of individuals } \\
\text { varied from one plantation to } \\
\text { another, for instance a larger } \\
\text { number corresponded to young } \\
\text { plantations since advanced- } \\
\text { aged ones ( }>15 \text { years of age) } \\
\text { are scarce in Costa Rica. }\end{array}$ \\
\hline VI & $1-11$ & $\begin{array}{l}\text { Over } 150 \text { plots of approximately } 80 \\
\text { trees each (including missing trees) } \\
\text { were measured, with ages between } 1 \\
\text { and } 47 \text { years. In total, } 10707 \text { trees } \\
\text { were measured for this study. }\end{array}$ & $\begin{array}{l}\text { In addition, information from } \\
\text { studies I-V was used for the } \\
\text { development of the growth } \\
\text { scenarios. }\end{array}$ \\
\hline
\end{tabular}

\footnotetext{
* for site codes see Table 1
} 


\subsection{Methods}

Study I: The most appreciated wood properties of teak trees and their relationship with tree age

Stem cross-sectional samples (disks) were taken from each felled tree at 2.0 meter intervals. Total volume $\left(\mathrm{cm}^{3}\right)$ of sapwood, heartwood and stem (with and without bark) was calculated using the Smalian formulae (Clutter et al. 1983). Wood dry density was determined using wood samples of stem sections $(4 \times 2 \times 12 \mathrm{~cm})$ taken at the base of the tree and at the base of the living crown. Linear and non-linear regression analyses were used to determine the relationship of heartwood, sapwood and bark content, and wood dry density with tree age, DBH, stand density, and geographic location (plantation sites).

\section{Study II: The effects of pruning on tree growth and wood quality}

The trial consisted of a complete block randomized design with four treatments and three replications. Each plot contained 25 trees, planted at 3.5 x $3.5 \mathrm{~m}$ spacing. The treatments were:

\#1. Control, no pruning of branches

\#2. Pruning up to a height of 3.0 meters

\#3. Pruning up to a height of 4.0 meters

\#4. Pruning up to a height of 5.0 meters

Diameter at breast height $(\mathrm{DBH})$ and total height were measured before applying the treatments (2.2 years) and afterwards at ages of 3.2, 5.2, 6.1, and 7.3 years. Thirty-six trees from the thinning carried out at the age of 6.1 years were selected for measuring total volume per tree with the Smalian formulae (Clutter et al. 1983), and for carrying out a stem analysis including the evaluation of heartwood content, stem taper, and stem form factor. Analysis of Variance and Duncan's test were carried out for each variable using Systat 10 for Windows.

\section{Study III: The effects of thinning on wood quality}

Stem cross-sectional samples (disks) were taken from each felled tree along the stem at 2.0 $\mathrm{m}$ intervals. The total volume $\left(\mathrm{m}^{3}\right)$ of sapwood, heartwood, and stem (with and without bark) was calculated using the Smalian formulae (Clutter et al. 1983). Wood basic density was determined using wood samples of stem sections $(4 \times 2 \times 12 \mathrm{~cm})$ taken at DBH $(1.3 \mathrm{~m}$ high).

In order to evaluate the effect of stocking on heartwood content at stand level, per hectare volume was projected for each treatment based on the average percentages of heartwood volume of the sampled trees. Analysis of variance (ANOVA) was carried out in Systat 6.0 for the different treatments, including the initial stand density of each plot as covariate for reducing variations due to initial stand differences (initial BA varied from 13.5 to $21.0 \mathrm{~m}^{2} \mathrm{ha}^{-1}$ ). ANOVA was carried out in two-way analysis, i.e. the three thinning regimens (light, moderate, and heavy) in addition to two timings (on time and late) were compared in order to separate the timing effect from the thinning effect. 
Study IV: The effects of thinning on tree growth and stand yield

The trial consisted of different thinning intensities applied at ages 4 and 6 years. The treatments were:

(1) Unthinned [Control],

(2) On time - Light thinning; removal of $25 \%$ of the original trees (1600 trees ha ${ }^{-1}$ ) on the $4^{\text {th }}$ year $\left[25 \% 4^{\text {th }}\right]$,

(3) On time - Moderate thinning; removal of $25 \%$ of the original trees on the $4^{\text {th }}$ year and $25 \%$ of the original trees on the $5^{\text {th }}$ year $\left[25 \% 4^{\text {th }} \& 5^{\text {th }}\right]$,

(4) On time - Moderate thinning; removal of $40 \%$ of the original trees on the $4^{\text {th }}$ year $[40 \%$ $4^{\text {th }}$,

(5) On time - Heavy thinning; removal of $60 \%$ of the original trees on the $4^{\text {th }}$ year $[60 \%$ $\left.4^{\text {th }}\right]$,

(6) Late - Light thinning; removal of $25 \%$ of the original trees on the $6^{\text {th }}$ year $\left[25 \% 6^{\text {th }}\right]$,

(7) Late - Moderate thinning; removal of $40 \%$ of the original trees on the $6^{\text {th }}$ year $[40 \%$ $\left.6^{\text {th }}\right]$,

(8) Late - Heavy thinning; removal of $60 \%$ of the original trees on the $6^{\text {th }}$ year $\left[60 \% 6^{\text {th }}\right]$.

Diameter at breast height (DBH) and total height $(\mathrm{H})$ were measured annually, using a diameter tape and a Suunto altimeter, respectively. The last measurement was carried out at age 8 years, with the aim of evaluating the treatments on two different timings (ages 6 and 8 years) with a similar response period of 2 years after the corresponding thinning interventions (ages four and six years). Average DBH $(\mathrm{cm})$, total height $(\mathrm{m}), \mathrm{BA}\left(\mathrm{m}^{2} \mathrm{ha}^{-1}\right)$, total volume $\left(\mathrm{m}^{3} \mathrm{ha}^{-1}\right)$ and their corresponding Current Annual Increment (CAI) were calculated for each treatment, on each replication, and for each year of measurement. Total volume over bark $\left(\mathrm{V}_{\mathrm{o}}\right)$ was calculated using the volume equations developed for $T$. grandis in Costa Rica by Pérez and Kanninen (2003). Analysis of Variance (ANOVA) and other statistical analyses were carried out using the Systat 10 for Windows.

\section{Study V: Total and merchantable volume equations}

Stem cross-sectional samples (disks) were taken from each felled tree along the stem at 2.0 $\mathrm{m}$ intervals. The total volume $\left(\mathrm{m}^{3}\right)$ was calculated using the Smalian formulae (Clutter et al. 1983). For the estimation of variable-top-height and variable-top-diameter merchantable volume equations, tree volume was calculated at different stem diameter and tree heights, starting from $1.3 \mathrm{~m}$ high (DBH) and ending at the top of the tree (cumulative values). Linear and non-linear regression analyses were used to model the relationship between total volume and $\mathrm{DBH}$, and between $\mathrm{DBH}$ and total height. A total of 12 volume equations found in the literature were tested in this study. The best models were selected based on the coefficient of determination $\left(r^{2}\right)$, the adjusted coefficient of determination $\left(r^{2}\right.$-adj), the root mean square error (RMSE), and the Furnival Index. The latter was used to compare models with different forms of the dependent variable (Furnival 1961).

Equation 1 was used to develop variable-top-diameter merchantable volume equations. Merchantable volume equations of this type have been used by Burkhart (1977), Clutter (1980), and Honer (1964): 


$$
\mathrm{V}_{\mathrm{m}}=\mathrm{V} *\left(1-\mathrm{a} *\left(\mathrm{D}_{\mathrm{m}}\right)^{\mathrm{b}} *(\mathrm{DBH})^{\mathrm{c}}\right)
$$

Where

$\mathrm{V}_{\mathrm{m}}$ : merchantable stem volume $\left(\mathrm{m}^{3}\right)$ to a top diameter $\mathrm{D}_{\mathrm{m}}$,

$\mathrm{V}$ : total stem volume $\left(\mathrm{m}^{3}\right)$ as given by a total volume equation,

$\mathrm{D}_{\mathrm{m}}$ : upper stem merchantability limit (expressed as minimum diameter in $\mathrm{cm}$ )

DBH: diameter at breast height (cm), and

a, b, c: regression coefficients.

Taper equations were not developed in this study since Clutter (1980) showed that for any volume formula of the type of Equation 4 there is a corresponding uniquely defined compatible taper function. The exact form of the taper function can be derived from the volume equation. For a better fit, and in order to correct the non-homogeneity of the variance, the regression coefficients should be estimated by the method of weighted least squares (Cunia 1964), weighting the equation with (DBH) ${ }^{2}$.

Equation 2 was used for developing variable-top-height merchantable volume equations. Merchantable volume equations of this type are reported by Avery and Burkhart (1983), and Kozak et al. (1969).

$$
\mathrm{V}_{\mathrm{m}}=(\pi / 4) *(\mathrm{DBH})^{2} *\left(\mathrm{a} * \mathrm{~h}+(\mathrm{b} / 2) *\left(\mathrm{~h}^{2} / \mathrm{H}\right)+(\mathrm{c} / 3) *\left(\mathrm{~h}^{3} / \mathrm{H}^{2}\right)\right)
$$

Where

$\mathrm{V}_{\mathrm{m}}$ : merchantable stem volume $\left(\mathrm{m}^{3}\right)$ to a top height $\mathrm{h}$,

DBH: diameter at breast height $(\mathrm{cm})$,

h: upper stem merchantability limit (expressed as merchantable height in $\mathrm{m}$ ),

$\mathrm{H}$ : total tree height $(\mathrm{m})$, and

a, b, c: regression coefficients.

\section{Study VI: Stand growth scenarios}

The development of growth functions for DBH and total height with age was based on a fitted curve (Chapman-Richards model). For this, dominant trees (approximately 3800 observations) were selected from the database, corresponding to the $4^{\text {th }}$ Quartile ( $>85^{\text {th }}$ Percentile). The reason for this data selection was to develop different scenarios based on the potential growth of the species under intensive management, i.e. discarding plantations with no adequate management and low growth rates. The DBH and total height growth curves used for developing the management scenarios were constructed for a site class I ( $100 \%$ of the potential), for a site class II ( $80 \%$ of the potential), and for a site class III (60\% of the potential). Anamorphic curves were constructed because the lack of sufficient data, particularly sufficient for stratification of soil, terrain, and other climatic factors did not allow the construction of polymorphic curves. The growth curves used in this study are not based on consecutive measurements in permanent sample plots only but rather on data from both temporal and permanent plots at different plantation ages. 
Stand density indicators

Based on these ecological criteria, and following the methodology used by Alder (1979), a curve of maximum observed $\mathrm{CAI}_{\mathrm{DBH}}$ values was plotted against stand BA. An exponential function was fitted to points of maximum $\mathrm{CAI}_{\mathrm{DBH}}$ line. A second index used in this study contemplates the relationship between the size and the spatial distribution of the canopy with the amount of light intercepted by the leaves, followed by an appropriate plantation density definition for an optimum crown development and the consequent optimization of tree growth (Suri 1975, Beadle 1997). Crown closure is commonly assumed to represent the threshold of strong competitive interaction and stand development (Jack and Long 1996). Finally, a third density index was based on the concept of maximum number of trees possibly encountered in a stand and their negative correlation with the average diameter. The curve representing this relationship assumes a straight-line form when plotted on logarithmic paper and is termed the "reference curve" (Reineke 1933).

The development of growth scenarios was based on fitted curves (Chapman-Richards model) for the modeling of diameter $(\mathrm{DBH})$ and height $(\mathrm{H})$ growth with age. For this, a sub-selection of data discards all plantations categorized as "outliers" due to their significantly different growth and yield patterns (often very poor development). The reason for this data selection is based on the assumption that the management scenarios should reflect the potential growth of the species under intensive management, i.e. discarding plantations with inadequate management and low growth rates.

Three different indices for stand density competition were used for the development of the growth scenarios. The first index consists of Competition Factor (CF), based on the reduction of Current Annual Increment of $\mathrm{DBH}\left(\mathrm{CAI}_{\mathrm{DBH}}\right)$ as a function of different stocking densities expressed as Basal Area (BA). The second index consists of Maximum Site Occupancy (MSO) based on the maximum crown area occupancy in the stand. The third competition index corresponds to the Reineke Density Index - RDI (Reineke 1933).

The Competition Factor (CF) allowed a maximum BA of $30 \mathrm{~m}^{2} \mathrm{ha}^{-1}$ with a growth reduction of maximum $20 \%$ (when the CAI in $\mathrm{DBH}$ reduces in $20 \%$, in relation to the potential growth, a thinning intervention is being trigged), while the Reineke Density Index (RDI) allowed only a maximum BA of $20 \mathrm{~m}^{2} \mathrm{ha}^{-1}$ before exceeding the upper limit of Zone II (maximum individual tree growth), and the Maximum Site Occupancy permitted a total BA of $22 \mathrm{~m}^{2} \mathrm{ha}^{-1}$ for a full site occupancy. When comparing the RDI, the MSO, and the $\mathrm{CF}$, it was evident that both RDI and MSO are basically linear functions of BA, whereas $\mathrm{CF}$ is a non-linear one. In terms of site occupancy allowance, the RDI was "less tolerant" than the MSO and both were "less tolerant" than the CF $(\mathrm{RDI}<\mathrm{MSO}<\mathrm{CF})$.

The first index consisted of a Competition Factor (CF), based on the reduction of Current Annual Increment of $\mathrm{DBH}\left(\mathrm{CAI} \mathrm{DBH}_{\mathrm{DH}}\right.$ ) as a function of different stocking densities, expressed in terms of Basal Area (BA). The CF was defined as:

$$
\mathrm{CF}=1-\left(\mathrm{a} * 10^{\mathrm{b} * \mathrm{BA}}\right)
$$

Where

$\mathrm{CF}=$ Competition factor (relative values between 0 and 1 )

$\mathrm{BA}=$ Stand basal area $\left(\mathrm{m}^{2} \mathrm{ha}^{-1}\right)$

Coefficient $\mathrm{a}=0.003$

Coefficient $b=0.160$ 
It was assumed that $\mathrm{CAI}_{\mathrm{DBH}}$ is maintained close to its maximum at low stand densities, decreasing rapidly (non-linearly) with increasing stand density. The CF values range from 1 (no growth reduction) to 0 (no growth at all).The second index consisted of Maximum Site Occupancy (MSO) based on the maximum crown area occupancy in the stand. The MSO model was defined as:

$$
\mathrm{MSO}=(\mathrm{a} / \mathrm{CA}) / \mathrm{N}
$$

Where

$\mathrm{MSO}=$ Maximum Site Occupancy (relative values between 0 and 1)

$\mathrm{a}=$ area of one hectare $\left(\mathrm{m}^{2}\right)$

$\mathrm{CA}=$ Crown area of the mean tree $\left(\mathrm{m}^{2}\right)$

$\mathrm{N}=$ Initial stand density (trees ha ${ }^{-1}$ )

The crown diameter was estimated from DBH using the model developed by Pérez and Kanninen (2003), and the crown area (CA) was calculated as a geometric circle. It was assumed that the maximum stand density was reached when the site was fully occupied by the crowns. Plantation density was kept within the maximum density limits using the MSO of the standing trees. The Maximum Site Occupancy is expressed in relative values. We assumed the initial stand density $(\mathrm{N})$ to be the maximum stand density at all stages, therefore any possible densities greater than $\mathrm{N}$ (at early stages trees have very small DBH values and the model gives possible stand densities greater than $\mathrm{N}$ ) will be considered as equal to $\mathrm{N}$ and consequently $\mathrm{MSO}=1.0$.

The third competition index corresponds to the Reineke Density Index - RDI (Reineke 1933), defined as:

$$
\mathrm{RDI}=\mathrm{N} *(\mathrm{a} / \mathrm{DBH})^{\mathrm{b}}
$$

Where

RDI= Reineke Density Index (values from 1 to 1049 for $T$. grandis in Costa Rica)

$\mathrm{N}=$ Stand density (number of trees per hectare)

$\mathrm{DBH}=$ diameter at breast height $(\mathrm{cm})$

Coefficient $\mathrm{a}=25$

Coefficient $b=-1.9175$

Construction of the growth scenarios

The construction of the management scenarios was based on DBH and total height growth curves (Study VI). An initial stand density of 1111 trees per hectare, rotation periods of 20 and 30 years, and quality classes defined as high, medium, and low, resulted in a set of stand density management options. The objectives of production concentrated in the individual tree growth or in the stand growth. A maximum reduction on DBH growth was allowed according to the production objectives of the scenario and using the Competition Factor (CF) (Equation 3). The Maximum Site Occupancy criterion (Equation 4) and the Reineke Density Index (Equation 5) were used for comparing the competition levels allowed by the CF. 
A thinning intervention was carried out when the CF caused a reduction in the CAI of DBH equal than $20 \%$ and $50 \%$, for individual tree growth and stand growth objectives, respectively. On each thinning intervention, the Basal Area (BA) was reduced from 20-24 $\mathrm{m}^{2} \mathrm{ha}^{-1}$ (values reached near the upper limits of competition) to $14-17 \mathrm{~m}^{2} \mathrm{ha}^{-1}$ (minimum BA considered for an adequate recovery within a reasonable period of time). In the present scenarios, the extracted BA would be recovered in approximately 4 or 5 years, which we considered a reasonable period of time for carrying out the following intervention. In addition, the extracted volume on each thinning will yield interesting returns as merchantable timber. An exception for using these management criteria was done in the first thinning of all scenarios, as the timing for the first thinning is driven more by light competition and not so much by site productivity (expressed in terms of BA occupancy, for example). Therefore, the first thinning was carried out on most scenarios before reaching the thinning criteria implemented in the following interventions.

\section{Financial analysis}

Based on reforestation and management costs and wood prices, a financial analysis was carried out aiming at generating provisional profitability estimates for teak plantations in Costa Rica under different site quality conditions, management regimens, and rotation periods. The Net Present Value (NPV) and the Internal Rate of Return (IRR) were the two financial indicators used for the analysis. Both indicators have an important role in the analysis of soil value, stand value, and rotation period definition, and for estimating the possible return on investment of a forestry project. Generally spoken, a project is acceptable if the NPV is greater than zero:

$$
N P V=\sum_{y=0}^{n} R_{y} /(1+r)^{y}-\sum_{y=0}^{n} C_{y} /(1+r)^{y}
$$

Where

$\mathrm{NPV}=$ Net Present Value $\left(\mathrm{US} \$ \mathrm{ha}^{-1}\right)$

$\mathrm{Ry}=$ revenues of each year $\left(\mathrm{US} \$ \mathrm{ha}^{-1}\right)$

$\mathrm{Cy}=$ costs of each year (US\$ ha-1)

$\mathrm{y}=$ years $(1,2, \ldots, n)$

$\mathrm{r}=$ interest rate $(\%)$.

The IRR of a project is the discount rate at which the NPV equals zero. In other words, the IRR is the discount rate at which the present value of revenues equals the present value of costs:

$$
\sum_{y=0}^{n} R_{y} /(1+I R R)^{y}-\sum_{y=0}^{n} C_{y} /(1+I R R)^{y}=0
$$

Where

IRR Internal Rate of Return (US\$ ha-1)

$\mathrm{Ry}=$ revenues of each year $\left(\mathrm{US} \$ \mathrm{ha}^{-1}\right)$

$\mathrm{Cy}=$ costs of each year (US\$ ha ${ }^{-1}$ ) 
$\mathrm{y}=$ years $(1,2, \ldots, n)$

$\mathrm{r}=$ interest rate $(\%)$

\section{Reforestation and management costs}

Reforestation costs of the two companies were obtained from records for the first five years only. For the remaining years, the management scenario of each company was used for the cost structure definition. Technical and administrative costs were collected from both companies; thinning and harvest costs included tree felling, sectioning, piling and truck loading with short-distance transportation. Based on the information obtained from the companies, infrastructure costs from year 3 onwards (maintenance of infrastructure) were estimated to be $10 \%$ of the average costs of the first two years. Administration, farming, and plantation maintenance costs were estimated to be between $10 \%$ and $25 \%$ of the average costs up to year 5 .

Costs of different management activities (shoot pruning, circle weeding, initial mowing, complement mowing, replanting) were compiled from the companies. Thinning and harvest costs were estimated based on the expected growth scenarios of each company and harvesting costs reported for teak in Costa Rica. Five studies reported in the literature for Costa Rican teak plantations were included in this study for comparison.

The following modifications were considered to be necessary in order to improve the plantation costs for the financial analysis:

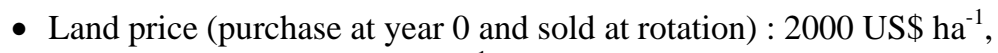

- Land preparation: 288 US\$ ha-1,

- Plantation maintenance: 100 US\$ ha ${ }^{-1}$ for years 1 and 2, and 66 US\$ ha $^{-1}$ for years 3 and 4.

\section{Wood prices}

The actual wood prices were collected during several visits carried out to different sawmills, furniture companies, and independent wood traders working on teak products for local and international markets.

Sensitivity analysis

A sensitivity analysis allows the evaluation of changes in the overall financial analysis when modifying one variable at a time. This approach offers the possibility of identifying the variables with greater influence on the financial equation and which consequently should be studied more in order to know the probability of sudden and drastic changes that would eventually affect the overall investment project positively or negatively.

Four variables were chosen for the sensitivity analysis: (1) Land price, (2) Establishment costs (including land preparation), (3) Maintenance and management costs (including thinning and harvesting costs), and (4) Wood price. These variables were considered to have great significance on the profitability of the plantation project. Reforestation and management costs, and wood prices were adapted to the growth scenarios developed in Study VI, obtaining different profitability scenarios. Each of the four variables was tested individually, lowering and raising the default value by $20 \%$, while the other variables remained unchanged. As several growth scenarios were developed in Study VI, the sensitivity analysis was limited to only those on the high quality site. 


\section{RESULTS}

\subsection{Wood quality (Study I)}

In Study I it was found that the highest heartwood proportion from the tree total volume was $61 \%$, while the lowest only $4.6 \%$. The proportion of sapwood ranged between 24 and $72 \%$, while bark represented from 14 to $37 \%$ of the total volume. Heartwood proportion increased with increasing age, while the proportion of sapwood and bark decreased (Figure 3a). Similar tendencies were observed between heartwood, sapwood and bark proportion and $\mathrm{DBH}$; however they showed a better fit with $\mathrm{DBH}$ than with age. Wood dry density increased slightly with age (Figure 3b), presenting a higher correlation at the base of the tree $(r=0.61)$ than at the base of the crown $(r=0.51)$. Dry density values (both at the base of the tree and at the base of the crown) were statistically different $(\mathrm{P}<0.05)$ only between 8-year-old trees or younger and 47-year-old trees.

The sample data presented high variability, especially at young ages ( $<10$ years). The high variability at young ages may be caused by the physiological instability of trees in relation to wood formation and structure, reflected mainly in the variables: heartwood content and wood density. In addition, tree samples were taken throughout the country, therefore climatic and site conditions may increase the encountered differences, particularly at early stages. In relation to this instability or variability at early plantation stages, Moya et al. (2003) carried out a similar study for T. grandis in Costa Rica and concluded that differences in stand density management had no permanent effect on wood density, as the significant differences found at cambium ages of 6 and 8 years were not significant at year 10. This conclusion suggests that high variability is normal at young ages and tends to decrease after age 10 years for $T$. grandis in Costa Rica.

\subsection{Pruning regimens and the effect on wood properties and tree growth (Study II)}

Study II reports that at 5.2 years of age (3 years after pruning), differences among pruning heights were statistically significant $(\mathrm{P}<0.05)$ for the variables $\mathrm{DBH}$ and total height. $\mathrm{DBH}$ was higher in the stand without pruning and statistically higher from the other pruning heights (4.0 and 5.0 meters) but not from the pruning height of 3.0 meters (Figure 4a). Differences in total height were also significant between the non-pruned stand and the pruning height of 3.0 meters, and between these two and the pruning heights of 4.0 and 5.0 meters. Basal area was not statistically different among pruning heights; however it tended to decrease with increasing pruning height. Per hectare total volume was higher (32\%) for the non-pruned stand and for the pruning height of 3.0 meters than for the pruning heights of 4.0 and $5.0 \mathrm{~m}$, three years after pruning, i.e. at age 5.2 years (Figure $4 \mathrm{~b}$ ). The significant differences on tree growth found between the pruning height of 3.0 and that of 4.0 meters is caused by the location of the branches in young teak stands. At the moment of pruning, trees presented an average tree height of $7.0 \mathrm{~m}$, concentrating the foliage biomass (and branches) between the $4^{\text {th }}$ and the $6^{\text {th }}$ meter of height. Consequently, the removal of an extra portion of branches above 3.0 meters of height caused a significant reduction in tree growth. This result confirms the importance of carrying out an on-time and proper-intensive pruning on the species. 


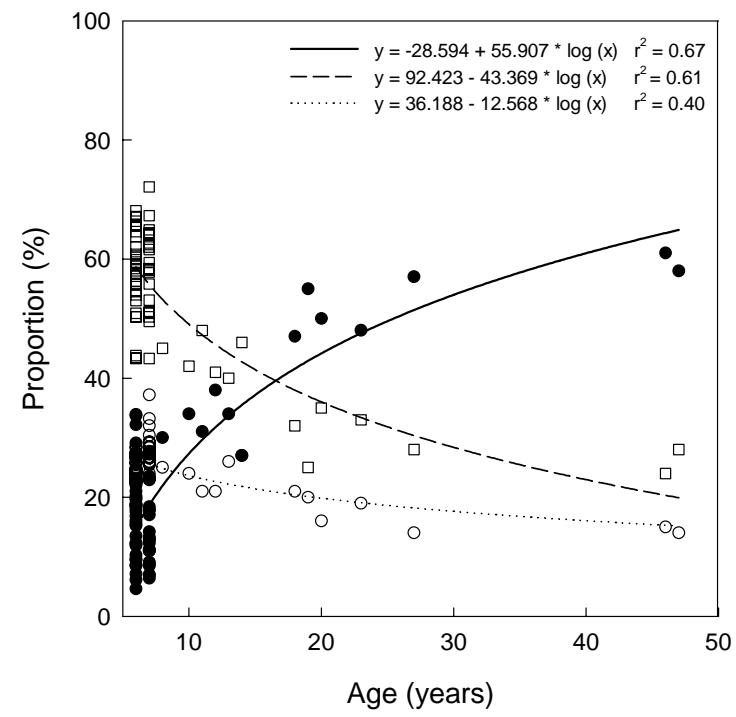

(a)

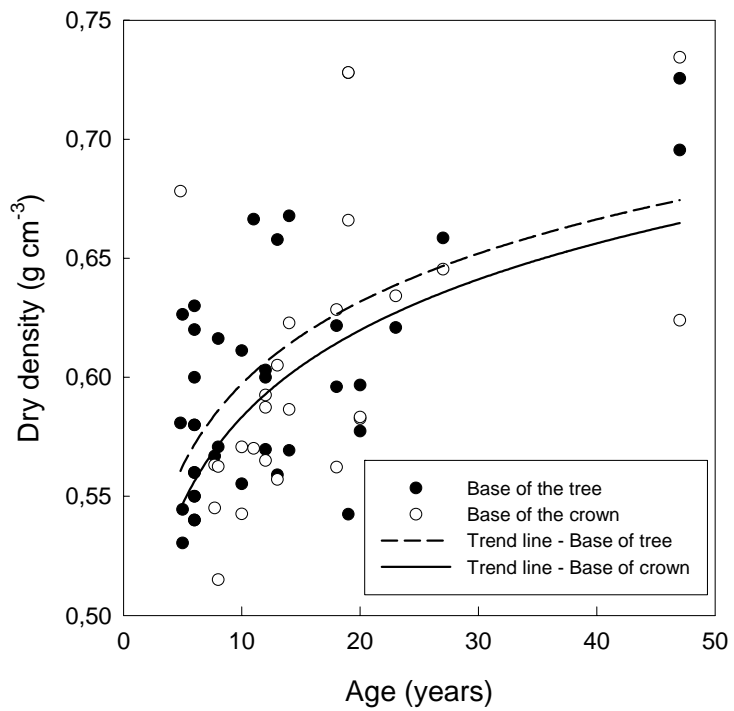

(b)

Figure 3. Relationship between bark, sapwood, and heartwood proportion (a), and wood dry density (b) and age for T. grandis in Costa Rica. 
Three years after pruning, per hectare heartwood volume was higher in the non-pruned stand and in the stand with 3.0-meter-high pruning than in the severely pruned stands (differences of $100 \%$ ). The highest content of heartwood was obtained with the pruning height of 3.0 meters (45 $\mathrm{m}^{3} \mathrm{ha}^{-1}, 23 \%$ of the total stand volume), while the lowest was achieved under the pruning height of 4.0 meters $\left(21 \mathrm{~m}^{3} \mathrm{ha}^{-1}, 13.5 \%\right.$ of the total stand volume). As a result of the intensive pruning regimen, it is estimated that approximately $40 \%$ of the tree total volume could be obtained free of knots at rotation (20-25 years of age). The improvement in wood quality by means of pruning can be achieved without affecting tree growth or stand productivity, in relation to the non-pruned stand (Figure 4b). Moreover, the pruning trial indicated that the plantations under the recommended pruning program of Pérez et al. (2003) presented similar or higher individual and stand growth than the stand without any pruning interventions at all.

Within the concept of intensive management system, it is of primary importance to develop a silvicultural strategy which includes both thinning and pruning and which recognizes clearly how these operations go together. On one hand, ease of operation and reduced operational costs are strongly desired on plantation forest projects, and on the other hand the pruning of trees should not be delayed in order to synchronize it with the thinning interventions, and vice versa. An optimum balance can be achieved by developing selection criteria for pruning only those trees that will remain standing after the first thinning or that might have an added value when thinned in subsequent interventions.

\subsection{Thinning regimens and the effect on wood properties (Study III)}

Study III reports stand density having positive and negative influences on wood properties. Heartwood content varied considerably within treatments of the thinning trial, presenting high and low percentages and showing therefore no significant differences $(\mathrm{P}<0.05)$ among treatments (Figure 5a). On average, light thinnings and the Control yielded slightly higher heartwood contents than moderate and heavy thinnings (16.8 and 18.0\% vs. 15.9 and $14.7 \%$, respectively). The Control also showed higher heartwood contents than the late and on time thinnings (Control $>$ Late $>$ On time). Absolute and relative heartwood content were linearly correlated $(r=0.98)$, indicating that large size trees presented higher percentages as well as total volume of heartwood than small size trees. However, no clear relationship could be established between thinning intensity or thinning timing and the heartwood content in absolute or percentage values, suggesting that treatments had no significant effect on heartwood formation.

Moderate thinnings executed on time yielded more cylindrical trees (form factors of 0.51 and 0.49 , respectively), while late thinnings and the Control formed less cylindrical trees (factors of 0.40 in both cases). ANOVA analysis indicated that the stem form factor was not statistically different $(\mathrm{P}<0.05)$ between treatments even after separating the thinning effect from the timing effect, averaging between 0.43 and 0.45 . 


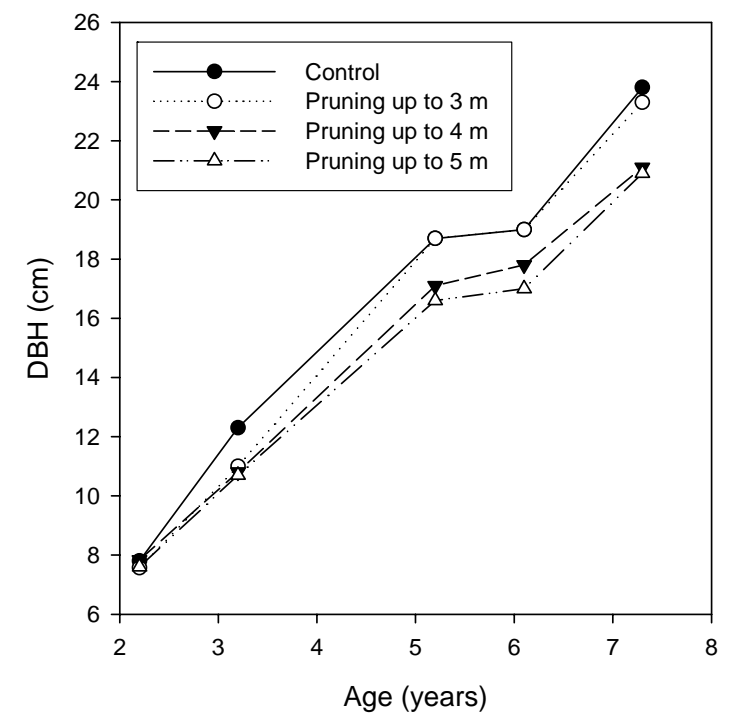

(a)

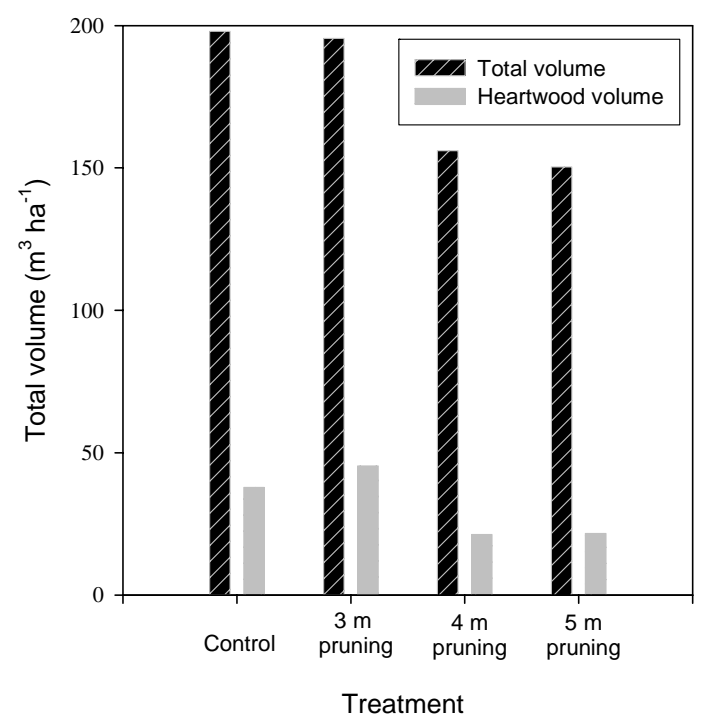

(b)

Figure 4. Stand development in terms of DBH (a), and total and heartwood volume projected to stand level (per hectare values) at the age of 6.1 years (b), for the different treatments of the pruning trial of $T$. grandis in Costa Rica. 
Considerable variations on wood basic density were found within treatments (Figure 5b). According to ANOVA analysis, wood basic density was found to be significantly higher $(\mathrm{P}<0.05)$ in treatment " $25 \% 4^{\text {th" }}$ ( $25 \%$ intensity, executed at age 4 years), reaching a maximum value of $0.76 \mathrm{~g} \mathrm{~cm}^{-3}$ and averaging $0.66 \mathrm{~g} \mathrm{~cm}^{-3}$. In general, light thinnings presented the highest wood densities $\left(>0.65 \mathrm{~g} \mathrm{~cm}^{-3}\right)$ but also very low values $\left(<0.50 \mathrm{~g} \mathrm{~cm}^{-}\right.$ ${ }^{3}$ ), making it difficult to establish a relationship. In addition, heavy thinnings executed on time showed high wood densities, e.g. treatment " $60 \% 4^{\text {th" }}$ " with densities $>0.65 \mathrm{~g} \mathrm{~cm}^{-3}$.

Light and heavy thinnings executed at age 4 years presented the highest per hectare heartwood volume (between 35 and $40 \mathrm{~m}^{3} \mathrm{ha}^{-1}$ at age 8 years); light and medium thinnings executed at age 6 years yielded middle values of $25-35 \mathrm{~m}^{3} \mathrm{ha}^{-1}$, and the remaining treatments (including the Control) showed heartwood volumes of $20 \mathrm{~m}^{3} \mathrm{ha}^{-1}$ and less. In terms of wood quality, it was found that if maximization of heartwood content and wood basic density is required, T. grandis plantations should be managed throughout the rotation keeping the BA close to $26 \mathrm{~m}^{2} \mathrm{ha}^{-1}$ and the total volume around $190 \mathrm{~m}^{3} \mathrm{ha}^{-1}$. Although present results relating stand density management with wood quality are preliminary, no negative effect of high intensity management on wood quality was found, which should be considered as a positive effect, opening the potential for improving management techniques without expecting a detrimental effect on wood quality.

\subsection{Thinning regimens and the effect on tree growth and stand productivity (Study IV)}

Study IV found that on time and heavy thinnings are better than late and light interventions for timber wood production objectives, as T. grandis is very sensitive to competition and consequently as competition commences, a drastic reduction in average DBH follows. The $60 \%$ thinning intensity applied at age four years, and the two consecutive $25 \%$ thinnings at ages four and five years gave the highest values in terms of $\mathrm{DBH}$, while the control was the lowest. The total height was not statistically different between treatments, although the $\mathrm{H}$ of control was lower than that of other treatments.

The basal area (BA) of the treatments carried out at year 4 (beginning of the trial) ranged between 14.6 and $18.2 \mathrm{~m}^{2} \mathrm{ha}^{-1}$ (Figure 6a). The thinning with the highest intensity (60\% of the standing trees) reduced the BA in $48 \%$, decreasing from 15.9 to $8.2 \mathrm{~m}^{2} \mathrm{ha}^{-1}$. At year 6 , when the same treatments were repeated 2.0 years after, the BA of treatments without any intervention yet ranged between 23 and $26 \mathrm{~m}^{2} \mathrm{ha}^{-1}$. The highest intensity thinning brought the BA from 23 to $13.1 \mathrm{~m}^{2} \mathrm{ha}^{-1}$ (43\% extracted), similar to the highest intensity thinning performed at year 4.0. The recovery of the BA was faster in the treatments carried out at year 4.0 than those carried out at year 6.0, when both were measured 2.0 years after the thinning.

The total volume $\left(\mathrm{V}_{\mathrm{o}}\right)$ varied from 90 to over $200 \mathrm{~m}^{3} \mathrm{ha}^{-1}$, at corresponding BA between 12 and $28 \mathrm{~m}^{2} \mathrm{ha}^{-1}$. As mentioned before, the highest CAI of BA occurred at BA of $18 \mathrm{~m}^{2}$ $\mathrm{ha}^{-1}$, corresponding to a total volume of 120 to $150 \mathrm{~m}^{3} \mathrm{ha}^{-1}$. When the $\mathrm{V}_{\mathrm{o}}$ for the 8 treatments was plotted against $\mathrm{DBH}$, different intensities and timings of thinning yielded different stand volume and individual tree size (DBH) combinations (Figure 6b). 


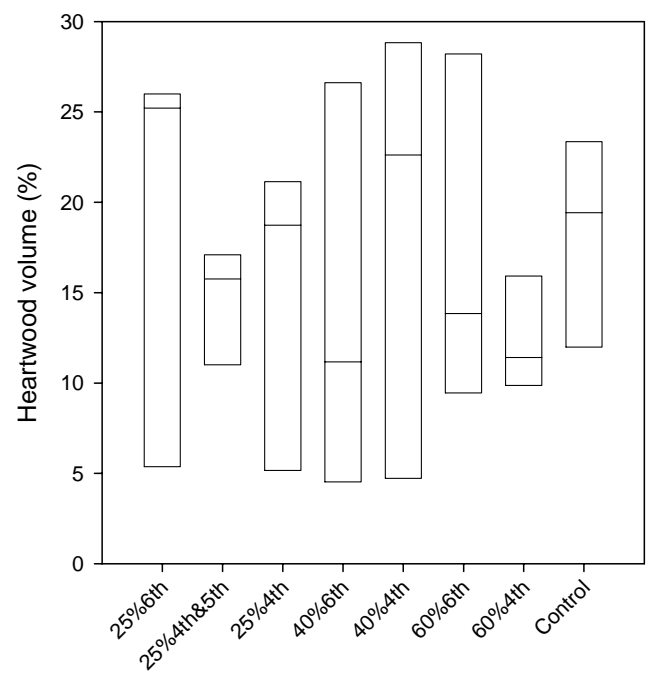

Treatment

(a)

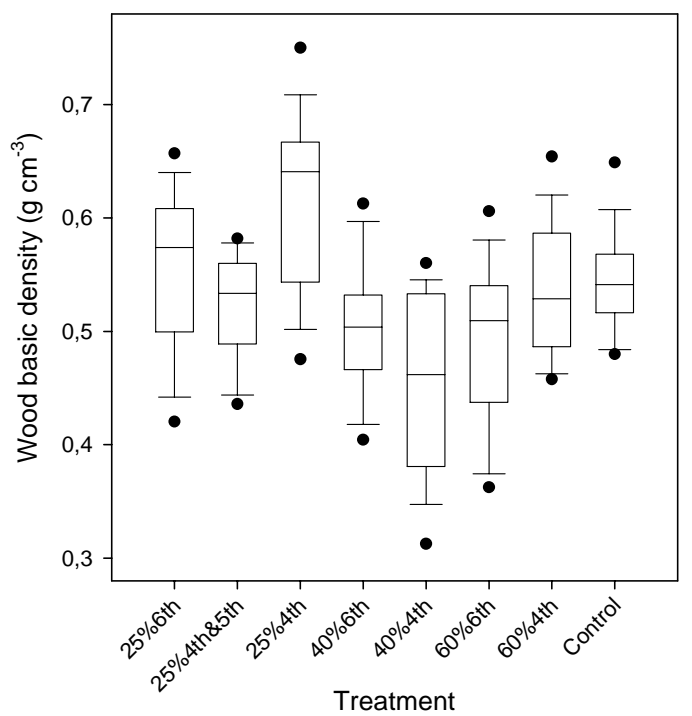

(b)

Figure 5. Heartwood volume (a) and wood basic density (b) of the different thinning treatments of the trial established for Study III. Treatments' legend should be read as "percentage of thinned trees" (e.g. 25\% thinning intensity) harvested at "an age of" (e.g. $4^{\text {th }}$ year of age). For details, see Study III. 


\subsection{Total and merchantable volume equations (Study V)}

In Study V volume equations were developed for estimating the total tree volume (with and without bark), merchantable volume (up to variable minimum diameter or variable top height) and total volume of logs (of specific length and minimum diameter). In addition, a logistic model was used to predict $\mathrm{V}_{\mathrm{o}}$ as a function of age (Figure $7 \mathrm{a}$ ). A comparison of one of the best models tested in the study with other models tested for $T$. grandis elsewhere was carried out for comparison (Figure 7b). In general, the equations developed in this study predict similar values of total volume (over bark) than other models but only at $\mathrm{DBH}<30$ $\mathrm{cm}$, afterwards they predict lower values than most of the models, including the one tested for T. grandis in Costa Rica by Camacho and Madrigal (1997).

A model validation was carried out using an independent data set. In general, the first group of models overestimates total volume with an average difference between estimated and predicted values between $8.3 \%$ and $10.5 \%$. The second group of models predicts merchantable volume slightly higher on small trees (mean difference of $17.4 \%$ ), while the third group of models overestimates volume in general for any top-height, with an average difference of $17.6 \%$. In order to improve the goodness of fit of the present equations it is necessary to increase the number of sample trees with $\mathrm{DBH}>35 \mathrm{~cm}$. Another option is to develop two separate models, one for small trees ( $\mathrm{DBH}<35 \mathrm{~cm}$ ) and another one for large trees $(\mathrm{DBH}>35 \mathrm{~cm})$, since those few sample trees with $\mathrm{DBH}>35 \mathrm{~cm}$ have large leverages and the tested models may not be, in some cases, adequate for use on young stands with smaller trees.

The validation made it possible to observe the goodness-of-fit of the best models recommended in this study, although the independent dataset contained few trees and did not cover the range of the dataset used for the tested models. In general, the total volume equations slightly underestimate the observed volume in small trees, and overestimate it in the large ones.

Merchantable volume equations presented more accuracy when estimating volume from $\mathrm{DBH}$ and variable top-diameter than when predicting it from $\mathrm{DBH}$ and variable top-height. In the latter, predicted values were considerably higher than the measured values near the base and near the top of the tree. For better accuracy (error less than 10\%), models should be calibrated with local data.

\subsection{Growth scenarios (Study VI)}

In Study VI a set of intensive management scenarios was developed for T. grandis in Costa Rica. For their construction, different curves for the site quality classes defined as $100 \%$, $80 \%$, and $60 \%$ of the growth potential in DBH and total height were developed for high, medium, and low quality sites, respectively (Figures 8a and 8b). The set of curves for total height showed similar projections to the site index curves developed for T. grandis in Costa Rica by Vasquez and Ugalde (1995). 

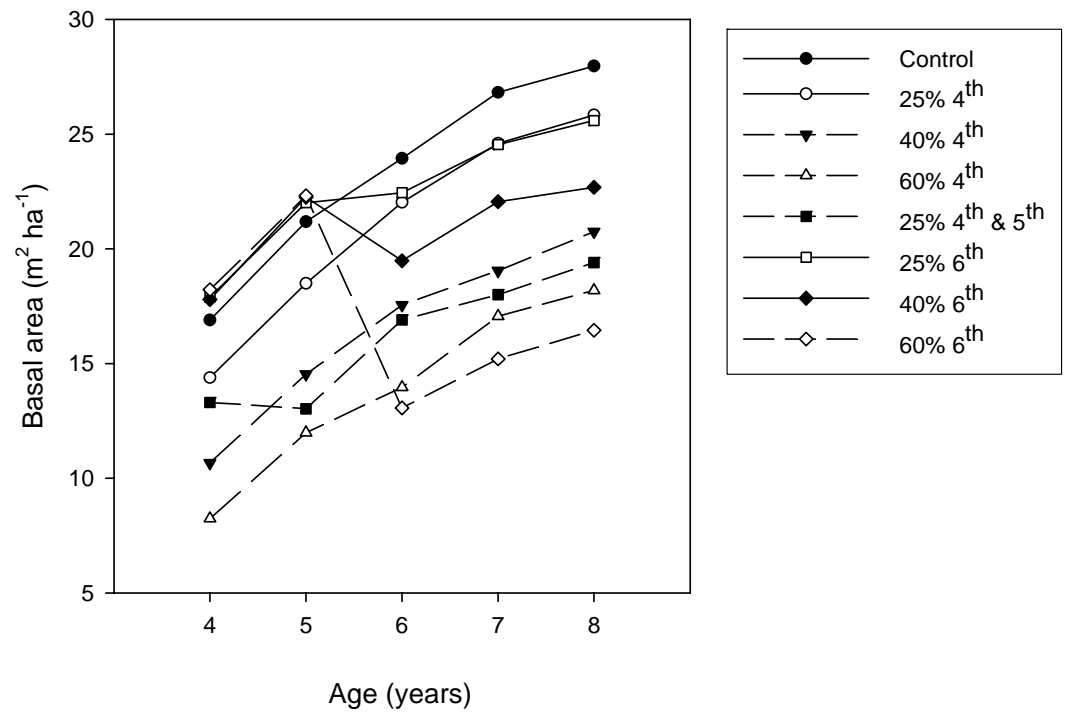

(a)

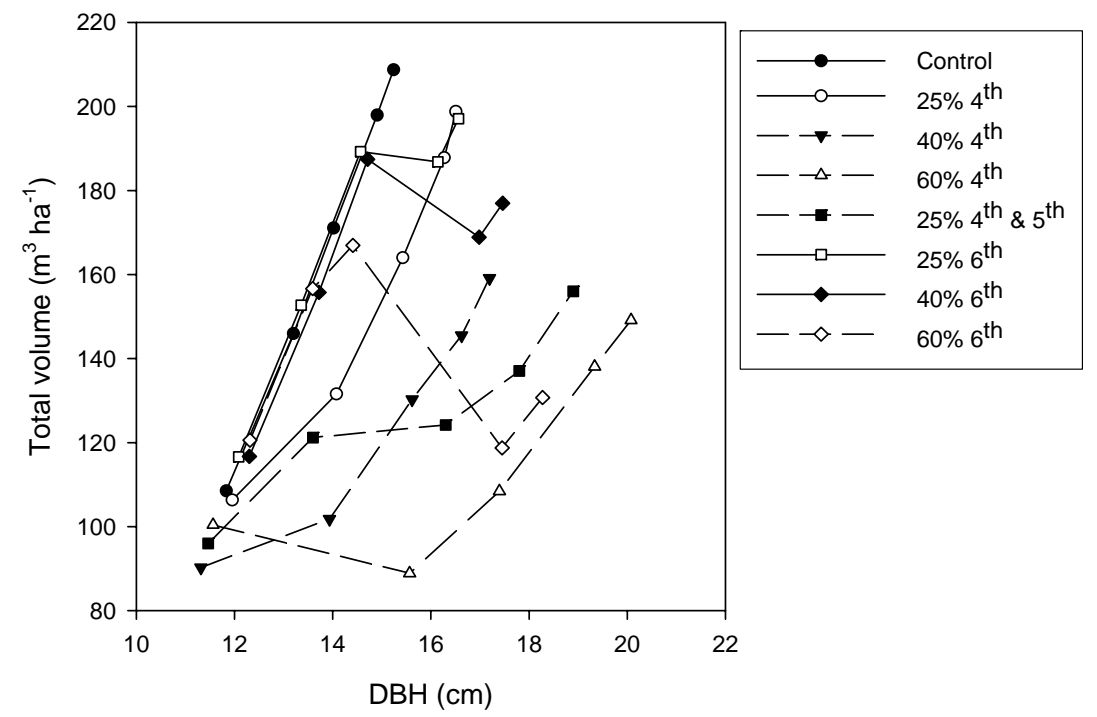

(b)

Figure 6. Relationship between (a) Age and BA, and (b) DBH and total volume in the different thinning treatments of the trial established for Study III. The percentages in the legend correspond to the thinning intensity, while the ordinal numbers refer to the year of thinning. 
Competition factors were implemented in the growth scenarios to represent the inter tree competition and the effects on stem diameter reduction. While the Competition Factor (CF) influenced directly the reduction in individual and stand growth (mean DBH) with increasing BA (Figure 9a), the Maximum Site Occupancy (MSO) and the Reineke Density Index (RDI) were used as reference parameters for keeping the stand density at different ages below the suggested maximum limits. The MSO and the RDI were not strictly followed in the scenarios as they provide in some moments or plantation stages, a very conservative stand density management limit, which would result (if followed) in a very frequently and unpractical thinning program (Figure 9b).

Two rotation periods of 20 and 30 years of age were defined for the different growth scenarios, basically following the most common expected turn over periods for teak in Costa Rica and Central America. The difference of 10 years between the two rotation periods implied an evident difference in stand yield. Increments of $15 \%$ to $20 \%$ in individual tree growth and stand productivity (DBH and total volume, respectively) occurred when extending the rotation period from 20 to 30 years of age. Other changes between rotation lengths included an increment in wood properties (Study I), basically an increment in heartwood content (5-10\%), in wood basic density (3-5\%), in stem size (10$15 \%)$, and in stem form (8-12\% more cylindrical), with increasing rotation length, enhancing the performance for sawn wood production.

Growth scenarios for 20- and 30-year rotations and for the objective of high individual tree growth and high stand growth were developed for high, medium, and low quality sites. The scenarios for high quality sites are presented in Table 3, those for medium and low quality sites can be found in Study VI.

At the end of the rotation, stand densities varied between 120 and 447 trees ha ${ }^{-1}$, with mean DBH of 24.9 to $47.8 \mathrm{~cm}$, and mean total heights between 23.0 and $32.4 \mathrm{~m}$ (including medium and low quality sites). The mean annual increment in total volume ( $\left.\mathrm{MAI}_{\mathrm{Vol}}\right)$ at the end of the rotation varied from 11.3 to $24.9 \mathrm{~m}^{3} \mathrm{ha}^{-1} \mathrm{year}^{-1}$, accumulating a total volume from 268 to $524 \mathrm{~m}^{3} \mathrm{ha}^{-1}$. The highest volume corresponded to the scenario in the high quality site and under a 30-year rotation period, while the lowest value corresponded to the scenario in the low quality site and under a 20 -year rotation period. Stand density remained within the criterion of intensive management, i.e. without falling into high competition or self-thinning levels. For this reason, differences between the scenarios (high individual tree growth - Figure 10a vs. high stand growth - Figure 10b are not as evident as expected, since neither DBH nor volume maximization were intended to be achieved at the expense of site sub-occupancy or excess site occupancy.

Total merchantable volume and total volume in logs were estimated for the set of growth scenarios. The volume estimations for the scenarios in high quality sites are presented in Table 4, those for medium and low quality sites can be found in Study VI. From the 1,111 harvested trees during rotation (20 and 30 years), between 1,067 and 2,931 logs of 4.0 meter length and $15 \mathrm{~cm}$ of minimum diameter could be obtained depending on the selected scenario. After the sectioning of the merchantable stem into 4.0-meter length logs, the saleable volume varied between 145 and $386 \mathrm{~m}^{3} \mathrm{ha}^{-1}$, with an estimated heartwood volume of 45 to $195 \mathrm{~m}^{3} \mathrm{ha}^{-1}$ (30-50\%), depending on rotation period length and site quality. Scenarios with the objective of high individual tree growth resulted in similar or greater merchantable volume and number of sawn logs, with greater diameter and earlier than the scenarios aiming at high stand growth. Present results offer the possibility to modify the dimension, quantity, and distribution of growth in a teak stand according to production purposes. 


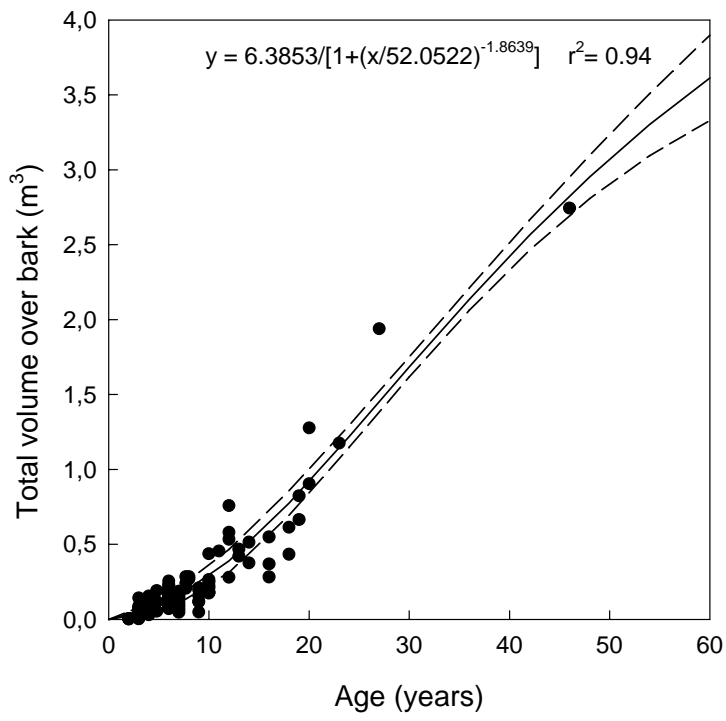

(a)

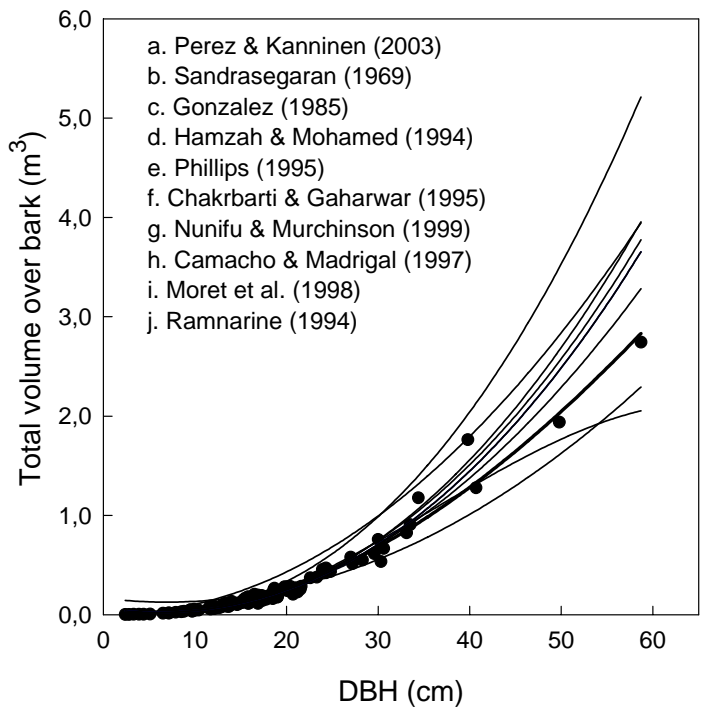

(b)

Figure 7. (a) Fitted equation with 95\% confidence interval (dashed line) for the relationship between age and total volume over bark and (b) Comparison of models tested previously for $T$. grandis elsewhere with the best model tested in the present study for $T$. grandis in Costa Rica. Dots correspond to sample trees. For model description see Study V. 


\subsection{Financial analysis}

The growth scenarios of Study VI were complemented with a financial analysis to support the management proposals with a simple but realistic economic feasibility overview. The financial indicators Net Present Value (NPV) and Internal Rate of Return (IRR) were calculated for different rotation periods, management objectives, and site quality classes, at interest rates of 5.0, 7.5, and 10.0\%. The NPV varied considerably among Site Classes, increasing with increasing site quality (Site I > Site II > Site III). Site Class I yielded over $67 \%$ higher NPV than Site Class II and over six times higher than Site Class III, while the NPV of Site Class II was three times higher than that of Site Class III. The highest NPVs were 43759, 23208, and 6491 US\$ ha ${ }^{-1}$ for Site Classes I, II, and III, respectively (Table 5).

The IRR also increased with increasing site quality, varying on average from 19.8 to 23.6\%, from 13.9 to 16.3, and from 8.5 to 8.9, for Site Qualities I, II, and III, respectively. Within each site quality, the scenarios with the objective of high individual tree growth (maximization of DBH) presented the highest IRR values (Table 5).

The scenarios with the objective of high individual tree growth (maximization of DBH) yielded higher NPV values than those scenarios with the objective of high stand growth (maximization of volume). Scenarios with different objectives and with similar rotation periods varied from $3.0 \%$ to $30.0 \%$. Largest differences occurred between scenarios with 20-year rotations for site quality I and II and scenarios with 30-year rotation periods in site quality III. The NPV was higher for 30-year rotations than for 20-year rotations, with differences of $16.4 \%$ (within Site Class I) to over $75 \%$ (within Site Class III), with the exception of the scenarios with the objective of DBH maximization in Site Quality I, where 20-year rotations presented a higher NPV than 30-year rotations (approx. 13\% higher).

\subsection{Sensitivity analysis}

Wood price was the only variable significantly sensitive to increments/reductions of $20 \%$ of the original values. This variation of $\pm 20 \%$ in the wood price modified the NPV by approximately $\pm 25 \%$, and tended to increase with increasing interest rates, i.e. $23 \%, 25 \%$, and $28 \%$ of variation at interest rates of $5.0 \%, 7.5 \%$, and $10.0 \%$, respectively (Table 6). Besides the wood price, no other variables presented significant changes in the NPV when modifying their value in $\pm 20 \%$, as variations in NPV were of maximum $5.0 \%$ in relation to the original values of NPV.

The modification of $\pm 20 \%$ in the land price, establishment costs, and management costs caused no significant changes in the IRR. The scenarios with no variable modification presented an IRR between 19.81 and $23.44 \%$, while the $\pm 20 \%$ variation altered the range to $18.99-24.45 \%$, respectively. The IRR showed sensitive changes only with modifications on wood price, with an average difference of $\pm 2.0 \%$ in relation to original values (Table 6 ). The scenarios of DBH maximization seemed to be more robust to changes than the other scenarios, although no significant differences were found in the present study. 


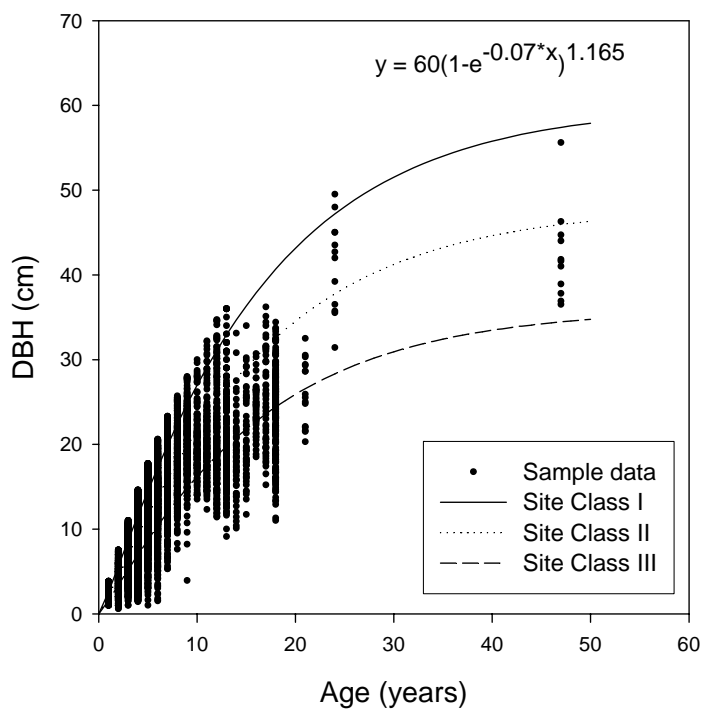

(a)

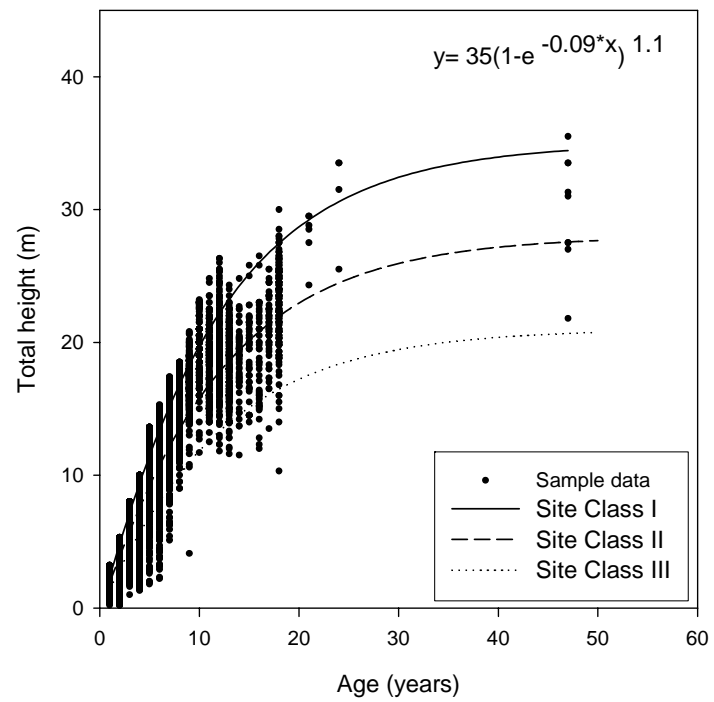

(b)

Figure 8. Fitted curve for the relationship between a) age and $\mathrm{DBH}$, and b) age and total tree height used for the development of the scenarios for $T$. grandis plantations in Costa Rica. Data correspond to field measurements of individual dominant trees (> Percentile 85). Curve for Site Class I corresponds to $100 \%$ of the potential; Site Class II corresponds to $80 \%$ of the potential, and Site Class III to $60 \%$ of the potential. 


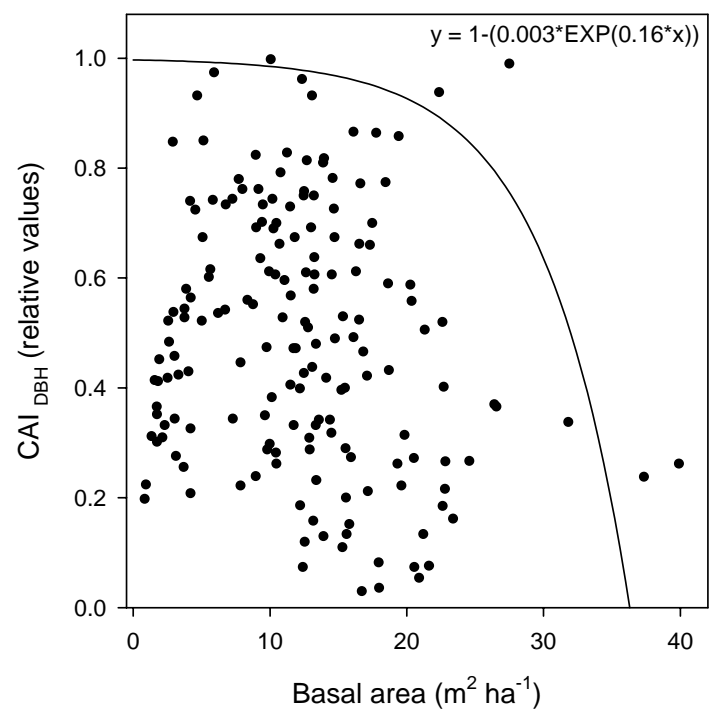

(a)

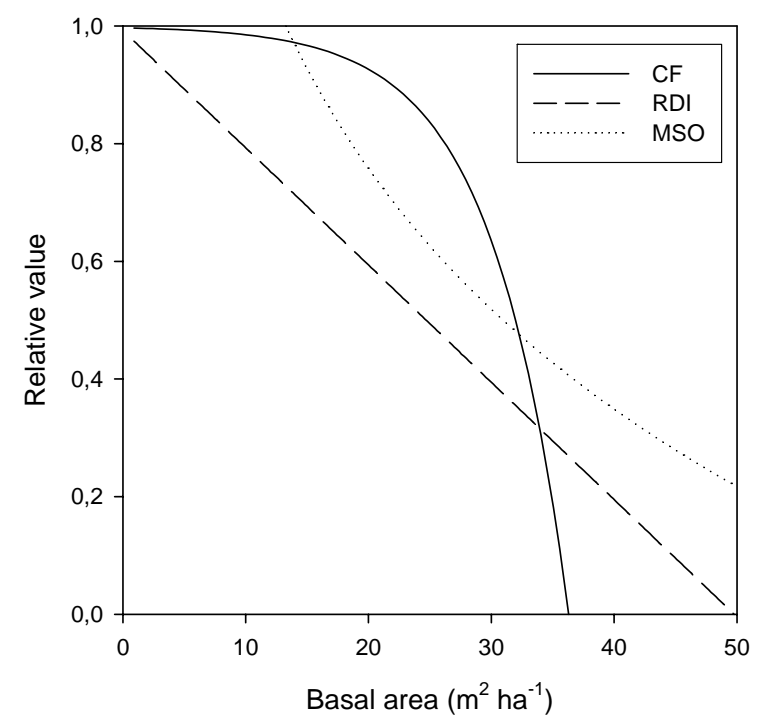

(b)

Figure 9. (a) Relationship between relative $C A I_{\mathrm{DBH}}$ (fraction of the maximum observed value: $5.0 \mathrm{~cm}$ year ${ }^{-1}$ ) and stand Basal Area and (b) Comparison between the Competition Factor (CF), the Maximum Site Occupancy (MSO), and the Reineke Density Index (RDI), used in the growth scenarios to define the stand competition with increasing stand basal area. High values represent low competition and low values represent high competition. 
Table 3. Summary of stand growth scenarios for $T$. grandis on high quality sites in Costa Rica. For growth scenarios in medium and low quality sites, see Study VI. ${ }^{\text {(a) }}$

\begin{tabular}{|c|c|c|c|c|c|c|c|c|c|c|c|}
\hline Scen & Age & $\begin{array}{c}\text { Thinn } \\
\#\end{array}$ & $\mathrm{~N}$ & $\begin{array}{l}\text { Thinn } \\
\text { Int }\end{array}$ & $\mathrm{DBH}$ & $\mathrm{H}$ & $\begin{array}{c}\text { Rem } \\
\text { BA }\end{array}$ & $\begin{array}{l}\text { Ext } \\
\text { BA }\end{array}$ & $\begin{array}{c}\text { Rem } \\
\text { Vol }\end{array}$ & $\begin{array}{l}\text { Ext } \\
\text { Vol }\end{array}$ & $\begin{array}{l}\text { Acc } \\
\text { Vol }\end{array}$ \\
\hline \multirow{6}{*}{$\begin{array}{c}30 \\
\text { years } \\
\text { Max. } \\
\text { DBH }\end{array}$} & 4 & 1 & 556 & 50 & 11.5 & 9.4 & 5.8 & 5.8 & 36 & 36 & 36 \\
\hline & 8 & 2 & 333 & 40 & 21.8 & 16.8 & 12.4 & 8.3 & 104 & 69 & 105 \\
\hline & 12 & 3 & 200 & 40 & 29.7 & 22.2 & 13.8 & 9.2 & 126 & 84 & 189 \\
\hline & 18 & 4 & 150 & 25 & 38.3 & 27.5 & 17.3 & 5.8 & 165 & 55 & 244 \\
\hline & 24 & 5 & 120 & 20 & 44.0 & 30.6 & 18.2 & 4.6 & 178 & 45 & 289 \\
\hline & 30 & Final & 0 & 100 & 47.8 & 32.4 & 0.0 & 21.5 & 0 & 213 & 501 \\
\hline \multirow{5}{*}{$\begin{array}{c}20 \\
\text { years } \\
\text { Max. } \\
\text { DBH }\end{array}$} & 4 & 1 & 611 & 45 & 11.5 & 9.4 & 6.4 & 5.2 & 39 & 32 & $\begin{array}{c}32 \\
117\end{array}$ \\
\hline & 8 & 2 & 336 & 45 & 21.6 & 16.8 & 12.3 & 10.1 & 103 & 84 & 185 \\
\hline & 12 & 3 & 225 & 33 & 29.5 & 22.2 & 15.4 & 7.6 & 140 & 69 & 238 \\
\hline & 16 & 4 & 169 & 25 & 35.6 & 26.0 & 16.8 & 5.6 & 158 & 53 & \multirow{2}{*}{445} \\
\hline & 20 & Final & 0 & 100 & 40.2 & 28.7 & 0.0 & 21.5 & 0 & 207 & \\
\hline \multirow{5}{*}{$\begin{array}{c}30 \\
\text { years } \\
\text { Max. } \\
\text { Vol. }\end{array}$} & 6 & 1 & 556 & 50 & 16.5 & 13.4 & 11.8 & 11.8 & 89 & 89 & 89 \\
\hline & 10 & 2 & 333 & 40 & 24.2 & 19.7 & 15.4 & 10.2 & 133 & 89 & 177 \\
\hline & 14 & 3 & 200 & 40 & 30.0 & 24.2 & 14.2 & 8.0 & 129 & 71 & 249 \\
\hline & 21 & 4 & 120 & 40 & 37.8 & 28.7 & 13.5 & 9.0 & 128 & 86 & 334 \\
\hline & 30 & Final & 0 & 100 & 45.3 & 32.4 & 0.0 & 19.4 & 0 & 190 & 524 \\
\hline & 6 & 1 & 556 & 50 & 16.5 & 13.4 & 11.8 & 11.8 & 89 & 89 & 89.0 \\
\hline 20 & 10 & 2 & 333 & 40 & 24.2 & 19.7 & 15.4 & 10.2 & 133 & 89 & 177 \\
\hline & 15 & 3 & 200 & 40 & 31.6 & 25.2 & 15.6 & 8.0 & 144 & 71 & 249 \\
\hline Vol. & 20 & Final & 0 & 100 & 37.8 & 28.7 & 0.0 & 22.4 & 0 & 214 & 463 \\
\hline
\end{tabular}

(a) Scen: stand growth scenarios for different site quality (high, low, medium), rotation cycle (20 and 30 years), and objective (high individual tree growth vs. high stand growth); Age (years): age of the stand; Thinn \#: serial number of the thinning interventions; $\mathbf{N}$ : stand density (tree ha ${ }^{-1}$ ); Thinn Int (\%): thinning intensity based on the number of standing trees; $\mathbf{D B H}(\mathbf{c m})$ : mean diameter at breast height; $\mathbf{H}(\mathbf{m})$ : mean total height of the plantation; Rem BA $\left(\mathrm{m}^{2} \mathbf{h a}^{-1}\right)$ : remnant (standing) basal area after thinning; Ext BA $\left(\mathrm{m}^{2} \mathrm{ha}^{-1}\right)$ : extracted basal area in each thinning; Rem Vol $\left(\mathrm{m}^{3} \mathrm{ha}^{-1}\right)$ : remnant (standing) total volume after thinning; Ext $\operatorname{Vol}\left(\mathrm{m}^{3} \mathbf{h a}^{-1}\right)$ : extracted total volume in each thinning; Acc Vol $\left(\mathrm{m}^{3} \mathbf{h a}^{-1}\right)$ : accumulated total volume extracted in each thinning and in the final cut. 


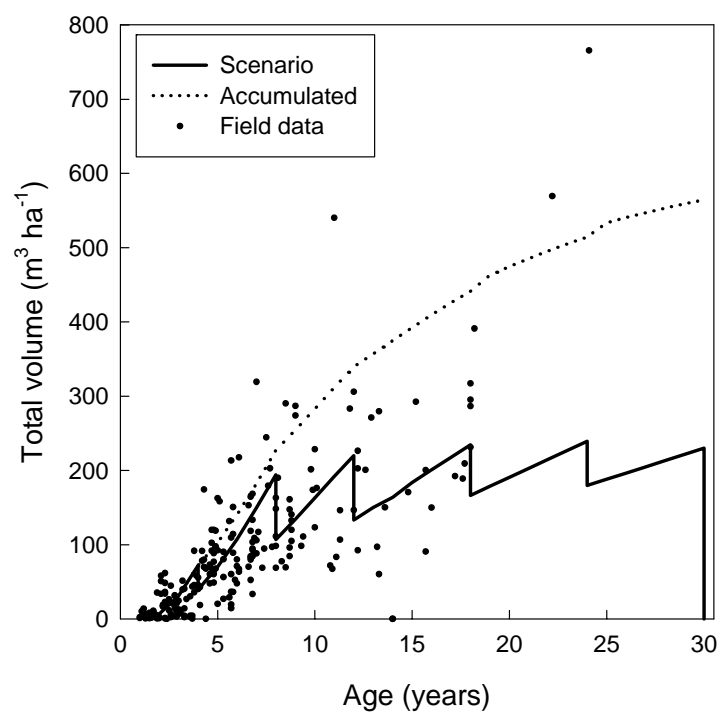

(a)

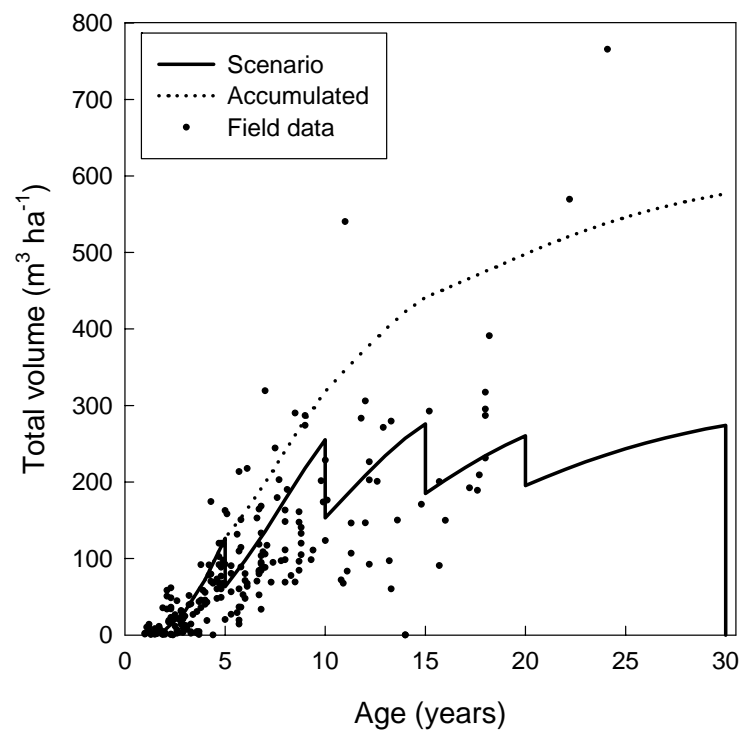

(b)

Figure 10. Remaining stand total volume (management scenario) and accumulated total volume simulations for a $T$. grandis plantation in Costa Rica in a high quality site, with a $30-$ year rotation, and with the objective of (a) high individual tree growth and (b) high stand growth. Dots represent the field observations. 
Table 4. Merchantable volume projections for the $T$. grandis stand growth scenarios in high quality sites of Costa Rica. For medium and low quality sites see Study VI. (a)

\begin{tabular}{|c|c|c|c|c|c|c|c|c|c|c|c|c|}
\hline Scenario & Age & $\begin{array}{c}\text { Thinn. } \\
\#\end{array}$ & $\begin{array}{l}\text { Thinn. } \\
\text { trees }\end{array}$ & $\begin{array}{c}\text { Merch. } \\
\text { Vol. }\end{array}$ & $\begin{array}{l}\text { Vol. } \\
\text { Logs }\end{array}$ & $\begin{array}{l}\text { Hw } \\
\text { Vol. } \\
\text { Logs }\end{array}$ & $\begin{array}{c}\text { Log } \\
\# 1\end{array}$ & $\begin{array}{c}\log \\
\# 2\end{array}$ & $\begin{array}{c}\text { Log } \\
\# 3\end{array}$ & $\begin{array}{c}\log \\
\# 4\end{array}$ & $\begin{array}{c}\log \\
\# 5\end{array}$ & $\begin{array}{c}\mathrm{N} \\
\text { Logs }\end{array}$ \\
\hline \multirow{5}{*}{$\begin{array}{c}\text { High } \\
\text { quality } \\
30 \text { years } \\
\text { Max. } \\
\text { DBH }\end{array}$} & 8 & 2 & 223 & 48 & 35 & 10 & 18.2 & & & & & 223 \\
\hline & 12 & 3 & 133 & 71 & 71 & 28 & 27.1 & 20.5 & 15.0 & & & 399 \\
\hline & 18 & 4 & 50 & 51 & 48 & 24 & 36.9 & 29.5 & 23.3 & 17.9 & & 200 \\
\hline & 24 & 5 & 30 & 42 & 41 & 22 & 43.5 & 35.4 & 28.8 & 23.0 & 17.7 & 150 \\
\hline & 30 & Final & 120 & 203 & 191 & 111 & 47.8 & 39.4 & 32.4 & 26.3 & 20.8 & 600 \\
\hline \multicolumn{7}{|c|}{ Average log diameter } & 34.7 & 31.2 & 24.9 & 22.4 & 19.2 & \\
\hline \multicolumn{7}{|c|}{ Number of logs } & 556 & 333 & 333 & 200 & 150 & 1572 \\
\hline \multicolumn{4}{|c|}{ Total volume } & 414 & 386 & 195 & & & & & & \\
\hline High & 8 & 2 & 275 & 57 & 42 & 11 & 18.4 & & & & & 275 \\
\hline quality & 12 & 3 & 111 & 58 & 59 & 23 & 27.6 & 20.8 & 15.3 & & & 333 \\
\hline 20 years & 16 & 4 & 56 & 48 & 47 & 22 & 34.8 & 27.4 & 21.3 & 16.0 & & 224 \\
\hline $\begin{array}{l}\text { Max. } \\
\text { DBH }\end{array}$ & 20 & Final & 169 & 192 & 193 & 99 & 40.5 & 32.6 & 26.1 & 20.4 & 15.1 & 845 \\
\hline \multicolumn{7}{|c|}{ Average log diameter } & 30.3 & 27.0 & 20.9 & 18.2 & 15.1 & \\
\hline \multicolumn{7}{|c|}{ Number of logs } & 611 & 336 & 336 & 225 & 169 & 1677 \\
\hline \multicolumn{4}{|c|}{ Total volume } & 355 & 340 & 155 & & & & & & \\
\hline High & 10 & 2 & 223 & 71 & 65 & 21 & 21.4 & 15.5 & & & & 446 \\
\hline quality & 14 & 3 & 110 & 65 & 70 & 28 & 28.1 & 21.7 & 16.5 & & & 330 \\
\hline 30 years & 21 & 4 & 73 & 62 & 74 & 36 & 36.8 & 29.6 & 23.7 & 19.2 & & 292 \\
\hline $\begin{array}{l}\text { Max. } \\
\text { Vol. }\end{array}$ & 30 & Final & 150 & 193 & 170 & 96 & 45.3 & 37.4 & 30.8 & 25.0 & 19.7 & 750 \\
\hline \multicolumn{7}{|c|}{ Average log diameter } & 32.9 & 26.1 & 23.7 & 22.1 & 19.7 & \\
\hline \multicolumn{7}{|c|}{ Number of logs } & 556 & 556 & 333 & 223 & 150 & 1818 \\
\hline \multicolumn{4}{|c|}{ Total volume } & 391 & 379 & 180 & & & & & & \\
\hline High & & & & & & & & & & & & 446 \\
\hline quality & 10 & 2 & 223 & 71 & 68 & 22 & 22.7 & 16.5 & & & & 330 \\
\hline 20 years & 15 & 3 & 110 & 65 & 61 & 25 & 31.7 & 24.8 & 19.1 & & & 892 \\
\hline $\begin{array}{l}\text { Max. } \\
\text { Vol. }\end{array}$ & 20 & Final & 223 & 188 & 179 & 83 & 38.3 & 30.8 & 24.7 & 19.2 & & \\
\hline \multicolumn{7}{|c|}{ Average log diameter } & 30.9 & 24.0 & 21.9 & 19.2 & & \\
\hline \multicolumn{7}{|c|}{ Number of logs } & 556 & 556 & 333 & 223 & & 1668 \\
\hline Total volt & & & & 324 & 308 & 131 & & & & & & \\
\hline
\end{tabular}

(a) Scenario: stand growth scenarios for different site qualities (high, low, medium), rotation cycles (20 and 30 years), and objectives (high individual tree growth vs. high stand growth); Age (years): age of the stand; Thinn. \#: serial number of the thinning; Thinn. trees: harvested trees in each thinning (tree $\left.\mathrm{ha}^{-1}\right)$; Merch. Vol.: total merchantable volume with minimum diameter of $15 \mathrm{~cm}\left(\mathrm{~m}^{3} \mathrm{ha}^{-1}\right)$; Vol. Logs: total volume of the logs harvested in each intervention $\left(\mathrm{m}^{3} \mathrm{ha}^{-1}\right)$; Hw. Vol. Logs: heartwood volume from the total volume of logs $\left(\mathrm{m}^{3} \mathrm{ha}^{-1}\right)$; Log \#: 4m-length logs are numbered consecutively from the base to the top of the tree as $\# 1, \# 2, \ldots$, the total amount under these columns refers to the diameter of the logs at smaller end; $\mathbf{N}$ Logs: number of logs harvested in each intervention. 
Table 5. Financial analysis for the different growth scenarios developed for $T$. grandis in Costa Rica.

\begin{tabular}{|c|c|c|c|c|c|c|}
\hline \multirow[b]{2}{*}{$\begin{array}{l}\text { Site Class } \\
(\mathrm{I}, \mathrm{II}, \mathrm{III})\end{array}$} & \multirow{2}{*}{$\begin{array}{l}\text { Scenario } \\
\text { Objective } \\
\text { (max. of) }\end{array}$} & \multirow[b]{2}{*}{$\begin{array}{l}\text { Rotation } \\
\text { (years) }\end{array}$} & \multicolumn{3}{|c|}{$\begin{array}{l}\text { NPV (US\$ per ha) } \\
\underline{\text { Interest rate }}\end{array}$} & \multirow[t]{2}{*}{$\begin{array}{l}\text { IRR } \\
\text { (\%) }\end{array}$} \\
\hline & & & $5.0 \%$ & $7.5 \%$ & $10.0 \%$ & \\
\hline 1 & $\mathrm{DBH}$ & 30 & 39154 & 21115 & 11458 & 19.8 \\
\hline 1 & $\mathrm{DBH}$ & 20 & 44188 & 27453 & 17017 & 23.4 \\
\hline 1 & Vol & 30 & 40517 & 22926 & 13174 & 21.8 \\
\hline 1 & Vol & 20 & 34814 & 21662 & 13415 & 22.6 \\
\hline II & DBH & 30 & 23649 & 11758 & 5499 & 15.3 \\
\hline II & $\mathrm{DBH}$ & 20 & 18858 & 10817 & 5856 & 16.5 \\
\hline II & Vol & 30 & 22825 & 11321 & 5290 & 15.3 \\
\hline II & Vol & 20 & 14565 & 7739 & 3617 & 14.2 \\
\hline III & $\mathrm{DBH}$ & 30 & 6932 & 1808 & -715 & 9.1 \\
\hline III & $\mathrm{DBH}$ & 20 & 3982 & 1021 & -722 & 8.8 \\
\hline III & Vol & 30 & 5644 & 1249 & -974 & 8.7 \\
\hline III & Vol & 20 & 4056 & 1008 & -773 & 8.7 \\
\hline
\end{tabular}




\section{DISCUSSION}

\subsection{General overview}

The reason for the rapid expansion of fast-wood plantations is purely economic. Fast-wood plantations can produce one and a half to two times more wood per hectare per year, and reach maturity two to three times faster, than longer-rotation plantations. Quality matters too, and it depends to a considerable extent on successful management practices. Fast, good-quality wood comes from plantations with uniformity in tree size and shape, wood free of defects, less internal tension for saw timber, etc. This leads to cheap and efficient harvesting, lower transport and processing costs, and high value products (Cossalter and Pye-Smith 2003).

Teak has been grown under plantation conditions for 150 years. However, the high value of teak timber due to its appearance and mechanical properties, the strong markets for teak products combined with a declining stock from natural stands have attracted increasing attention to the potential of teak plantations as an investment with an attractive return in the last decade (Ball et al. 2000). Although there is a long history of teak planting and considerable experience has been gained, relevant information is not available in an easily retrievable and usable form.

Further, there is a considerable gap between what is known and what is applied. In other words, there are significant barriers to accessing and applying existing information. Although the technology of teak planting is well understood, many small and medium sized plantations are managed under low intensity or low investment regimens, or both; the uptake of research results is poor and known technologies are not effectively applied. Large-scale projects, on the other hand, are keen to apply productivity enhancing technologies to maximize returns on investment (Nair et al. 1999).

First time investors in teak plantations are particularly concerned about the end uses and prices of poles and small diameter logs obtained from pre-commercial thinnings and the final harvest. The high proportion of sapwood, variation in physical and mechanical properties, the appearance of wood as compared to what is obtained from natural forests and long rotation plantations, and the feasibility of processing and marketing of smaller dimensions are critical in making the investment profitable (Nair et al. 1999). In the present study, merchantable volume equations were developed for an accurate prediction of the potential saleable volume in a stand, aiming at generating more trustworthy information when valuing teak tree plantations. In addition, different wood properties were studied and relationships with growth and yield parameters were evaluated, aiming at developing management strategies for optimizing both stand productivity and wood quality.

Teak has traditionally been grown on long rotations of 60 to 80 years or more for the production of veneer- or saw-logs, but there is a trend to shorter rotations with the move towards the ownership of teak plantations by small landowners or by out-growers who cannot lock up capital over long periods. Teak has for many years been grown on short rotations for the profitable production of poles; now shorter rotations of 20 to 30 years are being tested and advocated for saw-log plantations in such countries as Malaysia, India, Brazil, and Costa Rica (Ball et al. 2000). 
Table 6. Sensitivity analysis for the growth scenarios in high quality sites developed for $T$. grandis plantations in Costa Rica. For scenario details, see Study VI.

\begin{tabular}{|c|c|c|c|c|c|c|}
\hline \multirow[t]{3}{*}{ Scenario } & \multirow{3}{*}{\multicolumn{2}{|c|}{ Variable }} & \multirow{2}{*}{\multicolumn{3}{|c|}{$\begin{array}{c}\text { NPV } \\
\text { Interest rate (\%) }\end{array}$}} & \multirow{3}{*}{$\begin{array}{l}\text { IRR } \\
(\%)\end{array}$} \\
\hline & & & & & & \\
\hline & & & 5.0 & 7.5 & 10.0 & \\
\hline & \multicolumn{2}{|c|}{ Control } & 39154 & 21115 & 11458 & 19.81 \\
\hline & $+20 \%$ & Land price & 38861 & 20785 & 11115 & 18.99 \\
\hline & $-20 \%$ & Land price & 39447 & 21444 & 11801 & 20.75 \\
\hline Max. DBH & $+20 \%$ & Estab. costs & 39053 & 21016 & 11362 & 19.58 \\
\hline \multirow[t]{8}{*}{30 years } & $-20 \%$ & Estab. costs & 39255 & 21213 & 11554 & 20.04 \\
\hline & $+20 \%$ & 6 Manage. costs & 38306 & 20499 & 10984 & 19.18 \\
\hline & $-20 \%$ & Manage. costs & 39909 & 21671 & 11893 & 20.43 \\
\hline & $+20 \%$ & Wood price & 48184 & 26401 & 14713 & 21.63 \\
\hline & $-20 \%$ & Wood price & 30124 & 15828 & 8203 & 17.72 \\
\hline & Contrc & & 44188 & 27453 & 17017 & 23.44 \\
\hline & $+20 \%$ & Land price & 43807 & 27080 & 16654 & 22.55 \\
\hline & $-20 \%$ & Land price & 44569 & 27825 & 17381 & 24.45 \\
\hline \multirow{9}{*}{$\begin{array}{l}\text { Max. DBH } \\
20 \text { years }\end{array}$} & $+20 \%$ & Estab. costs & 44087 & 27354 & 16921 & 23.19 \\
\hline & $-20 \%$ & Estab. costs & 44288 & 27551 & 17114 & 23.69 \\
\hline & $+20 \%$ & 6 Manage. costs & 43610 & 26992 & 16638 & 22.90 \\
\hline & $-20 \%$ & Manage. costs & 44764 & 27913 & 17396 & 24.00 \\
\hline & $+20 \%$ & Wood price & 54152 & 33970 & 21367 & 25.31 \\
\hline & $-20 \%$ & Wood price & 34223 & 20935 & 12668 & 21.24 \\
\hline & Contrc & & 40517 & 22926 & 13174 & 21.79 \\
\hline & $+20 \%$ & Land price & 40136 & 22554 & 12811 & 20.85 \\
\hline & $-20 \%$ & Land price & 40898 & 23298 & 13538 & 22.88 \\
\hline \multirow{9}{*}{$\begin{array}{l}\text { Max. Vol. } \\
30 \text { years }\end{array}$} & $+20 \%$ & Estab. costs & 40417 & 22828 & 13078 & 21.53 \\
\hline & $-20 \%$ & Estab. costs & 40618 & 23024 & 13271 & 22.06 \\
\hline & $+20 \%$ & 6 Manage. costs & 39917 & 22459 & 12795 & 21.18 \\
\hline & $-20 \%$ & Manage. costs & 41117 & 23392 & 13554 & 22.43 \\
\hline & $+20 \%$ & Wood price & 49847 & 28600 & 16795 & 23.86 \\
\hline & $-20 \%$ & Wood price & 31188 & 17252 & 9553 & 19.42 \\
\hline & Contrc & & 34814 & 21662 & 13415 & 22.57 \\
\hline & $+20 \%$ & Land price & 34433 & 21289 & 13051 & 21.63 \\
\hline & $-20 \%$ & Land price & 35195 & 22034 & 13779 & 23.64 \\
\hline \multirow{6}{*}{$\begin{array}{l}\text { Max. Vol. } \\
20 \text { years }\end{array}$} & $+20 \%$ & Estab. costs & 34713 & 21563 & 13319 & 22.31 \\
\hline & $-20 \%$ & Estab. costs & 34914 & 21760 & 13511 & 22.84 \\
\hline & $+20 \%$ & 6 Manage. costs & 34238 & 21200 & 13033 & 21.97 \\
\hline & $-20 \%$ & Manage. costs & 35389 & 22123 & 13797 & 23.19 \\
\hline & $+20 \%$ & Wood price & 42902 & 27022 & 17047 & 24.58 \\
\hline & $-20 \%$ & Wood price & 26725 & 16301 & 9783 & 20.22 \\
\hline
\end{tabular}


While a broad range of productivity rates derived from experimental plots are available, actual estimates for yield under different agro-ecological conditions and management regimens are sporadic or do not exist at all. Also, the term "productivity" and "mean annual increment" are used ambiguously and make comparisons difficult. There is a need to define the precise meaning according to the products and dimensions; just as crucial is the need for defining the quality parameters (Nair et al. 1999).

Above all, considerable uncertainty regarding the basic information needed to plan future teak plantation programs persists. There is a lack of reliable information on yield and reforestation costs but especially on future markets and prices for plantation-grown teakwood for the calculation of returns. The cost of plantation establishment and maintenance depends on numerous factors such as topography, soil type, location, availability and cost of labour, plantation technology, intensity of management, and plant spacing; therefore costs do vary among localities (Ball et al. 2000). The plantation costs normally included in most financial analyses are basic, i.e. not including land mechanization costs, drainage costs, use of new technologies such as GIS mapping, genetic improvement, high-tech infrastructure costs, road construction costs, among others. Merchantable volume is arbitrarily defined and roughly calculated with form factors and subjective definition on the merchantable height of trees. Wood prices are just arbitrarily set up in relation to visual assessment of the quality, quantity, and provenance of the product. Consequently, the real merchantable value of the stock may be much lower or much higher than the estimates.

The limited studies on historical prices for teakwood suggest an upward trend, although no supply and demand assessments have been made at the global, regional or national levels. The products from teak plantations and forests vary in size and quality with wide ranging end uses and, consequently, prices. Further, teakwood prices for the same kind of products vary across different transaction points. Detailed spatial and temporal information on quantity, quality, and price relationships is not readily available. Considering the declining supply from natural forests, the long-term prospects for plantation-grown teak seems very promising. Properly managed teak plantations can generate attractive returns on investment (Nair et al. 1999).

The private sector has become more involved in the establishment of tree plantations than it was 10 or 20 years ago, and the direct role of the public sector has diminished. Within the private sector there is a trend towards increasing number of small-scale farmers acting as out-growers, who incorporate trees into farming systems, or as small blocks, and who grow trees to supply large-scale industries, the case of teak in Thailand, Costa Rica, and Ghana (Ball et al. 2000). Teak plantations can be an attractive investment; however more transparent analyses are essential, including sensitivity analyses that consider the diversity in management and markets to build investor confidence and to prevent speculative investment based on misleading claims (Nair et al. 1999). The need for reliable and objective information is especially important to the growing number of investors in the private sector, especially small-scale landowners who may lack the means of or the knowledge to carry out their own assessments of the potential risks and rewards from a stake in a teak plantation. Such risks may not only be financial but may be environmental as well (Ball et al. 2000).

Teak plantations grow fast in Central America compared to other countries such as India and Indonesia. Most of the actual teak plantations in Costa Rica will reach the second or third thinning (with high commercial value) within the next 5 to 10 years, and most of these plantations have no clear management guidelines matching production objectives, yield expectations, or even an idea of the possible return on investment. The present study aimed at contributing with supportive information on efficient methods and tools for 
achieving higher quality and growth potentials for teak plantations in Central America. The different components (Studies I-VI) of the intensive management system proposals for $T$. grandis in Costa Rica presented in this work should be a supporting tool for the evaluation of investment projects on teak plantations. The aim of the study has been accomplished in the sense that the growth scenarios provide a diversity of management options supported by data, growth models, density management guidelines, volume equations, and information on the economic profitability of teak plantations in Central America.

\subsection{Quality of data}

The different studies (I-VI) are based on field information collected by the author from 1997 to 2003. The information on wood quality (Studies I and III), pruning and thinning regimens (Studies II, III, and IV), volume equations (Study V), stand growth scenarios (Study VI), was collected from private plantations available at the moment. The sample data was very heterogeneous in terms of climate, site quality, management systems, ages, and the distribution of these and other geographic characteristics, as in the end some areas presented many more sample points than others.

There are no proper records in the national forestry inventory on the existence of teak plantations in the country, as all the projects are privately funded. A small proportion has been covered by forestry incentives and, therefore, is registered; however, these records contain little information on the plantations' management history. For Studies II, III, and $\mathrm{IV}$, two private companies allowed the establishment of the corresponding thinning and pruning trials. The evaluation of the thinning trial was limited to evaluation of the effects after the first intervention; similarly for the pruning trial.

Two companies shared financial information. As the information from the two companies covered only partially all the rotation activities (mostly up to year 5), complementary information was obtained from other sources to cover the silvicultural activities for the entire rotation period, in particular the thinning and harvest activities (and the corresponding incomes and outcomes).

Deficient management practices and poor growth rates were evident on many teak plantations evaluated in the present study. Many teak plantations presented a particular limiting factor that had negatively influenced the species' potential growth, e.g. site quality, planting material, late pruning or thinning, high planting densities, etc. Consequently, a data selection was necessary for representing intensive management scenarios instead of average or even under-average growth schemes, discarding plantations with poor quality development, which wouldn't even fall within the low quality classification of the scenarios.

\subsection{Accuracy of models}

The different models (competition factors, diameter and height growth curves, total and merchantable volume equations, heartwood volume estimators, etc) were developed based on data collected from different regions of the country, without any classification norms. This means that the distribution of data is not balanced, as more than $50 \%$ of the sampled plantations were less than 15 years old. Therefore, model parameters do not refer to any specific region, site quality, or plantation management regimen. Models should be calibrated with local data by the user to improve precision. 
Each of the models developed in the different studies were validated with the same database, as the insufficiency of data did not allow the validation using independent datasets, except for the volume equations in Study $\mathrm{V}$ where an independent data set was available. In this case, the validation indicated that all models estimate total and merchantable volume with relative accuracy at young ages (less than 10 years of age), where trees are more homogenous in shape, size, and growth, giving an error estimation of less than $7.0 \%$ for total volume and less than $14.0 \%$ for merchantable volume. In plantations older than 15 years, the variance of the model increased (error of estimation of $10.0 \%$ for total volume and $18.0 \%$ for merchantable volume as maximum), as a result merely inherent to age, to different growth patterns, to differences in silvicultural management, and to the relatively small sample size, as old plantations were scarce.

Heartwood content (Study I) varied considerably among trees of 5 years old and younger $(\mathrm{r}=0.31)$ and therefore could not be predicted accurately. However, at older ages the model presented a very encouraging coefficient of determination $r^{2}=0.67$, if one considers the still inconsistent heartwood formation at ages less than 25 years for fastgrown teak. Wood dry density increased slightly with age, presenting a higher correlation at the base of the tree $(r=0.61)$ than at the base of the crown $(r=0.51)$. Models predicting wood dry density from age, and DBH, presented poor goodness of fit $\left(r^{2}<0.40\right)$. The factors affecting wood properties were analysed one at a time. Because the factors correlate with each other, the analysis may lead to misleading interpretations. Multiple regression analysis could have been used to alleviate this problem. However, multicolinearity may have caused problems with this method, as a good and large enough data set would have been needed to predict more or less correctly, which would have not being the case with the available dataset.

Competition factors and growth models of the scenarios (Study VI) were developed from selected databases, aiming at representing the growth potential of the species under intensive management practices. The Maximum Site Occupancy (MSO), the Competition Factor (CF), and the Reineke Density Index (RDI) were used for modelling the stand competition and for the definition of thinning intensity and timing. The MSO and the RDI could not be strictly followed, as too many and too frequent interventions (every two years) would be necessary and would not be economically feasible to implement. The RDI limits were surpassed in all the scenarios with the objective of high individual tree growth, while in the scenarios with the objective of high stand growth the RDI remained within the limits set up by Reineke (1933) and calculated by Camacho and Blanco (1997) for Costa Rica.

When comparing the RDI, the MSO, and the CF (Figure 9b), it was evident that both RDI and MSO are basically linear functions of BA, whereas CF is a non-linear one. In terms of competition, the RDI was "less tolerant" than the MSO and both were "less tolerant" than the CF $(\mathrm{RDI}<\mathrm{MSO}<\mathrm{CF})$. For example, at BA of $25 \mathrm{~m}^{2} \mathrm{ha}^{-1}$, the reduction in growth according to each indicator RDI, MSO, CF would be $-50 \%,-35 \%$, and $-15 \%$, respectively. In order to keep the stand within the limits of RDI and MSO, a constant thinning regimen (every two years) would be necessary, while for the CF, a management regimen with less thinnings will keep the stand within the optimum growth limits. For RDI and MSO, competition begins at BA of $15 \mathrm{~m}^{2} \mathrm{ha}^{-1}$ or less, while for CF the competition starts to be evident at BA $20 \mathrm{~m}^{2} \mathrm{ha}^{-1}$. According to Kanninen et al. (2003), teak plantations in Costa Rica present their highest growth rate at BA between 17 and $20 \mathrm{~m}^{2} \mathrm{ha}^{-1}$. Jayaraman and Zeide (2003) found that for teak plantations in Kerala (Southern India) the upper limit of RDI was 475 (approximately a BA of $23 \mathrm{~m}^{2} \mathrm{ha}^{-1}$ ) for achieving high stand growth values, similar to those values obtained in this study for the scenarios with the objective of high individual tree growth. 
After applying competition factors, final growth projections were cross-checked with the different plantation and single tree entries of the database to find illogical predictions, such as unattainable tree size, stand densities, or stand yield. Reports from pervious studies as well as results from the thinning trial suggested a consistently realistic prediction of the scenarios developed in this study.

\subsection{Integrated growth scenarios}

\subsubsection{Effect of silvicultural management on wood properties}

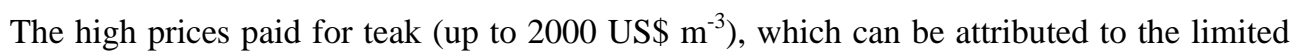
availability of natural teak in the international market, have prompted the establishment of a large and growing teak cultivation across the tropics. Unfortunately this has resulted in sacrifices in terms of wood quality. Compared to natural, forest-grown teak, plantation teak grown under rotations of 20-30 years presents a higher proportion of sapwood and juvenile wood, and a different external aspect regarding colour, grain, and texture (Akwasi 2004). However, some studies suggest that these differences may not always be considerable; hence rotation period of fast-grown teak can be reduced without affecting certain wood properties, such as timber strength (Bhat 1995, Bhat 1998, Bailleres and Duran 2000, Bhat et al. 2001).

Heartwood content and wood dry density, two of the most desired characteristics for teak wood and with important correlations with structural, aesthetic, and durability properties, have been found to be more related to tree maturity rather than to silvicultural management intensities (Malende and Ringo 1987, Wiemann and Williamson, 1989, Bhat 1995, Tewari 1999). Due to wood juvenility, some characteristics seem to be unstable and not clearly affected by management or site characteristics, although according to Study I, heartwood content is negatively correlated with annual precipitation. Moya et al. (2003) concluded that before age 10 years the effects on wood properties of teak growing in Costa Rica, caused by different management regimens, were temporal and therefore differences were no longer significant afterwards, suggesting that different management prescriptions can be applied to teak stands according to specific production objectives, without a reduction in wood quality.

Thinning and pruning intensities tend to improve stand properties, such as diameter distribution, stem taper, heartwood formation, and wood basic density in relation to dense and unpruned stands (Adegbeihn 1982, Morris et al. 1994). As mentioned previously, heartwood content and wood density are greatly influenced by age and acquire more stability at middle ages (over 15 years of age). Although differences in heartwood content, wood density, and stem form were correlated with stand density and thinning intensities, most results could not be strongly supported by statistical tests (Study I, III, IV). No clear relationship could be established between thinning intensity or thinning timing, or both, and heartwood content of trees, coinciding with Hillis' (1987) statement that heartwood content tends to vary considerably within the same stand and among trees of the same age at early plantation stages. However, it was concluded that on-time- and intense-thinning practices improved wood properties, with the possibility of enlarging those improvements at older stages. While moderate and heavy thinnings yielded the highest content of heartwood, light thinnings and no thinnings yielded higher values on average. The absence of thinning interventions showed higher heartwood contents than when thinning on time or late; suggesting that the timing of carrying out the thinning has no effect on the heartwood content. 
The stem was found to be slightly more cylindrical on high-intensity and on timeexecuted thinnings, showing only small variations (form factor values between 0.43 and 0.45). Contrary to this, Adegbeihn (1982) reported increments (0.39-0.41) in the stem form factor with increasing stand density on a spacing trial for teak in Nigeria. In other species, such as Jack Pine (Pinus banksiana), the stem form factor has been reported to increase with decreasing stand density (Morris et al 1994). The present results indicate that intensive thinnings have a positive effect on stem taper, producing trees with proportional dimensions of DBH and total height. Trees under high competition, such as the Control and the light thinned treatments, will hardly reach the desired proportion of 1:1 between these two variables. In his study about density management on teak, Adegbeihn (1982) found that $\mathrm{DBH} /$ total height ratio increased with decreasing stand density. In this study, all treatments presented ratios greater than 1.0 (ratio $1.0=1.0 \mathrm{~cm}$ DBH increment for each $1.0 \mathrm{~m}$ increment in total height), suggesting in general a good stem form despite big differences in stand density (748-2660 trees ha $\left.{ }^{-1}\right)$.

As wood basic density is considered an important indicator of wood quality and strength, the present results offer a scope for developing high intensity thinning programs. In other tropical plantation species, wood basic density has been reported to decrease with increasing thinning intensity but not at significant levels. Malende and Ringo (1987) concluded that different thinning schedules are unlikely to reduce wood density in Cupressus lusitanica grown in Northern Tanzania. Tewari (1999) cites several studies on teak in India where no significant variations in wood specific gravity were found with increasing DBH growth rate, i.e. under different stand densities.

Pruning has been commonly used as a silvicultural technique, although empirically developed, to obtain high quality timber (Hubert and Courrand 1988). Knots are widely considered as the most determinant defect for wood quality classification; to the point of influencing the origin and magnitude of other defects such as pith eccentricity, stem form deviation from the geometric cylinder shape, and bending (Rosso and Ninin 1998). Appropriate pruning intensities, suggested by Pérez et al. (2003), have shown positive effects on wood properties such as stem taper, knot-free wood, and heartwood content (Study II). Annual diameter or volume growth rates of severely pruned trees may eventually recover to equal un-pruned tree growth rates, however cumulative growth rates are unlikely to recover the lost growth (O’Hara, 1991). According to Rosso and Ninin (1998), wood with knots in 26-year-old teak in Venezuela can reach up to $20 \%$ of the total log volume, increasing with increasing stem height (first two logs present between 4.0 and $13.0 \%$ of the total stem volume). The authors also report an increment in stem bending, pith eccentricity, and ellipse-shape with increasing area of knots. Majid and Paudyal (1992) consider that pruning should be done on early stages in order to restrict knotty cores to a minimum. Moreover, early pruning (at 2.0 or 3.0 years of age for tropical species) should be performed on all trees in order to avoid suppression by neighboring trees. The regimen proposed by Gerrand et al. (1997) agrees with the previously mentioned criterion of the minimum defect core diameter, which according to them should be kept under $15 \mathrm{~cm}$.

International grading rules do not allow the appearance of knots on timber wood of "special” grade. For first quality or grade 1, the permissible amount of knots is one per linear meter, with a maximum diameter of $1.25 \mathrm{~cm}$. For the lowest grade within international standards (grade 3), a total of 3 knots per linear meter with a maximum diameter of $3.81 \mathrm{~cm}$ is allowed (Tanteak 1995). Lumber recovery rates reported for mature teak (70 years old) in Malaysia vary between 23 and 30\% for Prime grade (Grade 1) and Utility grade (Grade 6), respectively (Tze 1999). By means of an intensive pruning regimen that reduces the number, frequency, and diameter of knots, the lumber recovery and the 
grading will be improved considerably, as logs of higher quality will result in a higher lumber recovery rate.

In general, recommendations for tree species in Costa Rica are to prune trees up to $50 \%$ of the total height just after the first thinning (Keogh 1987, Chaves and Fonseca 1991), or according to commercial log sizes, i.e. up to $2.5 \mathrm{~m}$ sections (Murillo and Camacho 1997). Galloway (1993) recommends a first pruning in species that form large branches when tree height is only $3.0 \mathrm{~m}$, and in the case of teak $4.0 \mathrm{~m}$. The second pruning takes place after the first thinning and pruning to a multiple of log sections, since it is unlikely that someone will pay a premium price for a half-pruned log. Pruning is primarily an economic decision and the extra effort for high pruning would have to be compensated with a premium price.

According to present results, a more intensive and early pruning regimen would improve wood quality at harvest, achieving individual total volumes without knots of 0.839 $\mathrm{m}^{3}$ vs. total tree volumes of $1.364 \mathrm{~m}^{3}$, for a gain of $38 \%$ in volume without knots due to pruning, this at 20-year-old rotations (Study II).The pruning in teak should be carried out up to a final tree height of $7.0 \mathrm{~m}$, or higher if the last usable section exceeds this height and the plantation quality eventually assures an attractive return on investment. In concordance with present recommendations, Majid and Paudyal (1992) and Gerrand et al. (1997) consider that pruning should be done at early stages in order to restrict knotty cores to a minimum.

Most 20- to 30-year-old stands can be expected to produce between 40 and $55 \%$ of heartwood, a wood dry density between 0.60 and $0.65 \mathrm{~g} \mathrm{~cm}^{-3}, 40 \%$ of knot-free wood (from total volume, approx. 50-60\% from merchantable volume), reduced stem taper, more cylindrical bole shape, and other esthetical and structural characteristics which are highly valued on the international wood market. However, expected results may vary under different environmental and management conditions, even within the same stand and among trees of same age (Hillis 1987). The present results cannot entirely guarantee the maximization of those appreciated characteristics as research has been possible mostly on juvenile plantations.

Few plantation owners are receiving a premium price for clear wood at present in Costa Rica and many other teak-producing countries. By means of an intensive and on-time pruning regime, all the young teak plantations may increase considerably their wood quality (wood free of knots) and consequently their market value.

Towards the improvement of wood quality on teak, commercial planting programs should consider the establishment of a genetic improvement program in addition to the implementation of silvicultural management techniques. The differences in genotypic gain (an indirect measure of return on investment) especially in growth and stem quality characters can exceed $20 \%$ between the well-suited or superior provenances and the poorly adapted or inferior provenances depending on environmental conditions (Kaosa-ard 2000).

\subsubsection{Effect of silvicultural management on tree growth and stand yield}

Intensive thinning should avoid strong competition in teak stands by keeping the BA below 25-30 $\mathrm{m}^{2} \mathrm{ha}^{-1}$ with reductions to $15-20 \mathrm{~m}^{2} \mathrm{ha}^{-1}$ on each thinning (Keogh 1979, Lowe 1976, Torres 1982). Verification of thinning prescriptions through rotation is still missing, as most of the available studies are based on the first thinning carried out at young ages $(<10$ years). In the present study it was found that thinned stands differentiate from non-thinned ones, presenting variations as high as $5.0 \mathrm{~cm}$ (30\% higher) in $\mathrm{DBH}$ and $2.0 \mathrm{~m}$ (12\% higher) in total height at age eight years. Similar results were found in another thinning trial established at age four years in a $T$. grandis plantation in Costa Rica by Chaves and Chinchilla (1991). Adegbeihn (1982) found significant differences in diameter growth but 
not in mean height growth in a T. grandis spacing trial established in Nigeria, supporting the view that diameter growth is sensitive to spacing. Lowe (1976) carried out a thinning experiment on teak in Nigeria where a BA reduction from 32 to $13 \mathrm{~m}^{2} \mathrm{ha}^{-1}$ was performed in the heavy thinning treatment, showing notorious improvement in terms of individual as well as stand growth, and suggesting that BA should be brought below $20 \mathrm{~m}^{2} \mathrm{ha}^{-1}$ on each thinning intervention.

Ola-Adams (1990) concluded after evaluating a spacing trial in Nigeria that $T$. grandis should be planted at densities between 1189 and 1680 trees ha $^{-1}$, as individual tree growth declines on higher densities and stand growth potential is not reached at lower densities. In Costa Rica, the highest BA found in non-thinned stands was $28 \mathrm{~m}^{2} \mathrm{ha}^{-1}$. Therefore, if the management objective is to maximize individual tree size, teak stands should not reach this $\mathrm{BA}$, since over $20 \mathrm{~m}^{2} \mathrm{ha}^{-1}$ competition increases and the $\mathrm{DBH}$ growth decreases, particularly at BA over $25 \mathrm{~m}^{2} \mathrm{ha}^{-1}$. Other studies suggest that the critical point for the BA of T. grandis plantations varies between 15 and $32 \mathrm{~m}^{2} \mathrm{ha}^{-1}$ (Lowe 1976, Keogh 1979, Torres 1982).

Pruning is a necessary silvicultural activity for the production of high quality wood, i.e. without excess of knots and associated wood defects (bending, pith eccentricity, deficient strength, twisted grain, stem taper, etc). However, the intensity and timing of the interventions has been empirically developed, leading to very light pruning intensities, executed late, and with no significant improvements in wood quality, or to very strong interventions at early plantation stages and with significant detrimental effects on tree growth due to biomass removal. Annual diameter or volume growth rates of severely pruned trees may eventually recover to equal un-pruned tree growth rates, however cumulative loss growth is unlikely to be recovered (O'Hara 1991).

Results of the pruning trial in Study II evidence the loss in individual tree growth and stand yield when the pruning is executed improperly, i.e without taking into account the relationship between foliage biomass and stem growth, as indicated by Pérez and Kanninen (2003). High amounts of removed foliage caused a sudden reduction in crown potential for photosynthesis, with the consequent reduction of up to $28 \%$ of stand BA and $43 \%$ of stand total volume, three years after pruning. Similar results have been reported for Acacia mangium stands (1.5 to 4.0 years of age) in Peninsular Malaysia by Majid and Paudyal (1992), where different pruning treatments ranging from 2.5 to $6.0 \mathrm{~m}$ in pruning height were applied and resulted in a reduction in diameter growth. This reduction was more evident when crown removal was greater than $40 \%$. In other species, such as Eucalyptus nitens, no significant differences have been found in the tree volume increment of pruned and unpruned plots two years after following pruning, with less than $40 \%$ of green crown pruned at the age of 3 years (Gerrand et al. 1997).

The trigger for first thinning should be based on stand performance, not age. The first thinning should normally seek to sustain diameter growth on the best individuals, at the lowest cost and with the least damage possible to the residual stand. Pruning and thinning strategies have to be planned together and for pruning to make sense, diameter growth on superior trees must be sustained from early in the rotation. Under normal conditions and on medium-to-high quality sites, pruning and thinning interventions should happen simultaneously in the first 4 years after plantation establishment. The first decision to make is weather to prune all standing trees or focus on those who will probably remain, i.e. do not investing efforts on the trees with high probabilities of being removed in the first thinning. This decision seems to be quiet easy to make, and by pre-selecting the trees to be removed on the first thinning, only those remaining trees will be marked for pruning. However, the first inconvenient might be the lack of clarity in the field for pre-selecting the best trees and discarding the worse ones, as usually the first pruning takes place at age 2.0 
years, when trees might or might not show their real potential. In addition, it is still unknown if the pruning of only some trees might create an adverse environment due to the sudden dominance of those trees that kept their full canopy area. This adverse interaction may increase considerably in the subsequent pruning interventions, expected at ages 3, 4, and 5 (this varies according to site quality and pruning regimes).

If the pruning is performed on time, the option of carrying out a general pruning of all trees might not be a loss effort since many trees might improve in quality and growth and pruning costs may not be so different than pruning only the pre-selected trees, as preselection could then wait until the time for thinning comes (avoiding the need to verify the correctness of the pre-selection of trees to be thinned). No reports on the selective pruning of teak plantations were found in the literature. One reason for this might be the fact that pruning can be considered as a new silvicultural technique, at least for $T$. grandis plantations. Consequently, most pruning interventions occur either later than recommended or without proper planning in order to carry out a thinning pre-selection.

The first and second pruning on teak, usually carried out at ages 2 and 3 years, can be perfectly perform on all trees without implying considerable extra costs, and keeping the possibility of not having any pre-selected trees for the first thinning. Those suppressed trees will also be discarded or remained without pruning by using a criterion such as a minimum total height. For further pruning, which would be carried out on taller trees (containing bigger and higher branches), the criterion of pruning only the superior trees is totally valid. Further more, only the superior trees will produce a sufficient volume free of knots as to justify the cost of the activity.

\subsubsection{Growth simulation techniques of the management scenarios}

The design of a growth model for use in a particular situation depends on the resources available, the uses to which it will be put and the structure of the forest stand. One of the common uses or objectives in forest plantations is to predict the growth on a particular site to enable the land manager to make rational decisions. Often the growth model is required to provide information for conversion into economic measures to facilitate comparisons of a number of feasible investment options. A stand growth model describes the stand and predicts growth through general parameters (stand BA), through mean values (mean volume per tree), and through definitions of frequency distributions (form and variance) (Philip 1994). The main objective of the present study was to develop a set of practical tools for the intensive management of $T$. grandis plantations in Costa Rica, including the development of preliminary growth scenarios for different management objectives. The growth scenarios consisted of a combination of growth, yield, and competition models used under an empirical approach to simulate possible individual-tree growth and stand productivity under different management regimens.

Dynamic models predicting the response of a stand to changing conditions controlled by the manager have either to use mathematical integrals of growth functions over time, or to be iterated, i.e. the prediction has to be repeated at intervals with the output from one prediction or iteration becoming part of the input for the following one, up to the end of the rotation. Consequently errors may accumulate unless the model is constrained, or calibrated so that it provides predictions consistent with independent data (Philip 1994). The development of dynamic models that predict the effect of thinning for $T$. grandis plantations in Costa Rica encounters several limitations, as no consistent and long-period measurements were available. Consequently, growth and yield models for this species in 
Costa Rica (and very likely in Central and South America) are lacking of a satisfactory simulation of the stand dynamics.

Stand growth models should predict the differential effects of early, late, or no thinning on different original spacings and assist the manager to take decisions on thinning in a rational manner. The database, nevertheless, defines the range of feasible prediction, and extrapolation beyond this range of experience may be misleading (Philip 1994). The present study includes the result of different thinning intensities and timing on tree growth and stand yield, although the applicability of the results is very limited as the stand conditions where the experiment was carried out are very specific and cannot be considered as "average" for teak plantations in Costa Rica. However, the methodology and the analysis of results should be used as guidance for evaluating and developing management options based on particular production objectives.

Potential diameter growth is only the other side of "potential density". They both describe the ability of trees to use available space for growth. While potential density can be described by maximum stem number for a given diameter or maximum BA, potential diameter growth describes the same site property in terms of diameter growth of open grown trees. Equations and systems of equations in both single stem simulators and stand models that describe the modification of diameter and thus BA growth by density, stocking or competition have to comprise these principal points of potential growth. Different descriptions of maximum density lead to equations describing maximum stem number for a given diameter (Sterba 1989). The growth scenarios developed for teak in Costa Rica in the present study are based on competition factors and "calibrated" with two different maximum site occupancy models, aiming at allowing at all times the stocking of a real or possible number of trees per hectare according to their individual size. The use of the crown area for estimating maximum stocking density guarantee the avoidance of extreme intertree competition levels if followed accordingly, as once the crowns make physical contact, the model triggers a thinning to low the stocking density.

A stand simulator developed for Norway spruce contains a multiple of increment lines (diameter increment over DBH), the intercept and slope which depend on stocking degree. This system results in an optimum curve for increment over BA although a maximum of this curve has not been assumed. Simulating thinnings from below led to an optimum function of increment over BA when age and site index were kept constant. Thus, it can be concluded that there exists an optimum BA or at least an increasing nonlinear relationship with decreasing slope between stand BA and BA increment. The shape of this relationship varies not only with species but also with site; even for a given site index (Sterba 1989). Similar findings were obtained in the present study when developing the diameter growth curve in conjunction with the development of the competition factor. Based on the thinning trial, the BA of $30 \mathrm{~m}^{2} \mathrm{ha}^{-1}$ was considered the maximum for teak in Costa Rica, although the thinning interventions in the different scenarios were trigged at lower BA values.

The influence of site on potential height growth, potential diameter growth, and growth variations due to competition is not revealed completely by site-index. The shape of the height growth curve, the potential density, the height diameter ratio of open grown trees, and the influence of stand density on stand growth usually depend on different site properties which are not taken into account by site index classifications (Sterba 1989). Therefore, the growth curves of the present management scenarios (DBH and total height growth curves) were divided into "plantation growth quality classes" rather than site quality classes. The reason for this is that most of the teak plantations evaluated for the development of the growth scenarios belonged to different private owners, which influenced the application of different establishment and management systems. Consequently, and as growth and yield differences were evident, the classification of these 
stands by site index would not have allowed to represent the potential of the species in Costa Rica, which was necessary for developing the intensive management scenarios. In addition, there are several site index curve systems already developed for the species, therefore the present study concentrates more on the classification of stands by their actual growth and yield status.

Attempts to fit diameter growth equations have failed even when using permanent sample plot data, as not a single parameter seemed to be related to diameter increment. It has been possible however to fit a diameter increment equation using increment cores from temporary sample plots for Pinus patula in Southern Tanzania. The developed equation implied that while the rate of diameter growth decreases with age and stand density (in terms stand BA) it increases with site (dominant height) and initial size of the tree; the larger the tree the higher its competitive capability (Malimbwi and Philip 1989). One of the main limitations of the present study was the insufficient and irregular dataset, particularly at middle and advance ages (>15 years of age). Hilt and Teck (1988) developed and individual-tree diameter growth model for 14 species groups in northern New England. Individual trees for a given species were sorted in descending order according to their BA growth rates in each DBH and site-index class. The top 10 percent of the fastest growers in each class were then selected to develop the potential growth function. Similarly, for developing the $\mathrm{DBH}$ and total height growth curves, a subset of the dataset was selected in order to eliminate those records from extreme deficiently-managed stands. Moreover, only few records of re-measurements could be obtained, as most plantations were measured for the first time during the field work of the present study. Stem analysis was carried out on some trees at different ages and from different sites, however the development of growth equations with this information was not considered for the generation of yearly growth data, mainly because of the reduced data size.

The allocation of thinned trees in a mechanical thinning is simple since each stand has the same number of trees to be removed. Apart from stocking, the mean stand values do not change; in selective thinning however the numbers removed vary in the stand. The most common low thinning removes the inferior trees to give room to the growth of the better remaining individuals (Malimbwi and Philip 1989). For this, in most thinning simulations, like those of Pukkala and Miina (1998), the thinning interventions are specified by a BA that induces thinning, by removal percentages in different diameter classes, and an algorithm that computes the order in which trees are removed.

The growth simulations of the present scenarios used the BA as one of the main criterion for trigging a thinning intervention, together with the criteria of maximum site occupancy, growth reductions in DBH by competition, frequency and intensity of thinnings, etc. However, the simulations lack of a diameter class differentiation, which increases the uncertainty of the projections, particularly after each thinning intervention. Simplicity was chosen over precision as the nature of the dataset would have limited the development of a consistent diametric distribution to be included as parameter to the growth simulations. Consequently, the projections of the present growth scenarios are limited to average growth values and consider systematic thinning interventions carried out on time, i.e. providing a quiet homogenous tree removal and very likely an unnoticed variation in the diametric distribution. Under homogenous management systems and on genetic-improved stands, thinning without altering the diametric distribution and the stand mean diameter should be an indicative of an on-time and systematic intervention. Phillips (1995) developed a growth and yield model for teak plantations in Sri Lanka. The model was based on the variables Site Index, cumulative BA, and maximum stocking density. No self-thinning or no-thinning regimes were acceptable. The height and cumulative BA equations determine the basic performance of the simulation but the flexibility in thinning 
operations and yield comes from a third equation which describes the development of the diameter distribution. The relevant equation predicts the percentage of the annual BA increment that is assigned to a particular tree from a number of independent variables. The reasoning behind this approach is simply that dominant trees are responsible for more of the BA increment than smaller trees, but the limitation is that a relatively large tree of $20 \mathrm{~cm}$ $\mathrm{DBH}$ in a young stand will be a relatively small tree in an older stand. The inclusion of additional variables such as standing BA and BA increment in a multiple regression analysis help to overcome this problem.

The relation of mean tree size to tree number and stand age can be expressed in a correlated curve trend graphical model, with the mean tree size expressed as average diameter. Tree number and size are related, where tree size is expressed by average tree diameter or by average stem or total tree size in both the competition-density and selfthinning theories. Maximum tree number can be related to stand age, giving a reverse-J shape curve which can be found in many normal yield tables. A three dimensional model can be constructed in order to show that the generalized competition-density, sigmoid growth curve, and reverse-J tree number/age models are directly related for even-aged, single species stands on a given site in the theoretical absence of differentiation and mortality (self-thinning). Each model defines the same competition surface when represented on a three-dimensional system. The surface will contain a free growth zone, a zone of intraespecific competition, and an upper limit of stand density (McFadden and Chadwick 1988). The attempts of the present scenarios to model growth and yield for teak plantations in Costa Rica follow a similar approach than that of McFadden and Chadwick (1988), with the difference of having transformed the three-dimensional system into a set of growth scenarios. Both approaches show basically a simulation based on the relationships of age with stand diameter growth, tree size with stand density (including a competition factor), and stand density with age.

Density management diagrams effectively translate general management objectives into stand-specific thinning prescriptions (Kumar et al. 1995). The apparent simplicity of these diagrams belies in their ability to display the complex dimensional relationships of developing stands. Essentially, density management diagrams are simple stand average models which graphically characterize yield, density, and mortality at various stages of stand development. They are useful in designing alternate density management regimes, in displaying the consequences of stand density manipulation, and in translating general objectives into practical thinning regimes. The density management diagram developed for teak plantations in peninsular India by Kumar et al. (1995) uses the quadratic mean diameter and the number of trees per hectare; relative density or growing stock level is represented by Reineke's (1933) Stand Density Index, and two additional sets of curves, based on non-linear regression models, represent top height and total volume. These density management diagrams are based on a similar approach than that used for developing the present growth scenarios, in the sense that they are simple (at expenses of omitting some important variables such as diameter distribution) for characterizing growth and yield at various stages. The stand density is managed through competition and maximum occupancy indexes, which in conjunction with the production objectives trigger the different thinning regimens. Similar than the stand density diagram of Kumar et al. (1995) and the present growth scenarios for teak in Costa Rica, different growth simulations have been developed for other species with the characteristic of simplicity of construction and ease of use, aiming at presenting preliminary but useful management guidelines, despite the limited availability of data and complex relationships. For example, a simple average growth model was developed for Norway spruce pure even-aged stands in northeastern France by Houllier et al. (1995). This model was based on fairly restrictive assumptions 
about the homogeneity of the stands, i.e. all the trees are of the same size, are regularly scattered within the stand and the development of their crown is symmetrical around the vertical axis. Thinnings are neutral (the size of the thinned trees is the same as the size of the remaining trees) and do not disturb the regularity of the spatial distribution of the trees.

\subsubsection{Applicability of the management scenarios}

All variables in the present scenarios, such as plantation density, BA, and stand total volume, are based on field information collected from sample plots, meaning that although no intensively managed plantations were found in the field, separate analyses clearly showed the potential of the species under ideal management scenarios. Results from the thinning experiment (Study IV) support the stand density dynamics of the scenarios. High stand growth and yield should be achieved through thinnings rather that accumulating volume to the end of the rotation period, allowing stand volume maximization without causing considerable individual growth reductions due to high stand competition levels.

In the scenarios with high individual tree growth as objective (Study VI), thinnings were more intense and more frequent than in the scenarios with high stand growth, as in the latter the stand density was kept always higher in order to maximize stand volume. Either one extra thinning of approximately $40 \%$ of intensity or two thinnings of $20-25 \%$ of intensity differentiated the high individual tree growth scenarios from the high stand growth scenarios. The timing of each intervention was carefully analysed and defined based on the effects reported in Study IV, as well as based on the stand growth annual increments. In most cases, all factors or criteria for the set up of a thinning coincided, i.e. the growth annual increment dropped, the BA reached the established limits, the competition factor went below 0.8 (20\% growth reduction), and the site occupation indicators were reached or slightly surpassed.

Present scenarios were constructed for high, medium, and low quality sites. In relation to this, it is worth to mention that according to different country reports and personal experience, most of the teak plantations established in Central and South America with ages greater than 10 years hardly reach a satisfactory plantation quality status (similar to that of a medium quality site). The poor implementation of intensive management techniques originated from the selection of poor quality sites, the use of poor quality seedlings, and the late application or total absence of key silvicultural treatments such as thinning and pruning. In the last 10 years, practically a new era has started and intensive managed plantations offer a scope for visualizing the real potential of T. grandis in Central and South America.

Bermejo et al. (2004) recently published growth and yield models for teak plantations in a specific site of the northwestern region of Costa Rica, supporting their recommendations with newly developed volume equations, site index curves and provisional empirical yield tables. Stand development conditions in the specific study area may have been lower than in many other regions in Costa Rica, as teak potential is underestimated in terms of stand yield (thinnings are executed before reaching sufficient BA). In other words, implementing these management guidelines in other regions of Costa Rica may cause a loss of potential for maximizing stand growth, especially on high quality sites. It is suspected that the competition factor used for modeling stand density (Hart-Becking index) happens to be highly conservative and simulates strong competition too early. Another previous study was carried out by De Vriend (1998) on indicative growth tables for teak in Costa Rica. Projections are based on measurements carried out on 14-year-old plantations and younger (according to reports), which leads to the conclusion that the expected yield (over $850 \mathrm{~m}^{3}$ 
$\mathrm{ha}^{-1}$ on high quality sites) proposed in his scenarios are not supported by sufficient data. Consequently it is suspected that the projections may be overestimating productivity.

A minimum log size is required in many wood processes, and large log diameter usually means high sawing yield (Persson 1986). For the volume projections of a stand, special attention must be given to the fact that merchantable volume differs considerably and in certain cases enormously, in relation to total standing volume. This is important to consider when the wood trade is being carried out at the level of stem logs, since the percentage of bark from the total volume of the log is consider as part of the measuring allowance. If the objective is board feet production, the percentage of bark diminishing the sawing volume should be that on the smaller end of the log, much less than that based on the total volume of the log. The merchantable volume equations developed in Study $\mathrm{V}$ allowed the estimation of total as well as merchantable volume for different minimum diameter and for merchantable logs of any length. Scenarios with the objective of high individual tree growth showed a larger number of merchantable logs, with greater diameter, and obtained at younger ages than in the scenarios aiming at high stand growth. This result offers the possibility of modifying the dimension, quantity, and distribution of volume growth in teak stands according to production purposes (Study VI).

An accurate estimation of the real saleable volume is necessary instead of the total standing volume of a plantation, for marketing projection purposes. Most of the forestry projects in Central America lack appropriate planning of the real amount of saleable volume that is stocked in their plantations; therefore, it becomes impossible to assess their investment accurately. In some cases, the current value of teak projects is estimated by assuming it to be equal to the accumulated establishment and management expenses.

The set of scenarios in Study VI were constructed to the level of merchantable logs with a minimum diameter of $15.0 \mathrm{~cm}$ and a fixed length of 4.0 meters. Total standing volume was reduced by almost $40 \%$ when calculated as merchantable logs. Without considering the loss due to bark content and due to further processing, differences between stocking volume and final saleable volume are definitely of consideration when linking growth projections with financial profitability analysis. Differences in total and merchantable volume between the two management objectives were not as large as anticipated, since both scenarios relied on the criterion of intensive management, i.e. without causing a drastic reduction in growth because of extreme competition or under-use of the site potential due to extreme thinning intensities.

\subsection{Financial aspects of the growth scenarios}

Site classes, production objectives, and rotation periods showed clear differences in the financial profitability projections. As expected, high-quality sites presented the most profitable scenarios (based on NPV and IRR indicators) with the maximum volume productivity and individual tree size. Prioritizing high individual tree growth over high stand growth yielded a higher return on investment in all site classes, influenced by the higher yield in merchantable volume reachable under the log size specifications given in the scenarios. Rotation periods also had a considerable influence on the estimated returns of the scenarios; while on the high quality class the 20 year-old rotation scenario (with DBH maximization as objective) was clearly higher in return than the other scenarios, while in the medium and low quality sites the 30 year-old rotation scenarios were the most profitable options.

On low quality sites and with $10.0 \%$ discount rate, all scenarios presented negative $\mathrm{NPV}$, suggesting that under those specific circumstances the project lacks of economic 
interest. According to present results, the investment in teak plantations in Costa Rica can be categorized as highly secure in high quality sites (19.8\% < IRR $>23.4 \%)$, as secure in medium quality sites $(14.2 \%<$ IRR $<16.5 \%)$, and as fairly secure or insecure in low quality sites $(8.7<$ IRR $<9.1 \%)$. A short rotation of 20 years with high individual tree growth as the objective is the most recommended management scheme in high quality sites. In medium and low quality sites, the results of NPV suggest a longer rotation period (30 years) with preference for the DBH maximization but with similar results achievable with stand maximization as the production objective. The IRR gave highest values under scenarios with short rotations and DBH maximization as objective, for high and medium quality sites, while for low quality sites longer rotations (30 years) and similar production objectives should maximize the financial profitability of the plantation.

De Camino et al. (2002) evaluated private forest companies in Costa Rica, concluding that the present value of income for high-intense-managed teak plantations in the country could reach up to 31854 US\$ ha ${ }^{-1}$ with IRR values of $23.0 \%$ in rotation periods of 20 years, at interest rates of $4.0 \%$ and with no price increments (varying between 100 and 600 US\$ $\mathrm{m}^{-3}$ ). Scenarios of Study VI for high quality sites at rotation periods of 20 years yielded higher NPV (between 34000 and 43000 US\$ ha $^{-1}$ ) than those of De Camino el al. (2002), although total costs were higher in the former and wood prices were similar, suggesting that management schemes differ significantly (not available in the latter). De Vriend (1998) considers that NPV of average teak plantations over a 20-year rotation period ranges from 11700 to 31500 US\$ ha ${ }^{-1}$, with establishment and management costs between 6000 and 12000 US\$ ha ${ }^{-1}$. Oviedo (1997) determined the optimum financial rotation for teak in Costa

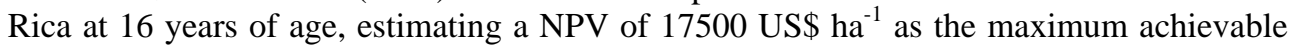
return on investment. Differences between studies, as well as wide ranges for investment returns given by authors like De Vriend (1998), evidence the need for more accurate information on overall plantation costs for different management options and environmental conditions, as well as on realistic prices for different wood products accordingly to the growth and management scenarios.

Wood price was the only variable that significantly affected the NPV of the growth scenarios. The other evaluated variables (basically plantation costs) were not as significant as wood price for the financial run, even though land price was a considerably high cost at year zero, i.e. without being softened by the discounting rate. The other costs were higher than the land price and were distributed throughout the rotation. Therefore, the increments and reductions did not significantly affect the NPV of the scenarios (maximum 5.0\% variation).

Similarly, the IRR was sensitive only to wood price variations ( $\pm 20.0 \%$ ). increasing and decreasing by a maximum of two percentage points (original IRR $\pm 2.0 \%$ ), which represents less than $10.0 \%$ difference in relation to the original scenario. Other variables showed no significant variation (original IRR $\pm 1.0 \%$ or less). These results confirm that the economic profitability of a $T$. grandis plantation can only be affected significantly by changes in wood price. Therefore, estimates of current and future wood prices (and possible yearly increments) should be very conservative in order to avoid unattainable or uncertain returns on investment. Contrary to this, Nieuwenhuyse et al. (2000) reported teak plantations to be insensitive to price changes between - $40 \%$ and $+60 \%$ of the base value of 95 US $\$ \mathrm{~m}^{-3}$ at rotations of 25 years of age (details about overall plantations costs are not given in the study). The reported insensitivity to price changes is suspected to be either because of very low and unrealistic overall plantation costs or to the low wood prices used in the analysis, which differ considerably with those prices found in the wood market during the field research of the present study. 


\subsection{Conclusions}

Wood quality of fast-grown T. grandis in Costa Rica was found to be similar to that growing elsewhere. Important characteristics, such as heartwood content and wood density were found to be related more to tree age than to silvicultural management practices, especially at early plantation stages. Wood quality did not vary with site or region, despite the climatic differences present in Costa Rica. Rainfall caused a negative effect on heartwood content, as trees in wet regions with less than three dry months per year tended to produce less heartwood than those in dry regions with more than three dry months per year. The present research on wood quality should be complemented with further studies aiming at a larger, more diverse database, as present models lack robustness after ages greater than 10 years due to the reduced number of sampled trees and to the diversity of growing conditions.

Pruning up to a reasonable height, performed at a reasonable time, under the criterion of intensive management, causes no reduction in tree growth and stand yield. Moreover, pruning may improve stem form (higher form factor, lower stem taper) and heartwood content, when compared to non-pruned stands and severely intensely pruned stands. Additionally, an intense pruning regimen like that proposed in this study may reduce the diameter of knots formed to a minimum, allowing the formation of up to $40.0 \%$ of the total tree volume free of knots, which correspond to approximately to $50.0-60.0 \%$ of the merchantable volume. This adds high value to the teak timber classification according to international grading rules. Continuation of the pruning trial is expected to generate more information about stand development and other factors of interest, such as the wood percentage free of knots obtained after processing trees from thinnings final harvest.

Thinning is the most important silvicultural activity in tree plantations, as it is the primary tool for density management and therefore defines the stand productivity within the species and site's potential, as well as the individual growth distribution. In the present study, density management by means of different thinning programs directed the stand development according to production objectives, site quality, and rotation periods. Intense and on time thinnings yield both individual-tree and stand volume, i.e. the objective of high individual tree growth is met without a severe reduction in stand yield. However, if maximization of stand yield is required and individual tree size is a secondary requirement, light thinnings will lead the stand to a different stock ability, where individual tree growth is significantly reduced because of inter-tree competition, but increasing the stand volume. Additionally, intensive thinning programs tend to produce higher quality trees, i.e. higher heartwood content, higher wood density, and better stem form. It is strongly recommended that the teak thinning scheme, that is to say further thinnings, continue to be evaluated, in order to create a set of thinning options for the entire rotation period, according to particular objectives and site potentials.

Models developed in the different studies are important tools for the quantitative and qualitative evaluation of teak stands. Growth projections, stand density competition factors, total and merchantable volume equations, heartwood and wood density estimates, together with information on growth and yield allow the construction of management scenarios for teak under any possible and logical circumstances. Further testing of such models with larger databases, particularly with plantations older than 10 years, is necessary to improve the goodness of fit and robustness, since current databases lack of sufficient data at middle and advanced ages.

Growth scenarios developed in this study offer different management possibilities for teak stands in Costa Rica, according to production objectives and site quality. In 
combination with the results on wood quality at different management levels, it is possible to place any teak plantation (under intensive management) within the different management scenarios and to project the future biological asset value of the stand. However, these scenarios should be used as a guide, not as a prescription. Constant monitoring of the stands to calibrate growth and yield projections is required to increase the accuracy of the estimates. Present scenarios are preliminary in nature, as field validation and eventual calibration is required, especially at ages over 10 years where the effects of management on growth, yield, and wood quality, is still uncertain and remains scientifically untested.

What costs and what pays are important questions which normally arise prior to any investment. Biological assets are more difficult to assess as many factors influence the costs and value of the products, in this case the wood. In addition, long rotation periods (normally over 15 years) necessary for the production of high quality wood make the return on investment more difficult to estimate and guarantee. The present financial analyses offer, under the concept of intensive management, a series of investment possibilities and returns based on various growth scenarios and wood prices. The Net Present Value and the Internal Rate of Return suggest great possibilities for safe and encouraging returns on investment, while the Sensitivity Analysis confirms that only wood price variations ( \pm $20 \%$ ) have a significant influence on the overall financial scenario of a $T$. grandis tree plantation project. A deeper exploration of teak markets is recommended in order to better understand the different grading rules, price variations, wood quality and timber dimension requirements, and new product preferences for the species. This feedback for the forestry companies will allow them to produce the timber quality expected by the international markets and by the consumers. The potential of the species has been confirmed, the management techniques and tools for analysis are being developed, and the plantations will reach their rotation period in a few years. Although more research is required as there are still many unknown facts regarding teak growing, a promising scenario for high quality wood production seems to have arisen.

\section{REFERENCES}

Adegbeihn, J.O. 1982. Preliminary results of the effects of spacing on the growth and yield of Tectona grandis LINN F. Indian Forester 108:423-430.

Alder, D. 1979. A distance-independent tree model for exotic conifer plantations in East Africa. Forest Science 25(1): 59-71.

Akwasi, A. 2004. Making the grade. ITTO Tropical Forest Update 14(1): 6-7.

Arce, V.H. 2001. Relación albura-duramen y características físicas de la madera de teca (Tectona grandis) en plantaciones de diez años con dos diferentes densidades de plantación en Playa Garza, Guanacaste. Tesis de grado, Universidad Nacional. Heredia, Costa Rica. 36 p.

Arias, G., Zamora, N. 1999. Diagnóstico de las oportunidades o amenazas para el proceso de reforestación nacional que implicaría un Tratado de Libre Comercio con Chile. COSEFORMA-CCF. San José, Costa Rica. 16 p.

Bailleres, H., Durang, P. 2000. Non-destructive techniques for wood quality assessments of plantation-grown teak. Bois et Forest des Tropiques 263(1):17-27.

Ball, J.B., Pandey, D., Hirai, S. 2000. Global overview of teak plantations. In: Regional Seminar on Site, Technology and Productivity of teak plantations. Chiang Mai, Thailand, 26-29 January 1999. p. 11-34. 
Bamber, R.K. 1976. Heartwood, its function and formation. Wood Science and Technology 10: $1-8$.

Beadle, C.L. 1997. Dynamics of leaf and canopy development. In Management of soil, nutrients and water in tropical plantation forests. E.K. Sadanandan Nambiar, A.G. Brown (Ed.). Australian Centre for International Agricultural Research, Canberra, Australia. p. 169-204.

Bermejo, I., Cañellas, I, San Miguel, A. 2004. Growth and yield models for teak plantations in Costa Rica. Forest Ecology and Management 189: 97-110.

Bertsch, F. 1995. La fertilidad de los suelos y su manejo. Asociación Costarricense de la Ciencia del Suelo. San José, Costa Rica. 157 p.

Bhat, K.M. 1995. A note on heartwood proportion and wood density of 8-year-old teak. Indian Forester 121(6): 514-516.

- 1998. Properties of fast-grown teakwood: Impact on end-user's requirements. Journal of Tropical Forest Products 4(1): 1-10.

- 2000. Timber quality of teak from managed tropical plantations with special reference to Indian plantations. Bois et Forêts des Tropiques 263(1): 6-15.

- , Hwan Ok Ma. 2004. Teak growers unite. ITTO Tropical Forest Update 14(1): 3-5.

- , Priya, P.B., Rugmini, P. 2001. Characterization of juvenile wood in teak. Wood Science and Technology 34: 517-532.

Betancur, C.A., Herrera, J.F., Mejía, L.C. 2000. Study on the physical and mechanical properties, workability and seasoning of teak in Puerto Libertador. (Estudio de las propiedades físicas y mecánicas, trabajabilidad y secado de la teca (Tectona grandis) de Puerto Libertador (Córdoba). Revista de la Facultad Nacional de Agronomia de Medellín 56 (1): 913-939.

Brennan, G.K., Radomiljac, A.M. 1998. Preliminary observations on the utilization and wood properties of plantation teak (Tectona grandis) and African mahogany (Khaya senegalensis) grown near Kununurra, Western Australia. Austrailian Forestry 61 (2): 120-126.

Briscoe, B. 1995. Silvicultura y manejo de teca, melina y pochote. Centro Agronómico Tropical de Investigación y Enseñanza (CATIE). Serie Técnica, Informe Técnico \# 270. 45 p.

Burkhart, H.E. 1977. Cubic foot volume of loblolly pine to any merchantable top limit. Southern Journal of Applied Forestry 1(2): 7-9.

Camacho, P., Madrigal, T. 1997. Ecuaciones de volumen preliminares para Tectona grandis. III Congreso Forestal nacional. 12-29 de Agosto. San José, Costa Rica. 131$133 \mathrm{p}$.

- , Blanco, M. 1997. Indice de Densidad del Rodal Preliminar para Tectona grandis. Instituto Tecnológico de Costa Rica. Departamento de Ingeniería Forestal-Flor y Fauna S.A. III Congreso Forestal Nacional. 27-29 de Agosto. San José, Costa Rica, p 134-136.

Castro, F., Raigosa, J. 2001. Crecimiento y propiedades físicas de la madera de teca (Tectona grandis L.F.) de 17 años en San Joaquín de Abangares, Costa Rica. Revista Forestal Centroamericana 35: 19-24.

Centeno, J.C. 1997. El manejo de las plantaciones de teca. Actualidad Forestal Tropical 5(2): 10-12.

Chakrbarti, S.K., Gaharwar, K.S. 1995. A study on volume estimation for Indian teak. Indian Forester 121(6): 503-509.

Chavarría, M., Quirós, L. 1985. Tectona grandis. Ministerio de Recursos Naturales Energía y Minas, Dirección General Forestal/FAO. San José, Costa Rica. 50 p.

Chaves, E., Chinchilla, O. 1991. Ensayos de aclareo de plantaciones de Tectona grandis en Cóbano de Puntarenas, Costa Rica. Ciencias Ambientales 7: 65-74. 
- , Fonseca, W. 1991. Teca (Tectona grandis): especie de árbol de uso múltiple en América Central. Proyecto MADELEÑA (Cultivo de Árboles de Uso Múltiple en América Latina), colección Guías Silviculturales (serie técnica). Informe técnico 179. Centro Agronómico Tropical de Investigación y Enseñanza (CATIE), Turrialba, Costa Rica. 44 p.

Chundamannil, M. 2000. Teak plantations in Kerala-An economic review. In: Regional Seminar on Site, technology and Productivity of teak plantations. Chiang Mai, Thailand, 26-29 January 1999. p 239-260.

Clutter, J.L., Fortson, J.C., Pienaar, L.V., Brister, G.H., Bailey, R.L. 1983. Timber management: a quantitative approach. John Wiley and Sons. 333 p.

Cunia, T. 1964. Weighted least squares method and construction of volume tables. Forest Science 10(2): 180-191.

Curtin, R.A. 1970. Dynamics of tree and crown structure in Eucalyptus oblicua. Forest Science 16(3): 321-328.

Datta, S.K., Kumar, A. 1987. Histochemical studies of the transition from sapwood to heartwood in Tectona grandis. IAWQ Bulletin 8: 363-368.

Daume, S., Robertson, D. 2000. A heuristic approach to modelling thinnings. Silva Fennica 34(3): 237-249.

De Camino, R., Alfaro, M., Sage, L.F. 2002. Teak (Tectona grandis) in Central America. Report prepared for Food and Agriculture Organization of the United Nations (FAO). Forestry Working paper 19. $78 \mathrm{p}$.

Devi, I., Varguese, S., Kumar, M., Pratheesh, V.S. 2003. Economics of teak plantations in Kerala. Memory Proceedings of the International Conference Quality Timber Products of Teak from Sustainable Forest Management. Kerala Forest Research Institute, Peechi, India, 2-5 December. 389-396 p.

Ericson, B. 1966. Effect of thinning on the basis density and content of latewood and heartwood in Scots pine and Norway spruce. Department of Forest Yield Research, Royal College of Forestry, Stockholm. Research Notes No 10.110 p.

Evans, J. 1992. Plantation forestry in the tropics. Second edition, Oxford Science Publications, Oxford. 403 p.

FAO. 2000. Global Forest Resources Assesment 2000. Forestry Paper 140. p. 23-38.

Fries, A., Ericsson, T. 1998. Genetic parameters in diallel-crossed Scots pine favor heartwood formation breeding objectives. Canadian Journal of Forest Research. 28: 937-994.

Furnival, G.M. 1961. An index for comparing equations used in constructing volume tables. Forest Science 7(4): 337-341.

Galloway, G. (ed.). 1993. Manejo de plantaciones forestales. Guía técnica para el extensionista forestal. Centro Agronómico Tropical de Investigación y Enseñanza (CATIE). Serie técnica, Manual Técnico 7. p. 16-47.

- , Ugalde, L., Vasquez, W. 2001. Importance of density reductions in tropical plantations: experiences in Central America. Forests, Trees and Livelihoods 11: 217-232.

Gerrand A.M., Neilsen, W.A., Medhurst, J.L. 1997. Thinning and pruning eucalypt plantations for sawlog production in Tasmania. Tasforests 9: 15-34.

Gomez, M., Reiche, C. 1996. Costos de establecimiento y manejo de plantaciones forestales y sistemas agroforestales en Costa Rica. CATIE 1996. 49 p.

González, G., Bonilla, L., Rivera, D. 1979. Properties and uses for teakwood growing in Quepos, Costa Rica. (Propiedades y usos de la madera de teca creciendo en Quepos, Costa Rica). Laboratorio de Productos Forestales, Universidad de Costa Rica. 16 p.

Hamzah, K.A., Mohamed, A.H. 1994. Volume equations and tables for teak (Tectona grandis Linn) in Mata Ayer, Perlis, Malaysia. FRIM Reports 65:18-33. 
Hedegart, T. 1988. Management plans for Longuza, Kwamkoro and Kolekole hardwood plantations. Second consultant report on Loguza teak plantations. Amani Forest Inventory and Management Plan Project. Forest Division of Tanzania, Joint Venture Finnmap-Silvestria. Helsinki, 1998. p.1-44.

Hillis, W. E. 1987. Heartwood and tree exudates. Springer Verlag, Berlin. 281 p.

Hilt, D.E., Teck, R.M. 1988. Individual tree diameter growth model for northern New England. Forest Growth Modelling and Prediction, US Department of Agriculture, p. 35-41.

Hoare, P., Patanapongsa, N. 1988. Long-rotation, high value trees: an alternative strategy for private forestry. Commonwealth Forestry Review 67(4): 351-361.

Hochbichler, E., Krapfenbauer, A. and Mayrhofer, F. 1990. Ein Pflegemodell für Eichenjungbestände - Grünastung, eine wirtschaftliche Problemlösung der Wertholzerziehung. Centralblatt für das gesamte Forstwesen 107 (1): 1-12.

Honer, T.G. 1964. The use of height and squared diameter ratios for the estimation of cubic foot volume. Forest Chronicle 40: 324-331.

Horne, J.E.M. 1966. Teak in Nigeria. Nigerian Information Bulletin (New Series) N 16.40 p.

Houllier, F., Leban, J.M., Colin, F. 1995. Linking growth modelling to timber quality assessment for Norway spruce. Forest Ecology and Management 74: 91-102.

Hubert, N., Courrand, R. 1988. Poda y formación de los árboles forestales. Edición Española (Madrid, 1989), traducido de edición francesa. Institut pour le Développement Forestier, Francia. 300 p.

ITTO (International Tropical Timber Organization). 2002. Market Information: International log prices, January 2002. [Online bulletin] Available from: http://www3.next-web.ne.jp/ itto/cgi-bin/itto/mis.cgi?page=archives2002/mns10102.html . [Cited 01 Oct 2002].

Jack, S.B., Long, J.N. 1996. Linkages between silviculture and ecology: an analysis of density management diagrams. Forest Ecology and Management 86: 205-220.

Jayaraman, K., Zeide, B. 2003. Optimal management of teak plantations. International Conference on Quality Timber of Teak from Sustainable Forest Management, Peechi, India, 2-5 December 2003: Kerala Forest Research Institute, Peechi, ITTO, Japan, Ministry of Environment and Forests, New Delhi, IUFRO. p. 448-456.

Kadambi, K. 1972. Silviculture and management of teak. Bulletin 24, School of Forestry, Stephen F. Austin State University, Texas. 25 p.

Kendall, J.A., Brown, J.K. 1978. Comparison of tree biomass estimators-DBH and sapwood area. Forest Science 24(4): 455-457.

Kandya, A.K. 1974. Weight dynamics in immature Anogeissus, Tectona and Terminalia. Indian Forester 100 (2): 93-100.

Keogh, R. 1979. El futuro de la teca en América Tropical. Unasylva 31(125): 13-19.

Kokutze, A.D., Baillères, H., Stokes, A., Kokou, K. 2004. Proportion and quality of heartwood in Tongolese teak. Forest Ecology and Management 189:37-48.

Krajicek, J.E., Brinkman, K.A., Gingrich, S.F. 1961. Crown competition - a measure of density. Forest Science 7(1): 35-42.

Kumar, B.M., Long, J.N., Kumar, P. 1995. A density management diagram for teak plantations of Kerala in peninsular India. Forest Ecology and Management 74:125-131.

Kyaw Min, U. 1996a. Export of Myanmar teak (saw timber). TEAKNET Newsletter 2: 1-8.

- 1996b. Some aspects of extraction and export of Myanmar teak logs. TEAKNET Newsletter 3:1-4.

Långström, B., Helqvist, C. 1991. Effects of different pruning regimes on growth and sapwood area of Scots pine. Forest Ecology and Management 44: 239-254. 
Lowe, R.G. 1976. Teak (Tectona grandis Linn. f.) thinning experiment in Nigeria. Commonw. Forest Review 55 (3): 189-202.

Magnussen, S., Keith, C.T. 1990. Genetic improvement of volume and wood properties of Jack pine: selection strategies. Forest Chronicle 66: 281-286.

Majid, N.M., Paudyal, B.K. 1992. Pruning trial for Acacia mangium plantation in Peninsular Malaysia. Forest Ecology and Management 47: 285-293.

Mäkelä, A. 1997. A carbon balance model of growth and self-pruning in trees based on structural relationships. Forest Science 43(1): 7-24.

Malimbwi, R.E., Philip, M.S. 1989. A growth yield model for Pinus patula at Sao Hill Southern Tanzania. Proceedings of a meeting sponsored by the International Union of Forestry Research Organizations and IUFRO. Vienna, Austria. September 18-22, 1989. p. 159-180.

Malende, Y.H., Ringo, W.H. 1987. Effect of thinning intensities on wood basic density in Cuppresus lusitanica. Indian Journal of Forestry 10(1): 21-26.

Malaysian Timber Council. 2002. Malaysian grading rules for sawn hardwood timber.

[Online journal]. Available at: http://www.mtc.com/publication/library/

grading/summary.htm. [Cited 22 June 2002].

Margolis, H.A., Gagnon, R. R., Pothier, D., Pineau, M. 1988. The adjustment of growth, sapwood area, heartwood area, and sapwood saturated permeability of balsam fir after different intensities of pruning. Canadian Journal of Forest Research 18: 723-727.

Maung, U. 2000. Teak Plantations in Myanmar. In: Regional Seminar on Site, technology and Productivity of teak plantations. Chiang Mai, Thailand, 26-29 January 1999. p. 8398.

McFadden, G., Oliver, C.D. 1988. Three-dimensional forest growth model relating tree size, tree number, and stand age: relation to previous growth models and to selfthinning. Forest Science 34 (3): 662-676.

Monserud, R.A., Sterba, H. 1996. A basal area increment model for individual trees growing in even- and uneven-aged forest stands in Austria. Forest Ecology and Management 80: 57-80.

Montero, M. 1999. Factores de Sitio que influyen en el crecimiento de Tectona grandis L.F. y Bombacopsis quinata (Jacq.) Dugand en Costa Rica. Universidad Austral de Chile, Facultad de Ciencias Forestales, Valdivia, Chile. M.Sc. Thesis. 111 p.

Monteuuis, O., Goh, D.K.S. 1999. About the use of clones in teak. Bois et Forêts des Tropiques 261(3): 28-37.

Morataya, R., Galloway, G., Berninger, F., Kanninen, M. 1999. Foliage biomass-sapwood (area and volume) relationships of Tectona grandis L.F. and Gmelina arborea Roxb.: silvicultural implications. Forest Ecology and Management: 113(2-3): 231-239.

Moret, A.Y., Jerez, M., Mora, A. 1998. Determinación de ecuaciones de volumen para plantaciones de teca (Tectona grandis L.) en la Unidad Experimental de la Reserva Forestal Caparo, Estado Barinas - Venezuela. Revista Forestal Venezolana 42(1): 4150.

Mörling, T. , Valinger, E. 1999. Effects of fertilization and thinning on heartwood area, sapwood area and growth in Scots Pine. Scandinavian Journal of Forest Research 14 : 462-469.

Morris, D.M. , Bowling, C. , Hills, S.C. 1994. Growth and form response to precommercial thinning regimens in aerially seeded jack pine stands : 5 th year results. The Forestry Chronicle 70(6) :780-787.

Moya, R. 2000. Características de la madera de teca de 5,7 y 9 años de edad creciendo en el Atlántico de Costa Rica. Escuela de Ingeniería Forestal, Instituto Tecnológico de Costa Rica. Cartago, Costa Rica. Boletín Curú 29. p. 12-14. 
- 2001. Propiedades de la madera de teca perteneciente a la Reforestadora el Buen Precio S.A. Instituto Tecnológico de Costa Rica. Escuela de Ingeniería Forestal. Centro de Investigación en Integración Bosque Industria 1(1): 1-8.

- , Pérez, L. D., Arce, V. 2003. Effect of spacing on wood basic density of Tectona grandis plantations in Costa Rica. Journal of Tropical Forest Products 9 (1 \& 2):153-161.

Murillo, O., Camacho, P. 1997. Calidad de la poda en plantaciones forestales: metodología para su evaluación. Agronomía Costarricense 21(2):229-238.

Nair, C.T.S., Ball, J.B., Kjaer, E.D. 1999. Site, technology and productivity of teak plantations. FORSPA Publication No 23, TEAKNET publication No. 2. 14 p.

Nieuwenhuyse, A., Hengsdijk, H., Bouman, B.A.M., Schipper, R.A., Jansen, H.G.P. 2000. Can forestry be a competitive land use option ?-Model simulations from humid tropical Costa Rica. Forest Ecology and Management 137: 23-40.

Nunifu, T.K., Murchinson, H.G. 1999. Provisional yield models of teak (Tectona grandis Linn F.) plantations in northern Ghana. Forest Ecology and Management 120: 171-178.

O’Hara, K.L. 1991. A biological justification for pruning in Coastal Douglas-Fir Stands. Western Journal of Applied Forestry 6(3): 59-63.

Ojansuu, R., Maltamo, M. 1995. Sapwood and heartwood taper in Scots pine stems. Canadian Journal of Forest Research 25:1928-1943.

Okuyama, T., Yamamoto, H., Wahyudi, I., Hadi, Y.S., Bhat, K.M. 2000. Growth stresses and some wood quality attributes in planted teak. In: Proceedings of the IUFRO Congress, Kuala Lumpur, Malaysia. 154 p.

Oliver, C.D., Larson, B.C. 1990. Forest Stand Dynamics. McGraw-Hill, USA. 467 p.

Oteng-Amoako, A.A. 2004. Making the grade. ITTO Tropical Forest Update 14(1):6-7.

Oviedo, J.A. 1997. Determinación del turno óptimo financiero y ambiental para cinco especies en plantaciones forestales de Costa Rica. Centro Agronómico Tropical de Investigación y Enseñanza (CATIE), Turrialba, Costa Rica. M.Sc. thesis. 129 p.

Pandey, D. 1998. Forest plantation areas, 1995. Report of the FAO project GCP/INT/628/UK. 94 p.

Pandey, D., Brown, C. 2000. Teak: a global overview. Unasylva 51(201): 3-13.

Pérez, L.D. 1998. Development of stand growth scenarios based on the relationship among the crown composition, the crown structure and the productivity of Tectona grandis and Bombacopsis quinata plantations in Costa Rica. M.Sc thesis, CATIE, Turrialba, Costa Rica. p.185.

- , Kanninen, M. 2003. Aboveground biomass of Tectona grandis plantations in Costa Rica. Journal of Tropical Forest Science 15(1):199-213.

- , Víquez, E., Kanninen, M. 2003. Preliminary pruning program for Tectona grandis in Costa Rica. Journal of Tropical Forest Science 15(4): 557-569.

Persson, A. 1986. Relation between thinning methods, wood quality and end timber. Sveriges Landbruksuniversitet, Stencil \# 34. Presented at the 18th IUFRO World Congress in Ljubljana, Slovenia. 11 p.

Philip, M.S. 1994. Measuring trees and forests. CAB International, Second Edition. Oxford Press, UK. 336 p.

Phillips, G.B. 1995. Growth functions for teak (Tectona grandis Linn. F.) plantations in Sri Lanka. Commonw. Forest. Rev. 74(4): 361-375.

Priya, P.B., Bhat, K.M. 1999. Influence of rainfall, irrigation and age on the growth periodicity and wood structure in teak (Tectona grandis). IAWA Journal 20(2): 181192.

Pukkala, T., Miina, J. 1998. Tree-selection algorithms for optimizing the thinning with distance-dependent growth models. Canadian Journal of Forest Research 28: 693-702. 
Ramnarine, S. 1994. Growth and yield of teak plantations in Trinidad and Tobago. University of New Brunswick, M.Sc. Thesis. 165 p.

Reineke, L.H. 1933. Perfecting a stand-density index for even-aged forests. Journal of Agricultural Research 46: 627-638.

Rosso, F., Ninin, P. 1998. Variabilidad de los defectos de trozas de la especie teca (Tectona grandis) en diferentes densidades arbóreas, en la Unidad Experimental de la Reserva Forestal de Ticoporo, Barinas-Venezuela. Revista Forestal Venezolana 42(2): 103-112.

Sage, L.F., Quiros, R. 2001. Proyección del volumen de madera para aserrío proveniente de las plantaciones de melina y teca y de otras fuentes. Paper presented at the Workshop "Reforestación en Costa Rica: situación actual y perspectivas”, July 12th-14th. Fondo Nacional de Financiamiento Forestal FONAFIFO. San José, Costa Rica. 23 p.

Sandrasegaran, K. 1969. A general volume table for Tectona grandis Linn f. (teak) grown in North-West Malaya. Malayan Forester 32(2):187-200.

Sanwo, S.K. 1987. The characteristics of the crown-formed and stem-formed wood in plantation grown teak in Nigeria. Journal of the Institute of Wood Science 11 (2): 8588.

Singh, S.P. 1981. Total tree volume table for Tectona grandis (teak). Indian Forester 107(10): 621-623.

Sterba, H. 1989. Concepts and techniques for forest growth models. Proceedings of a meeting sponsored by the International Union of Forestry Research Organizations and IUFRO. Vienna, Austria. September 18-22, 1989. p. 14-20.

Suri, S.K. 1974. Qualitative and quantitative analysis of teak saw logs of Bastar Forests. Indian Forester 100 (8): 483-490.

TANTEAK. 1995. Grading Rules. Trinidad and Tobago (Internal Document). 34 p.

Tewari, D.N. 1999. A monograph on teak (Tectona grandis). International Book distributors. Dehra Dun-248006 India. 235 p.

Torres, L.A. 1982. Influencia del sitio y la espesura en el crecimiento de plantaciones de teca (Tectona grandis) en Caparo, Venezuela. Universidad de los Andes, Facultad de Ciencias Forestales, Mérida. 67 p.

Torres, G., Luján, R., Pineda, M. 1995. Diagnóstico técnico del proceso de producción forestal en plantaciones a pequeña escala en Costa Rica. Departamento de Ingeniería Forestal, Centro de Investigación Bosque - Industria, Instituto Tecnológico de Costa Rica. Cartago, Costa Rica. 105 p.

Trockenbrodt, M., Josue, J. 1998. Wood properties and utilization potential of plantation teak (Tectona grandis) in Malaysia - A critical review. Journal of Tropical Forest Products 5(1): 58-70.

Troup, R.S. 1921. The silviculture of Indian trees. Vol II, Clarendon Press, Oxford. pp. 697-769.

Tze, W.T.Y. 1999. Recovery and quality of lumber from mature teak (Tectona grandis) planted in Sabah, Malaysia. Journal of Tropical Forest Products 5(2): 115-123.

Vallil, G. 1997. Utilization of teak. Proceedings International Teak Symposium 175-178.

Valencia, J. 1994. Utilización del Indice de Densidad de Reineke en Pinus douglasiana en Atenquique, Jalisco. Revista Ciencia Forestal en México 19 (76): 51-75.

Vallejos, O. 1996. Productividad y relaciones del Indice de Sitio con variables fisiográficas, edafoclimáticas y foliares para Tectona grandis L. F., Bombacopsis quinatum (Jacq.) Dugand y Gmelina arborea Roxb. en Costa Rica. Thesis M.Sc. CATIE, Turrialba, Costa Rica. 147 p.

Vásquez, W., Ugalde, L. 1995. Rendimiento y calidad de sitio para Gmelina arborea, Tectona grandis, Bombacopsis quinatum y Pinus caribaea en Guanacaste, Costa Rica. CATIE, Turrialba, Costa Rica. Serie Técnica. Informe Técnico Nº 256. 76 p. 
Vincent, A.J. 1964. Plantation teak (Tectona grandis L.) sample plot perlis $\mathrm{N}^{\circ} 1$ Mata Ayer Forest Reserve. Malayan Forester 27: 148-173.

Waring, R.H., Schlesinger, W.H. 1995. Forest Ecosystems: Concepts and Management . Academic Press, USA. 340 p.

Weerawardane, N.D.R. 2000. Site, technology and productivity of teak plantations in Sri Lanka. In: Regional Seminar on Site, technology and Productivity of teak plantations. Chiang Mai, Thailand, 26-29 January 1999. p. 69-81.

White, K.J. 1991. Teak-some aspects of research and development. Publication 1991/17. FAO, Bangkok. 44 p.

Wiemann, M.C., Williamson, G.B. 1989. Wood specific gravity gradients in tropical dry and montane rain forest trees. American Journal of Botany 76(6): 924-928.

Wykoff, W.R., Monserud, R.A. 1988. Representing site quality in increment models: a comparison of methods. Forest Growth Modelling and Prediction, US Department of Agriculture. p. 46-51. 